\title{
ANALYSIS OF ENVIRONMENTALLY FRIENDLY MARKING INK FOR MILITARY EQUIPMENT AND ELECTRONICS
}

\author{
A Thesis \\ presented to \\ the Faculty of California Polytechnic State University, \\ San Luis Obispo \\ by Liang C. Li \\ In Partial Fulfillment \\ of the Requirement for the \\ Degree Master of Science in Industrial Engineering
}


(C)2014

ALL RIGHTS RESERVED 


\section{COMMITTEE MEMBERSHIP}

TITLE:

AUTHOR:

DATE SUBMITTED:
Analysis of Environmentally Friendly Marking Ink for Military Equipment and Electronics

Liang C. Li

June 2014

COMMITTEE CHAIR: Jianbiao Pan, PhD

Professor of Industrial and Manufacturing Engineering

COMMITTEE MEMBER: Lizabeth Schlemer, PhD

Professor of Industrial and Manufacturing Engineering

COMMITTEE MEMBER: John Jacobs, PhD

Cal Poly Industry Advisor, Raytheon 


\begin{abstract}
Analysis of Environmentally Friendly Marking Ink for Military Equipment and Electronics

Liang C. Li

Recent advancements in corrosion-resistance coating technology has reduce the use of environmentally harmful compounds such as Hexavalent Chromium by replacing Hexavalent Chromium in primers and topcoat. However, marking inks were neglected in the process. Products such as Enthone 50 series are still widely used, which contain compounds such as lead, hexavalent chromium, bisphenol A (BPA), Cadmium Sulfide, and more. Excluding catalyst compositions in Enthone, the chemicals in the ink alone contained three reproductive toxicant and numerous carcinogens. Therefore, it was essential to search and validate the performance of potential marking ink that would meet the standards in military applications.
\end{abstract}

Eleven products were tested, and two products were recommended for use: Sherwin Williams MIL-PRF-22750 Type I and Union Ink Uniglaze. Both products contain at most one carcinogen ingredient and no reproductive toxicant. Both products passed MIL-STD 202G Method 215K solvent test, MIL-STD 202G Method 107G thermal shock test, MILSTD-810G, Method 507.5 humidity test, cleaning system test, ASTM D3359, measure adhesion by tape test. 


\section{ACKNOWLEDGMENTS}

I cannot express enough thanks to my advisors: Dr. John Pan, Dr. John Jacobs and Aaron Stein for their tremendous help and patience. I sincerely offer my appreciation for the learning opportunities that they have provided me.

The completion of this project could not have been possible without the funding from Raytheon and different facilities they offered. I would like to personally thank Andrew McBeath for his help using their cleaning systems and the Aaron Stein for volunteering during the holidays with the humidity test.

Finally, I would like to thank the various paint companies that provided free samples for this project. 


\section{TABLE OF CONTENTS}

$\begin{array}{lc} & \text { Page } \\ \text { LIST OF TABLES } & \text { viii } \\ \text { LIST OF FIGURES } & \text { ix }\end{array}$

Chapter 1. Introduction $\quad 1$

$\begin{array}{lr}\text { Chapter 2. Literature Review } & 6\end{array}$

2.1 Environmental and Health Concerns 6

2.1.1 Lead 6

2.1.2 Cadmium and hexavalent Chromium 6

$\begin{array}{lll}2.1 .3 & \text { Current Ink } & 10\end{array}$

$\begin{array}{lll}2.2 \text { New Solutions } & 12\end{array}$

2.2.1 Low-Cr Conversion Coating $\quad 12$

2.2.2 Non-chrome Primer for C-120J OML \&Non-chrome Primer-C130JIML 14

$\begin{array}{lll}\text { 2.2.3 Mg-Rich Treatment } & 15\end{array}$

2.2.4 Non-chrome, Low VOC Fuel Tank Coating (Mil Spec AMS-C-27725)

$\begin{array}{lll}\text { 2.2.5 Barrier coat for F-16 } & 15\end{array}$

$\begin{array}{ll}2.3 & \text { Adhesion of Marking Ink }\end{array}$

2.3.1 Reliability of Marking Ink 16 
$\begin{array}{lll}3.1 & \text { Product Selection } & 20\end{array}$

$\begin{array}{lll}3.2 & \text { Methods } & 22\end{array}$

3.2.1 Evaluation of Metal Panels 22

3.2.2 Painting Methodology and Curing Schedule 23

3.3 Design of Experiment 24

3.3.1 Solvent Resistivity 28

3.3.2 Thermal Shock \& Discoloration Test 31

3.3.3 Humidity Test 34

3.3.4 Cleaning System Test 36

3.3.5 Military Marking Ink Requirement 37

3.3.6 ASTM D3359 Tape Test 37

Chapter 4. Results and Analysis $\quad 39$

4.1 Phase 1 Test Results $\quad 39$

4.2 Phase 2 Test Results 43

4.2.1 Additional Solvent Resistivity 43

4.2.2 Thermal Shock \& Discoloration Test 45

$\begin{array}{lll}4.2 .3 & \text { Humidity Test } & 47\end{array}$

4.2.4 Cleaning System Test 49 


\section{APPENDICES}

A. Memo from Under Secretary of Defense, April $8^{\text {th }}, 2009$

B. TDS and MSDS of Union Ink: Uniglaze 59

C. TDS and MSDS of Sherwin Williams 67

D. Curing Schedule of 11 Products $\quad 71$

E. Phase 1 Test Results 73

F. Phase 2 Test Results $\quad 79$ 


\section{LIST OF TABLES}

Tables Page

Table 1- Selected OSHA Risk Estimates (Excess Cancers per 1000 Workers) 8

Table 2- Harmful Chemical ingredients of Enthone 50 Series. 11

Table 3- Different treatments for alloys AA6082-T6 and AA2014-T3

with 6 available treatment. 13

Table 4 - MIL-STD-202G, Method 107G Exposure time in air at temperature extremes.

Table 5 - MIL-STD-202G, Method 107G Thermal shock test conditions in air environment.

Table 6 - Summary of testing procedure of MIL-STD 202G Method 215K 39

Table 7 - Snapshot of samples in Phase 1 Testing 41

Table 8 - Results of Phase 1 Testing $\quad 42$

Table 9 - Snapshot of samples in Phase II, Additional Solvent Test 44

Table 10 - Results of Phase II, Additional Solvent Test 44

Table 11- Results of Phase II, Thermal Shock Test 45

Table 12 - Results of Phase II, Humidity Test 47

Table 13- Phase II, Cleaning Systems Test $\quad 50$

Table 14 - Harmful Chemicals in Sherwin WIlliams MIL-PRF-22750G Type I and Union Ink Uniglaze 53

Table 15- Carcinogenic and reproductive toxin comparison of Sherwin Williams MIL PRF-22750G Type I, Union Ink Uniglaze and Enthone 50 series product line. 


\section{LIST OF FIGURES}

Figures $\quad$ Page

Figure 1- Layer of coating in aerospace applications 10

Figure 2- Barrier coat encapsulating chrome primer 15

Figure 3- Before and after image of paint coat anchoring to the substrate. 17

Figure 4 - Water-break test, Left - contaminated panel, center- clean panel with acetone, right - clean panel.

Figure 5 - Top, 11-point font stencil provided by Raytheon, Bottom, M23377 T2 Class N primer with M22750 or M85285 topcoats

Figure 6 - Top, masking paper and scotch blue\#2093EL. Bottom, stencil covered by masking paper and scotch blue\#2093EL on Al panel.

Figure 7- Solution IV maintained at temperature of $63^{\circ} \mathrm{C}$ to $70^{\circ} \mathrm{C} \quad 30$

Figure 8- Temperature/Humidity Profile of MIL-STD-810G, Method 507.5G 35

Figure 9- Snapshot of 10x magnification of Thermal Shock results 46

Figure 10- Discoloration of Green Polyurethane in white 46

Figure 11- Snapshot of 10x magnification of Humidity Shock results 48

Figure 12- Snapshot of 10x magnification of Cleaning Systems Test of DEFT and DuPont samples.

Figure 13- Snapshot of 10x magnification of Cleaning Systems Test of Union Ink and Sherwin Williams samples. 


\section{Chapter 1 - Introduction}

Traditionally, aerospace coatings have been formulated for performance and corrosion resistance. In the 1950's, compounds such as hexavalent chromium were largely commercialized as a way to enhance the corrosion resistance. [1] Along with hexavalent chromium, other compounds such as lead, cadmium, and phenol solvents were also used in these coating and marking applications. Since then, the basic technology has essentially remained unchanged, while the environmental and toxicological hazardous of hexavalent chromium, cadmium, and lead have become well documented and regulations have eliminated some of these compounds from commercial and residential use; the use of these compounds can still be found in military applications.

In the past decade, there has been a growing interest to replace these compounds. This is partly due to ELV, RoHS, WEEE and REACH legislations in the EU. These regulations imposed international restrictions: ELV, the directive on End-of Life Vehicle 2000/53/EC is the first EU waste directive to prevent the use of certain heavy metals such as cadmium, lead, mercury, and hexavalent chromium for vehicles sold after July 2003. This was officially adopted by the European Parliament and Council in September 2000. The RoHS, Restriction of Hazardous Substances Directive 2002/95/EC, directive took effect on July 1, 2006. The directive restricted the sale of electronic equipment with the use of six substances: lead, mercury, cadmium, hexavalent chromium, polybrominated biphenyls, and polybrominated diphenyl ether from being used in the manufacturing of various types of electronic and electrical equipment. The WEEE, Waste Electrical and 
Electronic Equipment, directive set collection, recycling, and recovery targets for all types of electronics. The directive took effective August 13, 2005. REACH, Registration, Evaluation, Authorization and Restriction of Chemicals, is a comprehensive regulation for tracking, testing, and reporting on all chemicals used in the EU that started back in early 2009. While ELV, RoHS and WEEE are exempt from the defense sector, REACH is still effective toward defense sectors with an individual member states in the EU granting substance-specific exemptions for national security reasons. RoHS directive is also well known in the industry to be a temporary exemption according to Journal of Military Electronics and Computing, "Even if military equipment does remain exempt, since commercial component manufacturers and board makers supply both the military and commercial electronics, programs will definitely be affected."

In the United States, regulations on these compounds are largely exempted in the defense industry. However, with increasing international restrictions, stricter regulations will only be a matter of time. In a memorandum from the Under Secretary of Defense to Secretaries of Military Departments on April $8^{\text {th }}, 2009$, regarding minimizing the use of hexavalent chromium stated,

Due to the serious human health and environmental risk related to its use, national and international restrictions and controls are increasing. These restrictions will continue to increase the regulatory burden and life cycle cost for DoD and decrease material availability. OSD, DoD Components, and industry have made substantial 
investment in finding suitable replacements for hexavalent chromium for many of the current DoD applications.[2]

This memo further directed the DoD military departments to take action by approving the investment in appropriate research, as well as the development on substitutes and the use of alternative where they can perform adequately for the intended application and operating environment. (Please refer to Appendix A for complete memorandum.)

In 2011, a report was presented at the environment, energy security and sustainability (E2S2) symposium, emphasizing the scope of the hexavalent chromium effort of the DoD, Department of Defense. [3] The report stated the current and past hexavalent chromium efforts:

- Low-Cr Conversion Coating

- NC Primer for C-130J OML

- Non-chrome primer - C130J IML

- Mg-Rich Treatment

- Non-chrome, Low VOC Fuel Tank Coating (Mil Spec AMS-C-27725)

- Barrier coat for F-16

The current generation of commercial aerospace polyurethane topcoats have an expected service life of approximately 3-5 years. [4] In order to reduce the environmental impact of stripping and repainting aircraft, it is ideal to replace all of the primer, topcoat, and marking ink with formula free of chromium and other harmful agents. Marking ink is indelible ink for marking purposes. In our case, it could be warning sign for tactical 
equipment, sub-assembly part labeling, and identification marking ect. While these chromium treatments mentioned above are suitable for primer and coating, it does not suit the purpose of marking ink as described in detail in the literature review session. Marking ink is usually the last step of a work order; with the working conditions and the size of parts, it does not allow users to use theses treatments mentioned above.

In this study, a wide variety of marking inks were investigated for the purpose of replacing marking ink such as the Enthone 50 series ink, which is the most common marking ink used at Raytheon, a major American defense contractor and industrial corporation with core manufacturing concentration in weapons, military, and commercial electronics. Enthone 50 series ink, a two component, epoxy-based screen printing ink, is not compliant with any EU directive mentioned above. Enthone 50 series ink contains harmful substances such as lead, hexavalent chromium, bisphenol A (BPA), Cadmium Sulfide, solvent naphtha, 2-bytoxyethanol, tetraethylenepentamine, Ethylene Glycol Butyl Ether, 2-Ethyl-4methlimidazole and much more. [5-16]

In order to find an alternative ink that "can perform adequately for the intended application and operating environment," stated by the Under Secretary of Defense, a market research was conducted to discover the most suitable and environmentally friendly marking ink available on the market. These samples were exposed to two phases of tests: Phase I, solvent testing, Phase II, more solvent test, cleaning system test, and accelerated life testing including thermal shock test and humidity test. This study will 
address the effects of various environmental testing of marking ink to find an alternative that can perform adequately with the intended purpose of marking military equipment while reducing the usage of environmentally harmful chemical compounds and solvents. 


\section{Chapter 2 - Literature Review}

\subsection{Environmental and Health Concerns}

\subsubsection{Lead}

Lead is a naturally occurring element that is toxic to humans of all ages when ingested or inhaled. Lead can be bioaccumlated. While small exposure may not seem harmful, repeated exposure can build over time. In 1977, the Office of Information and Public Affairs issued a final ban on lead-containing household paint, toys, and furniture. [17] Due to the bioaccumulation effect, lead can cause permanent damage to human and marine life. While it is a dangerous compound, most coatings nowadays do not contain lead and it is no longer a main concern.

\subsubsection{Cadmium and Hexavalent Chromium}

Hexavalent chromium and cadmium compounds are extensively used in the coating to protect industrial ferrous and nonferrous from corroding. Typically cadmium plating is provided as an undercoat to chromate-base primers on steel to achieve a longer service life. [18] Chromates are also used as pigments such as strontium chromate, and zinc chromate. [19]

Both Cadmium and Hexavalent Chromium are carcinogenic and could be fatal if inhaled. $[12,14]$ OSHA, Occupation Safety and Health Administration, estimated that 558,000 
workers are potentially exposed to hexavalent chromium annually. They are typically exposed in the following area:

- Welding and "hot work" on stainless steel and other metals containing chromium

- Use of pigments, spray paints and coatings

- Operating chromate plating baths [20]

On October 1, 2004 The Federal Register reviewed the Proposed Rule: Occupational Exposure to Hexavalent Chromium; 29 CFR Parts 1910, 1915, 1917, 1918, and 1926. [21] The author illustrated the danger of hexavalent chromium as follow,

Taking a 45-year working life from age 20 to age 65, as OSHA has always done in significant risk determinations for previous standards, the Agency finds an excess lung cancer risk of approximately 100 to 350 per 1000 workers exposed at the previous PEL of $52[\mathrm{mu}] \mathrm{g} / \mathrm{m} 3 \mathrm{Cr}(\mathrm{VI})$. This risk is clearly significant, falling well above the level of risk the Supreme Court indicated a reasonable person might consider acceptable. Even assuming only a 20-year working life, the excess risk of about 50 to 200 per 1000 workers is still clearly significant. The new PEL of $5[\mathrm{mu}] \mathrm{g} / \mathrm{m} 3 \mathrm{Cr}(\mathrm{VI})$ is expected to reduce these risks substantially, to below 50 excess lung cancers per 1000 workers. However, even at the new PEL, the risk posed to workers with a lifetime of regular exposure is still clearly significant. [22] 
Table 1-Selected OSHA Risk Estimates (Excess Cancers per 1000 Workers) [22]

$\begin{array}{crrr}\text { Standard } & \text { Risk at prior PEL } & \text { Risk at new PEL } & \text { Federal Register date } \\ \text { Ethylene Oxide } & 63-109 \text { per } 1000 & 1.2-2.3 \text { per } 1000 & \text { June } 22,1984 \\ \text { Asbestos } & 64 \text { per } 1000 & 6.7 \text { per } 1000 & \text { June } 20,1986 \\ \text { Benzene } & 95 \text { per } 1000 & 10 \text { per } 1000 & \text { September } 11,1987 \\ \text { Formaldehyde } & 0.43-18.9 \text { per } 1000^{*} & .0056-2.64 \text { per } 1000^{*} & \text { December } 4,1987 \\ \text { Methylenedianiline } & 6-30 \text { per } 1000^{* *} & 0.8 \text { per } 1000 & \text { August } 10,1992 \\ \text { Cadmium } & 58-157 \text { per } 1000 & 3-15 \text { per } 1000 & \text { September } 14,1992 \\ \text { 1,3-Butadiene } & 11.2-59.4 \text { per } 1000 & 1.3-8.1 \text { per } 1000 & \text { November } 4,1996 \\ \text { Methylene Chloride } & 126 \text { per } 1000 & 3.6 \text { per } 1000 & \text { January } 10,1997 \\ \text { Chromium VI } & 101-351 \text { per } 1000 & 10-45 \text { per } 1000 & 2006 \\ \text { * range is based on maximum likelihood estimate }(0.43, .0056) \text { and upper } 95 \% \text { confidence limit }(18.9,2.64) & \\ \text { ** no prior standard; reported risk is based on estimated exposures at the time of the rulemaking }\end{array}$

The new $5 \mu \mathrm{g} / \mathrm{m}^{3}$ chromium regulation, however, does not apply to aerospace industry. OSHA permissible exposure limit (U.S.) of Hexavalent Chromium in the aerospace industry was only reduced to $25 \mu \mathrm{g} / \mathrm{m}^{3}$ of airborne chromium, calculated as an 8-hour time-weighted average instead of $5 \mu \mathrm{g} / \mathrm{m}^{3}$ as shown in Table 1. If the-average of the prior and current risk are taken, assuming linear relationship, the new aerospace industry cancer risk at the new PEL will yield 50-197 per 1000 workers. The calculation is shown below. Followed by cadmium and benzene, which are also common among aerospace painting operations. [22] 
Average cancer rate per 1000 people per $\frac{\mu \mathrm{g}}{\mathrm{m} 3}$ at lower extreme

$$
\begin{aligned}
& =\frac{\text { rate of death at } 52 \frac{\mu \mathrm{g}}{\mathrm{m} 3}+\text { rate of death at } 5 \frac{\mu \mathrm{g}}{\mathrm{m} 3}}{2}=\frac{\frac{101}{52}+\frac{10}{5}}{2} \\
& =1.97
\end{aligned}
$$

New Aerospace lower bound Risk $=(1.97)\left(25 \frac{\mu \mathrm{g}}{\mathrm{m} 3}\right)=50$ per 1000 workers

$$
\begin{aligned}
& \text { Average cancer rate per } 1000 \text { people per } \frac{\mu \mathrm{g}}{\mathrm{m} 3} \text { at upper extreme } \\
& \qquad \begin{aligned}
\text { rate of death at } 52 \frac{\mu \mathrm{g}}{\mathrm{m} 3}+\text { rate of death at } 5 \frac{\mu \mathrm{g}}{\mathrm{m} 3} \\
2
\end{aligned}=\frac{\frac{351}{52}+\frac{45}{5}}{2} \\
& =7.875
\end{aligned}
$$

New Aerospace upper bound Risk $=(7.875)\left(25 \frac{\mathrm{\mu g}}{\mathrm{m} 3}\right)=197$ per 1000 workers 


\subsubsection{Current Ink}

The most common marking ink used at Raytheon is Enthone 50 series. Enthone 50 series is a two-part, single stage polyurethane stencil ink. "Two-part" indicates the required mixing of catalyst and ink prior to application and "single stage", indicates that it only requires one layer of application. It is best for marking ink to be single stage, as it'll reduce curing time and complexity of marking a product. Marking ink is typically applied over a topcoat as displayed in Figure 1, or a corrosion resistance coating.

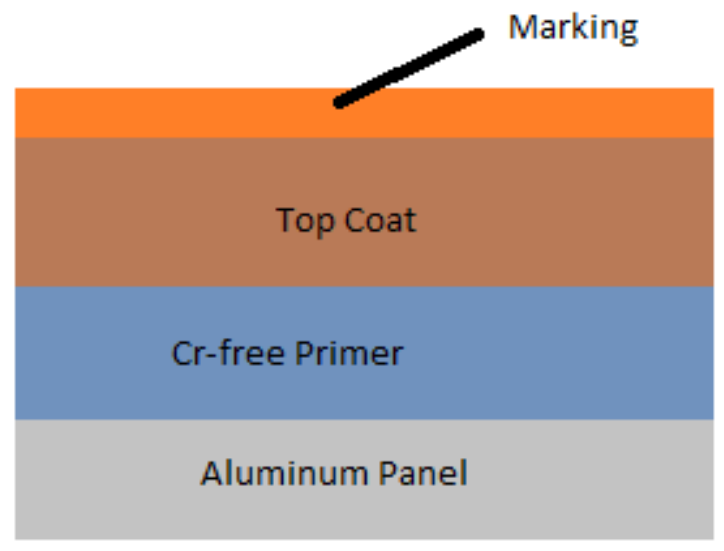

Figure 1-Layer of coating in aerospace applications.

Ideally, the Cr-free topcoat and Cr-free primer would be adequate for the aluminum panels to be resistant to corrosion as marking ink isn't applied to all parts of the equipment. However, this doesn't make the marking ink, such as Enthone 50 series, safe in anyway, as shown in Table 2 . There are numerous carcinogenic components, and three of the components may even cause genetic mutations. 
Table 2 - Harmful Chemical ingredients of Enthone 50 Series. [5-16]

\begin{tabular}{|c|c|c|c|}
\hline Chemical & $\frac{\text { Toxicological }}{\text { Information }}$ & Carcinogenic & $\begin{array}{l}\text { Environmental } \\
\text { Information }\end{array}$ \\
\hline \multirow{3}{*}{ Hexavalent Chromium } & $\begin{array}{l}\text { Acute toxicity, } \\
\text { Suspected human } \\
\text { reproductive toxicant }\end{array}$ & $\begin{array}{l}\text { IARC, International } \\
\text { Agency for } \\
\text { Research on } \\
\text { Cancer, Group 2B: } \\
\text { Possibly } \\
\text { carcinogenic to } \\
\text { humans }\end{array}$ & $\begin{array}{l}\text { Toxicity to fish, } \\
\text { daphnia, algae, } \\
\text { and other } \\
\text { aquatic } \\
\text { invertebrates. } \\
{[15]}\end{array}$ \\
\hline & $\begin{array}{l}\text { Toxic if swallowed or } \\
\text { in contact with skin. } \\
\text { Fatal if inhaled. } \\
\text { Suspected human } \\
\text { reproductive toxicant. } \\
\text { May cause } \\
\text { reproductive disorder. }\end{array}$ & $\begin{array}{l}\text { IARC Group 1- } \\
\text { Carcinogenic to } \\
\text { humans(Chromium } \\
\text { trioxide) }\end{array}$ & $\begin{array}{l}\text { Toxicity to fish, } \\
\text { daphnia, and } \\
\text { other aquatic } \\
\text { invertebrates. } \\
\text { Long lasting } \\
\text { effects [14] }\end{array}$ \\
\hline & $\begin{array}{l}\text { Acute toxicity. } \\
\text { Overexposure may } \\
\text { cause reproductive } \\
\text { disorder(s) based on } \\
\text { tests with laboratory } \\
\text { animals. }\end{array}$ & $\begin{array}{l}\text { No component of } \\
\text { this product present } \\
\text { at levels greater } \\
\text { than or equal to } \\
0.1 \% \text { is identified as } \\
\text { probable, possible } \\
\text { or confirmed human } \\
\text { carcinogen by } \\
\text { IARC }\end{array}$ & $\begin{array}{l}\text { Toxicity to fish, } \\
\text { daphnia, algae, } \\
\text { and other } \\
\text { aquatic } \\
\text { invertebrates. } \\
\text { [13] }\end{array}$ \\
\hline Cadmium Sulfide & $\begin{array}{l}\text { Toxic if swallowed. } \\
\text { Fatal if inhaled. } \\
\text { May alter genetic } \\
\text { material. }\end{array}$ & $\begin{array}{l}\overline{\text { IARC Group } 1-} \\
\text { Carcinogenic to } \\
\underline{\text { humans(Benzene) }}\end{array}$ & $\begin{array}{l}\text { Toxicity to fish, } \\
\text { daphnia and } \\
\text { other aquatic } \\
\text { invertebrates[12] }\end{array}$ \\
\hline $\begin{array}{r}\text { 2-bytoxyethanol } \\
\text { Present in Catalyst } 9\end{array}$ & $\begin{array}{l}\text { Toxic if swallowed. } \\
\text { Fatal if inhaled. } \\
\text { May cause } \\
\text { reproductive } \\
\text { disorders. } \\
\text { May cause congenital } \\
\text { malformation in the } \\
\text { fetus. }\end{array}$ & $\begin{array}{l}\text { No component of } \\
\text { this product present } \\
\text { at levels greater } \\
\text { than or equal to } \\
\underline{0.1 \% \text { is identified as }} \\
\text { probable, possible } \\
\text { or confirmed human } \\
\text { carcinogen by } \\
\text { IARC }\end{array}$ & $\begin{array}{l}\text { Toxicity to fish, } \\
\text { daphnia and } \\
\text { other aquatic } \\
\text { invertebrates }\end{array}$ \\
\hline Naphtha & No data & $\begin{array}{l}\frac{\text { IARC Group } 1-}{\text { Carcinogenic to }} \\
\underline{\text { humans(Benzene) }}\end{array}$ & No data[10] \\
\hline$\frac{\text { Tetraethylenepentamine }}{\text { Present in Catalyst } 9}$ & Acute toxicity & $\begin{array}{l}\text { No component of } \\
\text { this product present }\end{array}$ & $\frac{\text { Toxicity to fish, }}{\text { daphnia, algae, }}$ \\
\hline
\end{tabular}




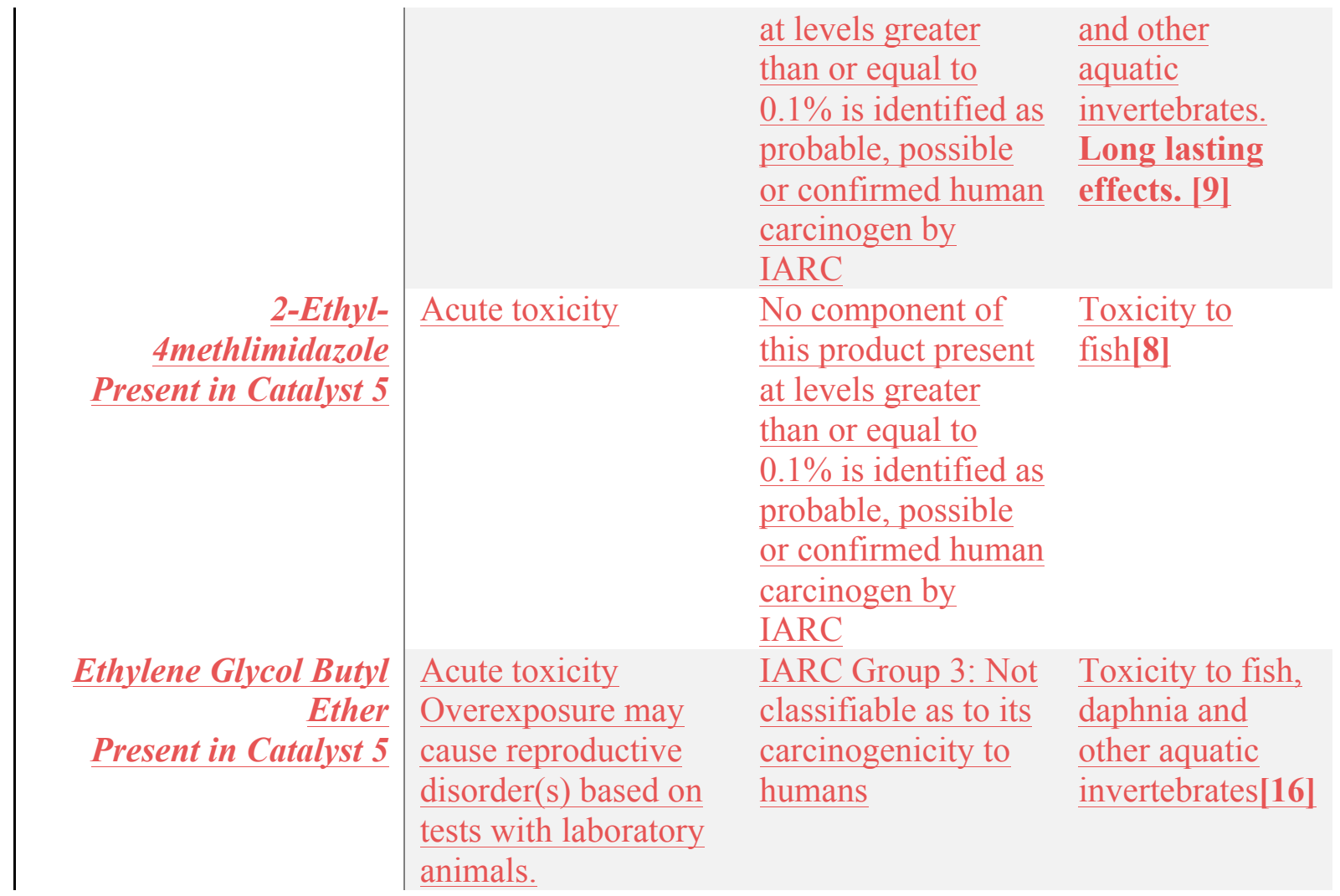

\subsection{New Solutions}

New developments in the coating industry have led to more environmentally friendly coating agents. [3] In the following section, each category of advancement will be examined and evaluated for criteria of suitable marking ink purposes.

\subsubsection{Low-Cr Conversion Coating}

Alternatives to hexavalent conversation coating have existed since the 1970 s, when they were based on trivalent chromium compounds, and had been limited primarily to lower performing coatings. [1] In 2013, a study was performed to test the corrosion resistance and the electrical contact resistance (ECR) of a new generation of 'true' chromium free 
conversion coatings as shown in Table 3. ECR was tested, as it is an integral part of the resistance of the overall circuit of a device. If ECR is significantly smaller than the total resistance of the circuit, it can impair the performance of a wide range of electric devices. A salt spray test (SST) was performed according to ASTM B117. The test was performed on AA2014-T3 and AA6082-T6 aluminum alloy with six different treatments of low-Cr or Cr-free conversion coating. The results were that, "among the 'true' chromium free treatments considered in this work, none can be considered a substitute for standard chromate process because requirements of both the SST and ECR test have not been satisfied". [23] While requirements for SST were satisfied, the coating couldn't be used due to ECR. This result indicates the new generation of conversion coating is only suitable for certain types of coatings that will not have contact with electronics.

Table 3 - Different treatments for alloys AA6082-T6 and AA2014-T3 with 6 availible treatment. [23]

\section{Different treatments for alloys AA2014-T3 and AA6082-T6}

\begin{tabular}{|l|c|c|}
\hline Treatments & AA2014-T3 & AA6082-T6 \\
\hline Treatment 1: Cr III & $\mathrm{X}$ & $\mathrm{X}$ \\
\hline Treatment 2: Talc & $\mathrm{X}$ & $\mathrm{X}$ \\
\hline Treatment 3: $\mathrm{Zr}$ & - & $\mathrm{X}$ \\
\hline Treatment 4: Talc $+\mathrm{Ce}$ & $\mathrm{X}$ & - \\
\hline Treatment 5: $\mathrm{Talc}+\mathrm{KMO}_{4}$ & $\mathrm{X}$ & - \\
\hline Treatment 6: $\mathrm{NaOH}+\mathrm{HNO}_{3}+$ Talc $+\mathrm{Ce}$ & & \\
\hline
\end{tabular}


Aside from the results, the coating process is highly unlikely to be used in a marking application due to the treatment process, which requires samples to be submerged in above room temperature, and $\mathrm{pH}$ as high as 11.5 . These processes could damage the parts for marking. [23]

\subsubsection{Non-chrome Primer for C-130J OML \& Non-chrome primer - C130J IML}

Non-chrome, primer for C-130J OML include both water-borne and solvent-borne nonchrome primer for C-130J Outer Mold Line and Non-chrome, primer for C-130J IML chrome primer for C-130J Inner Mold Line was developed by Lockheed Martin Aeronautics Company, and funded by Lockheed and US Air Force, ASC.

Primer for C-130J OML's performance actually exceeded chromate primers in a 3000 hour salt spray test. During the qualification test, the candidates finished as well as the baseline finish. There was no discoloration, chalking, thickness changes, adhesion loss or corrosion observed. [24] This product seemed to be an ideal candidate. However, because it is a primer it required a topcoat, making this product a duel stage product. 


\subsubsection{Mg-Rich Treatment}

Mg-rich treatment is a primer capable of sacrificial protection. Due to Aluminum's low position in the galvanic series, it's limited to anodic metals. [25] This work is capable of protection of high strength aircraft Al alloy such as 2024 T-3 and 7075 T-6 without the use of Chromium. However, these primer coatings need to be top-coated in order to function properly and have a long field life. [26]

\subsubsection{Non-chrome, Low VOC Fuel Tank Coating (Mil Spec AMS-C-27725)}

Mil Spec AMS-C-27725 is a polyurethane coating developed in 1969. It includes two classes, Class A and Class B. Class A is for general use in areas where air pollution regulation does not exist. Class B is for limited use. In today's environment, these products are obsolete. [27]

\subsubsection{Barrier coat for F-16}

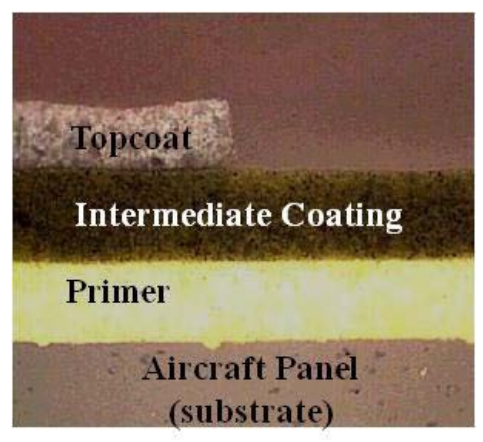

Figure 2 - Barrier coat encapsulating chrome primer. [3] 
As seen from Figure 2, Barrier coat's purpose is to encapsulate chrome primer.

Therefore, it would not be suitable for marking purposes.

\subsection{Adhesion of Marking Ink}

\subsubsection{Reliability of Marking Ink}

Reliability of marking ink depends on several factors, and any combination of these factors could attribute to failure. [28]

1. Poor or inadequate surface preparation and application of the paint to the substrate

2. Atmospheric effects

3. Structural defects in a paint film

4. Stresses between the bond and the substrate

5. Corrosion

Atmospheric effects, structural defects, stresses between bond and the substrate, are largely dependent on the structure and the operating environment, while corrosion depends on the chemical composition of the coating layers.

\subsubsection{Surface Preparation and Adhesion}

The surface preparation of the panels is critical in the adhesion of the marking ink. The consequences of poor surface preparation will yield results such as peeling, flaking, and delamination. The surface treatment needs to remove oils, dirt, grime, waxes, and loose particulates. In addition, surface treatment methods could also improve the adhesion 
properties by increasing surface roughness and surface energy, and reducing other factors that could trap unwanted particles between the substrate and the coating.

The adhesion of a coating is improved when a clean panel contains pores, holes, or crevices. The roughness of the surface creates a mechanical anchor on the panel surface. Thus, making the removal of the coating more difficult as shown in Figure 3.
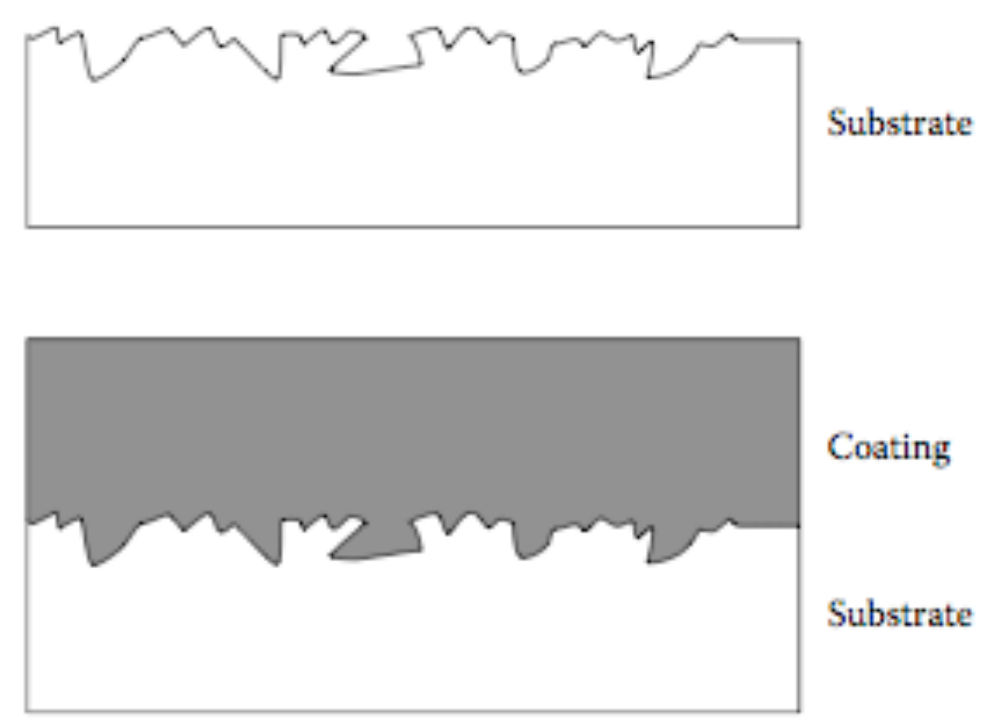

Figure 3 - Before and after image of paint coat anchoring to the substrate.[28]

Increasing the surface roughness could increase the surface area, as well as the bonding area by five times. [28] However, the effects of surface roughness are only possible if the coating can penetrate completely into all the surface irregularities. If compete penetration is not achieved, then there is less coating-to-interface contact. The typical method to increase surface area on a panel is to use either wet or dry sanding with grit of 40-400. [28] The grit size depends on the surface finish desired. Following the surface treatment, the panel must be removed of residual dust or grit and then treated with either detergent 
cleaning or solvent cleaning to remove the surface contamination by sanding. By sanding, it is also possible to get rid of the corrosion of the substrate. However, this does not apply to our case, due to the polymer coating that is already in place prior to the use of marking ink.

There are several other surface treatments that could improve the adhesion of paints and coatings:

1. Mechanical Treatments.

2. Chemical Treatments

i. Sulfuric Acid-Dichromate Etch

ii. Sodium Etch

iii. Sodium Hydroxide

iv. Sanitizing

v. Phenol

vi. Sodium Hypochlorite

\section{Plasma Treatment}

4. Flame Treatment

5. Corona Discharge

6. Primer [28] 
Most of these treatments are unsuitable for marking ink, simply because most product are at the end of its production stage when it is being marked, and it is unrealistic to perform these treatments that could damage the parts.

In addition to surface treatments, surface contamination is the major concern in the adhesion of the coatings. The easiest and most common procedure is to remove surface contamination by organic solvents such as acetone, methyl ethyl ketone, toluol, 1,1,1,trichloroethane, naphtha, and on occasion Freon. [28] The property of the organic solvents will remove process oils, dirt, grime, waxes, and other particulates left behind by sanding. These solvents are applied by simply wiping with a clean cotton pad in a swirling motion on the panel to remove the undesired contaminates. 


\section{Chapter 3 - Materials and Methods}

\subsection{Product Selection}

In order to evaluate alternatives to replace products such as Enthone, 17 companies were contacted to provide information about their eco-friendly product lines. The companies selected represented a diverse group ranging from small to large companies and included Domino and Leibinger from Europe.

$\begin{array}{llll}\text { - } & \text { Akzonobel } & \bullet & \text { Marco Ink } \\ \text { - } & \text { DuPont } & \text { Nazdar } & \text { Sherwin Williams } \\ \text { - } & \text { Markem Imaje } & \text { - } & \text { Domino } \\ \text { - } & \text { American Marking } & \text { - } & \text { Leibinger } \\ \text { - } & \text { Sun Chemical } & \bullet & \text { Nanotech } \\ \text { - DEFT } & \bullet & \text { Independent Ink } \\ \text { - } & \text { JanTech } & \bullet & \text { Union Ink } \\ \text { - } & \text { Jetec } & \bullet & \text { Go Green World Products }\end{array}$

In total, 11 product lines were selected for testing.

- AkzoNobel

1. Aerofine - a one compound low VOC, isocyanate free, waterborne topcoat.

2. Spray2Fix (Intergard 10301SC) - High solids epoxy primer.

- DuPont

3. Industrial Strength - Ultra low VOC polyurethane enamel high gloss topcoat.

4. Imron 1.2 HG - High gloss waterborne polyurethane copolymer topcoat. 
- DEFT

5. MIL-PRF-85285 - two compound polyurethane topcoat intended for use on exterior application on aircraft and aerospace equipment.

- American Marking

6. JS series - RoHS compliant solvent-based ink. (Acetone based)

7. WJ series - water-based pigmented environmentally-friend spray ink.

- Sherwin Williams

8. KEM AQUA-BP Enamel - One component low HAPS and low VOC water reducible enamel.

9. MIL-PRF 22750G Type I - 2.7 VOC compliant high solids two component epoxy topcoat. Intended for use as a top coat of interior ground equipment.

- Union Ink

10. Uniglaze - Two compound epoxy ink intended for application such as printed circuit board markings and electronic equipment panels.

- Go Green World Products

11. Green Polyurethane - Isocyanine polyurethane paint.

These product lines were selected due to their relative eco-friendly compositions. Of 11 products, there were 4 water-based products, 1 acetone-based product, 4 polyurethane products, and 2 Epoxy products. Green Polyurethane and Aerofine were also iscyanatefree, a compound attributed to the cause of asthma, which is rarely found in the industry. Of the 11 products, 2 were already being used in military applications and were selected due to their relative eco-friendliness. The Uniglaze product line was being used by part of Raytheon, and therefore served as a control. 


\subsection{Methods}

\subsubsection{Evaluation of Metal Panels}

Metal panels were evaluated for cleanliness prior to testing as shown in Figure 4. A qualitative water break test, ASTM F22, a procedure approved by the Department of Defense, was performed to determine if the surface contained any contaminates. This test method detects the presence of hydrophobic (non-wetting) films on surfaces and the presence of hydrophobic organic materials in process ambient. [29] A steady stream of water was applied across the panel at a $45^{\circ}$ angle. Panels were judged clean if the film of

water either did not break up or take a minute to do so. This is because water will bead up when it comes in contact with hydrophobic surface contaminates. Acetone was used to clean contaminated panels. This method is sufficient to provide a clean surface, but is not as thorough as using a batch or vapor degreaser cleaning system. However, batch or vapor degreaser cleaning systems are unpractical due to heat and moisture exposure to electrical systems and the sheer size of assembled tactical equipment. 

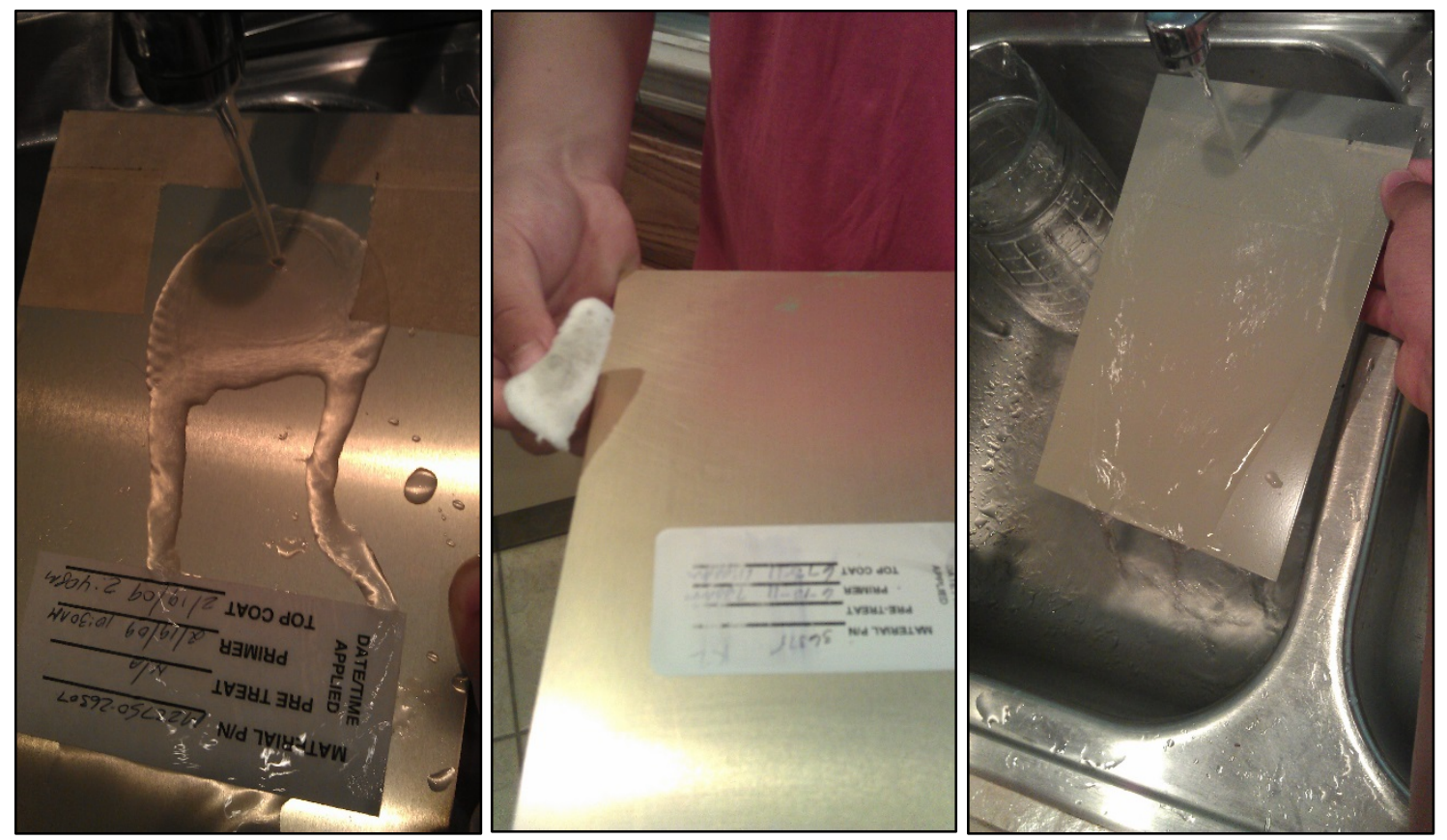

Figure 4 - Water-break test, Left - contaminated panel, center-clean panel with acetone, right - clean panel.

\subsubsection{Painting Methodology and Curing Schedule}

Clean panels were painted using the following steps:

Paint Instructions:

1. Clean panels with Acetone for at least 3 minutes.

2. Apply water onto the panel to confirm for surface cleanliness.

3. Arrange desired amount of stencils on the panel.

4. Use blue tape to secure the left and right sides of the stencils.

5. Use blue tape along with painter's masking paper to cover unused stencils.

6. Airbrush the stencils two inches away from the panel and apply at a steady pace for 2 passes (20-30 seconds). Dwelling time of the airbrush on the stencils vary with different paints due to varying viscosities. Dwell times were determined prior to painting the samples to produce a consistent thickness.

7. Pour away the unused paint and remove excess paint.

8. Pour airbrush cleaner and run airbrush for 3 minutes. 
9. Disassemble airbrush and clean with water.

10. Remove all masking paper once all paint has been applied.

11. Force cure the panels at $70{ }^{\circ} \mathrm{C}$ for 60 minutes.

Curing schedule of different materials varied due to varying composition (Appendix D). Insufficient curing times resulted in improper samples. A longer curing time does not adversely affect the paint. Epoxy paint has the longest average cure time (Appendix D); therefore, $70^{\circ} \mathrm{C}$ for 60 minutes was selected as the cure time.

It was observed that Green Polyurethane could not be applied using the airbrush due to its high viscosity. As a result, Green Polyurethane was applied via brushing. Due to the small size of the stencil, the numbers were deformed and the shape of the numbers were not as defined as other samples.

\section{3 Design of Experiment}

The selected marking inks were evaluated using the following performance standards:

1. Solvent resistivity.

2. Moisture resistivity

3. Discoloration due to high temperature.

4. Temperature related failures.

5. Cleaning system related failures.

6. Military requirements of marking ink. [30] 
Additionally, it would be beneficial for the implementation of these marking inks if the marking ink could validate the various MIL-STD parameters recommended by the Department of Defense. Therefore, most of these tests were derived from the recommendations of many military standards.

Samples marking inks were sprayed on both sides, the back was M5541 T1 Class3 Chem-Filmed aluminum and the front was painted aluminum using M23377 T2 Class N primer with M22750 or M85285 topcoats as shown in Figure 5. The samples were applied using an airbrush and an 11-point font stencil provided by Raytheon. Each stencil included 11 samples, and each sample consisted of one letter and a number that ranged from 1 to 55. Each time the paint samples were applied, it would be covered with masking paper and scotch blue\#2093EL as shown in Figure 6.

In the following test, 6 panels were painted front and back, yielding 66 samples on M5541 T1 Class3 Chem-Filmed aluminum and 66 samples on painted aluminum using M23377 T2 Class N primer with M22750 or M85285 topcoats. 


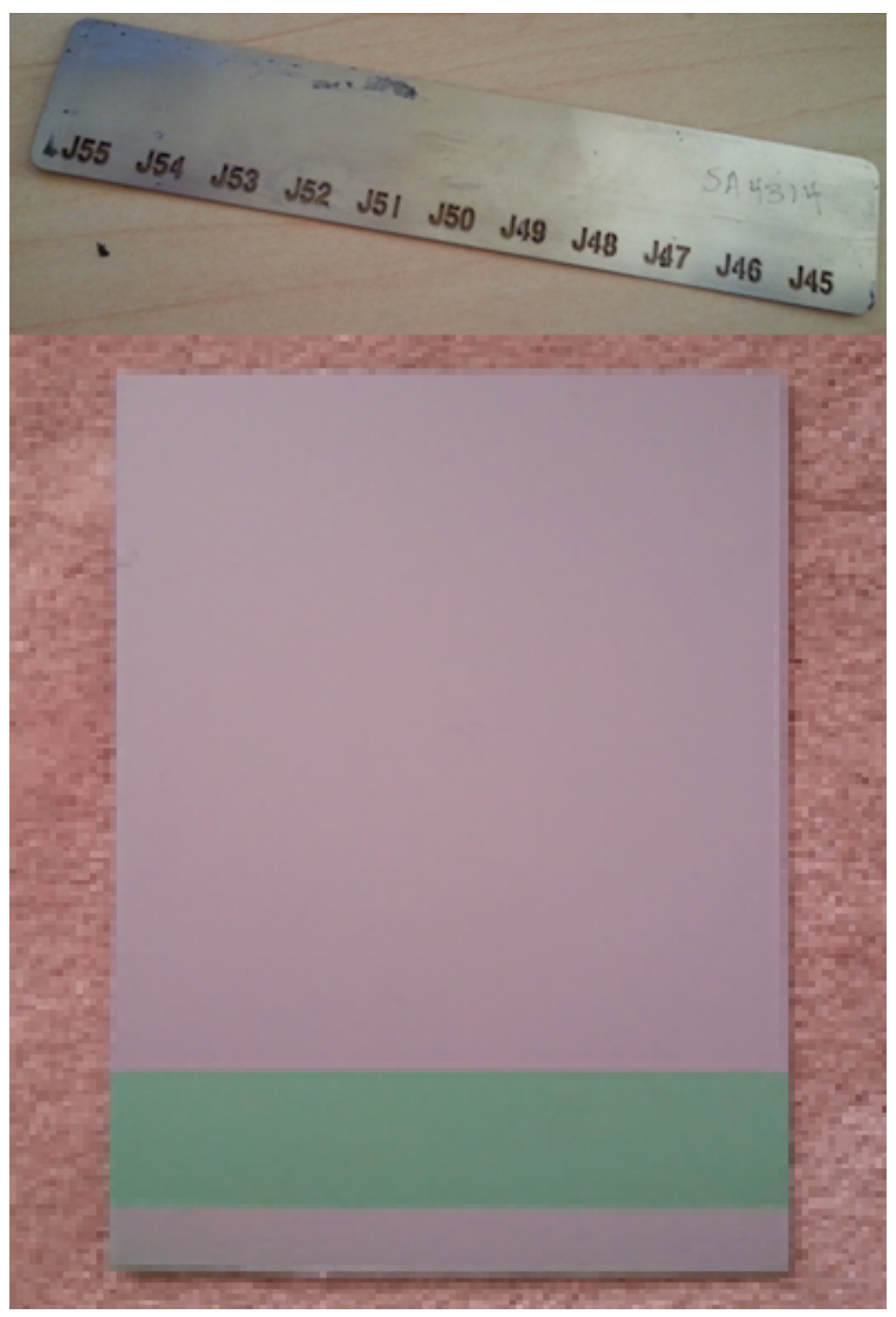

Figure 5-Top, 11-point font stencil provided by Raytheon, Bottom, M23377 T2 Class N primer with M22750 or M85285 topcoats 


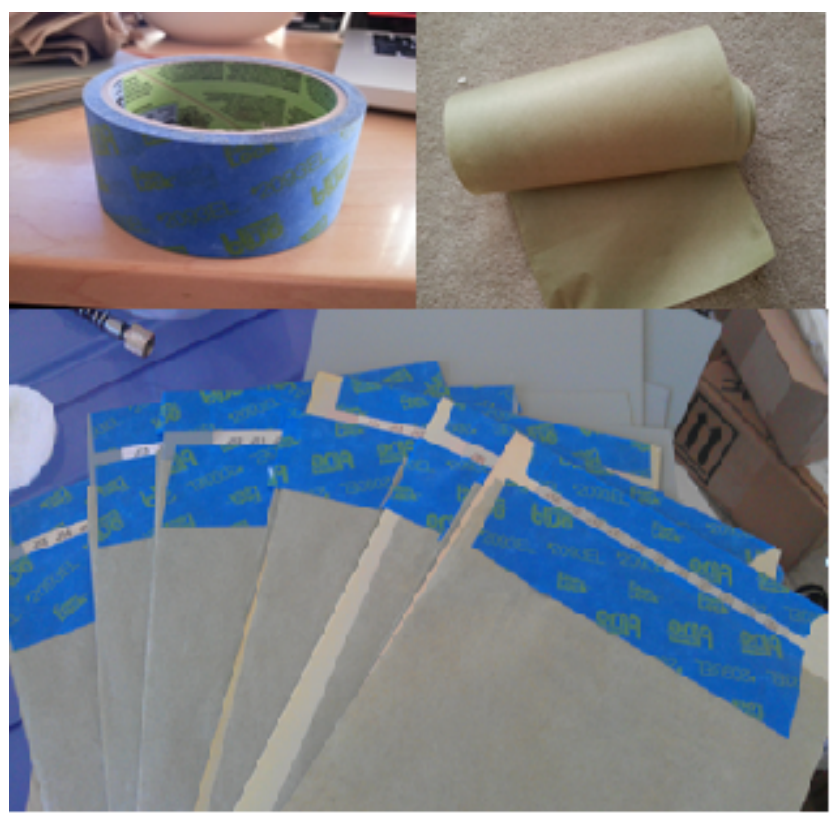

Figure 6-Top, masking paper and scotch blue\#2093EL. Bottom, stencil covered by masking paper and scotch blue\#2093EL on Al panel.

Testing consisted of two phases. Phase I determined if the material could pass a typical polar-nonpolar solvent resistivity test described in MIL-STD202G method 215K. Phase II, consisted of further solvent testing, a humidity test, a thermal shock test, and a cleaning system test. These tests were designed to test the performance criteria of the ink. 


\subsubsection{Solvent Resistivity:}

During phase I of testing, MIL-STD 202G, Method 215K was used to reduce the possible candidates. MIL-STD 202G, Method 215K verifies that marking and color will not become illegible or discolored when subjected to solvent and processes normally used to clean electronics. It also verifies that the component protective coatings and encapsulation materials are not degraded to the point where electrical or mechanical integrity is disturbed when subjected to solvents and processes normally used to clean solder flux, finger prints, and other contaminants from printed-wiring and terminal-board assemblies.

The original MIL-STD 202G included four solvent tests. Solvent II was removed from the current MIL-STD, leaving three solvent tests in the MIL-STD. Solvent tests I and III had the same procedures, while Solvent IV had a slightly different procedure.

Solvent I included 1 part isopropyl alcohol and 3 parts mineral spirits by volume. Solvent III was an over-the-counter commercial terpene defluxer. Isopropyl alcohol, mineral spirit, and terpene defluxer were bought off -the-shelf. Solvent IV was mixed in the lab with 1 part propylene glycol monomethyl ether (PGME), 1 part monoethanolamine (MEA) by volume, and 42 parts water by volume. 
Solvent I was maintained at a temperature of $25^{\circ} \mathrm{C} \pm 5^{\circ} \mathrm{C}$.

1. The specimens will be completely immersed for 2.5-3.5 minutes in the specified solution.

2. The bristle portion of the brush was dipped in the solution until wetted and the specimen shall be brushed with normal hand pressure (approximately 2 to 3 ounce force applied normal to the surface) for ten strokes on the portion of the specimen where marking has been applied.

3. The brush stroke shall be directed in a forward direction across the surface of the specimen being tested. Immediately after brushing, the procedure shall be repeated two more times, for a total of three immersions.

4. After completion of the third immersion and brushing, the specimens shall be airblown dry.

Solvent III was maintained at a temperature of $25^{\circ} \mathrm{C} \pm 5^{\circ} \mathrm{C}$.

1. The specimens were completely immersed for 2.5-3.5 minutes in the specified solution.

2. The bristle portion of the brush was dipped in the solution until wetted and the specimen was brushed with normal hand pressure (approximately 2 to 3 ounce force applied normal to the surface) for ten strokes on the portion of the specimen where marking had been applied.

3. The brush stroke was directed in a forward direction across the surface of the specimen being tested. Immediately after brushing, the procedures were repeated two more times, for a total of three immersions.

4. After the completion of the third immersion and brushing, the specimens were rinsed in approximately $25^{\circ} \mathrm{C}$ water and all surfaces were air-blown dry.

Solvent IV was maintained at a temperature of $63^{\circ} \mathrm{C}$ to $70^{\circ} \mathrm{C}$ as shown in Figure 7 .

1. The specimens were be completely immersed for 2.5-3.5 minutes in the specified solution. 
2. The bristle portion of the brush was dipped in the solution until wetted and the specimen was brushed with normal hand pressure (approximately 2 to 3 ounces of force was applied normally to the surface) for ten strokes on the portion of the specimen where marking had been applied.

3. The brush stroke was directed in a forward direction across the surface of the specimen being tested. Immediately after brushing, the procedure was repeated two more times, for a total of three immersions.

4. After completion of the third immersion and brushing, the specimens were rinsed in approximately $25^{\circ} \mathrm{C}$ water and all surfaces were air-blown dry.

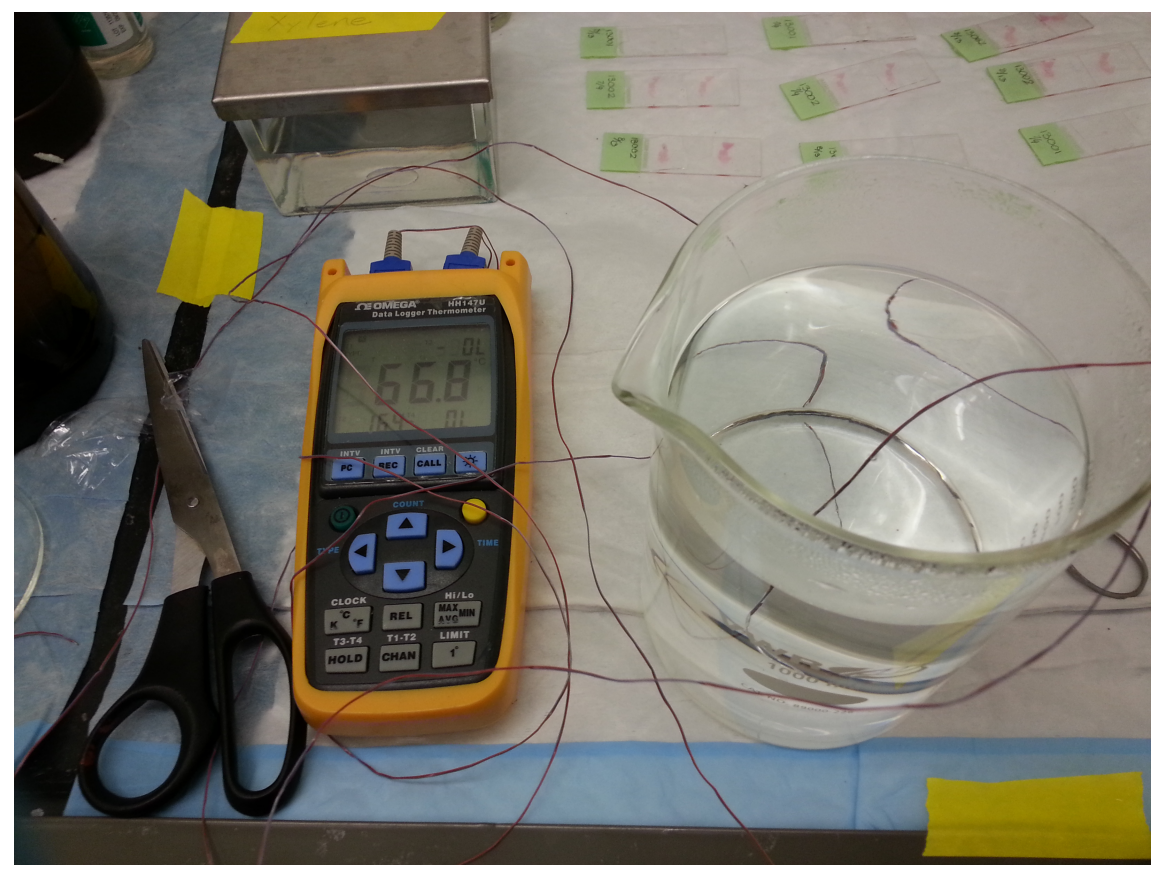

Figure 7 - Solution IV maintained at temperature of $63^{\circ} \mathrm{C}$ to $70^{\circ} \mathrm{C}$

After the test, the panels were examined from a distance of at least six inches with normal lighting without the aid of magnification. This was done to ensure that there no panels were entirely or partially missing, faded, smeared, blurred, or shifted to the extent that they could not be readily identified.

In phase II, additional solvent testing included jet fuel, hydraulic fluid, and ethylene glycol coolant/de-icing fluids. These solvents are common solvents found in the 
aerospace industry and are commonly presented in the environment of tactical equipment. In phase II, the procedures used were the same as Solvent I due to the common operating temperature and that the exposure these additional solvents were not washed off with water.

\subsubsection{Thermal Shock \& Color Discoloration Test}

The purpose of this test is to determine the resistance of a part to temperatures at high and low extremes. These conditions may be encountered in equipment operated continuously in low temperature areas and high temperatures areas. Permanent changes in operating characteristics and physical damage produced in thermal shock, principally results from variation in dimension and other physical properties.

In thermal shock, we used MIL-STD 202G, Method 107G to simulate the closest operating conditions of tactical equipment. Two extremes were considered: the coldest part of the atmosphere, the area between the stratosphere and troposphere, tropopause, which could reach as cold at $-57^{\circ} \mathrm{C}$, and the upper bound, which was chosen as $125^{\circ} \mathrm{C}$ due to operation conditions due to the heat produced by the engine and the environment. In testing, a recovery time of 5 minutes, a dwell time of 30 minutes in each of the chambers were established according to the weight of our panels, while the testing profile was set to profile B due to the two temperature extremes as shown in Table $4 \& 5$. 
Ten cycles were run and results were based upon the change in color of each specimen to ensure there were no discolorations due to high temperature.

Table 4 - MIL-STD-202G, Method 107 Exposure time in air at temperature extremes.

\begin{tabular}{|l|c|}
\hline Weight of Specimen & $\begin{array}{l}\text { Minimum time in } \\
\text { chamber (hours) }\end{array}$ \\
\hline 1 ounce & $1 / 4$ \\
\hline Above 1 ounce to .3 pounds $(28 \mathrm{~g}$ to $136 \mathrm{~g})$, inclusive & $1 / 2$ \\
\hline 3 pounds to 3 pounds $(136 \mathrm{~g}$ to $1.36 \mathrm{~kg})$, inclusive & 1 \\
\hline 3 pounds to 30 pounds $(1.36 \mathrm{~kg}$ to $13.6 \mathrm{~kg})$, inclusive & 2 \\
\hline 30 pounds to 300 pounds $(13.6 \mathrm{~kg}$ to $136 \mathrm{~kg})$, inclusive & 4 \\
\hline Above 300 pounds (above $136 \mathrm{~kg})$ & 8 \\
\hline
\end{tabular}


Table 5 - MIL-STD-202G, Method 107G Thermal shock test conditions in air environment.

\begin{tabular}{|c|c|c|c|c|c|c|}
\hline Step & $\begin{array}{l}\text { Test } \\
\text { Condition }\end{array}$ & $\begin{array}{l}\text { Number } \\
\text { of cycles }\end{array}$ & $\begin{array}{l}\text { Test } \\
\text { Condition }\end{array}$ & $\begin{array}{l}\text { Number } \\
\text { of cycles }\end{array}$ & $\begin{array}{l}\text { Test } \\
\text { Condition }\end{array}$ & $\begin{array}{l}\text { Number of } \\
\text { cycles }\end{array}$ \\
\hline & A & 5 & $\mathrm{~B}$ & 5 & $\mathrm{C}$ & 5 \\
\hline & A-1 & 25 & B-1 & 25 & $\mathrm{C}-1$ & 25 \\
\hline & A-2 & 50 & B-2 & 50 & $\mathrm{C}-2$ & 50 \\
\hline & A-3 & 100 & B-3 & 100 & $\mathrm{C}-3$ & 100 \\
\hline & $\begin{array}{l}\text { Temp } \\
\left({ }^{\circ} \mathrm{C}\right)\end{array}$ & & Temp $\left({ }^{\circ} \mathrm{C}\right)$ & & Temp $\left({ }^{\circ} \mathrm{C}\right)$ & \\
\hline 1 & $-50+0,-3$ & see table 4 & $-65+0,-5$ & see table 4 & $-65+0,-5$ & see table 4 \\
\hline 2 & $25+10,-5$ & $\begin{array}{l}5 \text { minute } \\
\text { maximum }\end{array}$ & $25+10,-5$ & $\begin{array}{l}5 \text { minute } \\
\text { maximum }\end{array}$ & $25+10,-5$ & $\begin{array}{l}5 \text { minute } \\
\text { maximum }\end{array}$ \\
\hline 3 & $85+3,-0$ & see table 4 & $125+3,-0$ & see table 4 & $200+5,-0$ & see table 4 \\
\hline 4 & $25+10,-5$ & $\begin{array}{l}5 \text { minute } \\
\text { maximum }\end{array}$ & $25+10,-5$ & $\begin{array}{l}5 \text { minute } \\
\text { maximum }\end{array}$ & $25+10,-5$ & $\begin{array}{l}5 \text { minute } \\
\text { maximum }\end{array}$ \\
\hline \multirow[t]{6}{*}{ Step } & $\begin{array}{l}\text { Test } \\
\text { Condition }\end{array}$ & $\begin{array}{l}\text { Number } \\
\text { of cycles }\end{array}$ & $\begin{array}{l}\text { Test } \\
\text { Condition }\end{array}$ & $\begin{array}{l}\text { Number } \\
\text { of cycles }\end{array}$ & $\begin{array}{l}\text { Test } \\
\text { Condition }\end{array}$ & $\begin{array}{l}\text { Number of } \\
\text { cycles }\end{array}$ \\
\hline & $\mathrm{D}$ & 5 & $\mathrm{E}$ & 5 & $\mathrm{~F}$ & 5 \\
\hline & D-1 & 25 & E-1 & 25 & F-1 & 25 \\
\hline & D-2 & 50 & E-2 & 50 & $\mathrm{~F}-2$ & 50 \\
\hline & D-3 & 100 & E-3 & 100 & F-3 & 100 \\
\hline & $\begin{array}{l}\text { Temp } \\
\left({ }^{\circ} \mathrm{C}\right)\end{array}$ & & Temp $\left({ }^{\circ} \mathrm{C}\right)$ & & Temp $\left({ }^{\circ} \mathrm{C}\right)$ & \\
\hline 1 & $-50+0,-3$ & see table 4 & $-65+0,-5$ & see table 4 & $-65+0,-5$ & see table 4 \\
\hline 2 & $25+10,-5$ & $\begin{array}{l}5 \text { minute } \\
\text { maximum }\end{array}$ & $25+10,-5$ & $\begin{array}{l}5 \text { minute } \\
\text { maximum }\end{array}$ & $25+10,-5$ & $\begin{array}{l}5 \text { minute } \\
\text { maximum }\end{array}$ \\
\hline 3 & $350+5,-0$ & see table 4 & $500+5,-0$ & see table 4 & $150+3,-0$ & see table 4 \\
\hline 4 & $25+10,-5$ & $\begin{array}{l}5 \text { minute } \\
\text { maximum }\end{array}$ & $25+10,-5$ & $\begin{array}{l}5 \text { minute } \\
\text { maximum }\end{array}$ & $25+10,-5$ & $\begin{array}{l}5 \text { minute } \\
\text { maximum }\end{array}$ \\
\hline
\end{tabular}




\subsubsection{Humidity Test}

Humidity test was perform to ensure the resistance of material to the effects of a warm and humid atmosphere. Due to the vastly different operating environments of tactical equipment, humidity resistance must be consider. Warm, humid conditions can occur year-round in tropical areas, seasonally, in mid-latitude areas in combination to changes in temperature and relative humidity. These Humidity test in DoD typically follows environmental engineering considerations and laboratory tests standards, MIL-STD810G, Method 507.5, Humidity testing. In general there are two types of humidity testing used in the Department of Defense: induced and aggravated.

"Induced" testing refers to storage and transit, and the typical test includes three unique cycles that may occur during storage or transit. Exposure to these temperatures showed drastically "lower" results when compared with the aggravated test.

Aggravated testing exposed samples to more extreme temperatures and humidity to simulate the worst-case scenario environment. Purpose of aggravated test procedure is to produce a representative effect that occurs when material is exposed to elevated temperature-humidity conditions. These cycles typically don't occur in nature or normal operating parameter. Thus, a failure in the test doesn't necessarily indicate failure in the real environment.

In our test, ten cycles were run in the temperature-humidity profile in Figure 8, an 
aggravated test. Each cycle indicates a full 24 hours. The relative humidity was kept at 95 $\%$ and the temperature varied from $30^{\circ} \mathrm{C}$ to $60^{\circ} \mathrm{C}$.

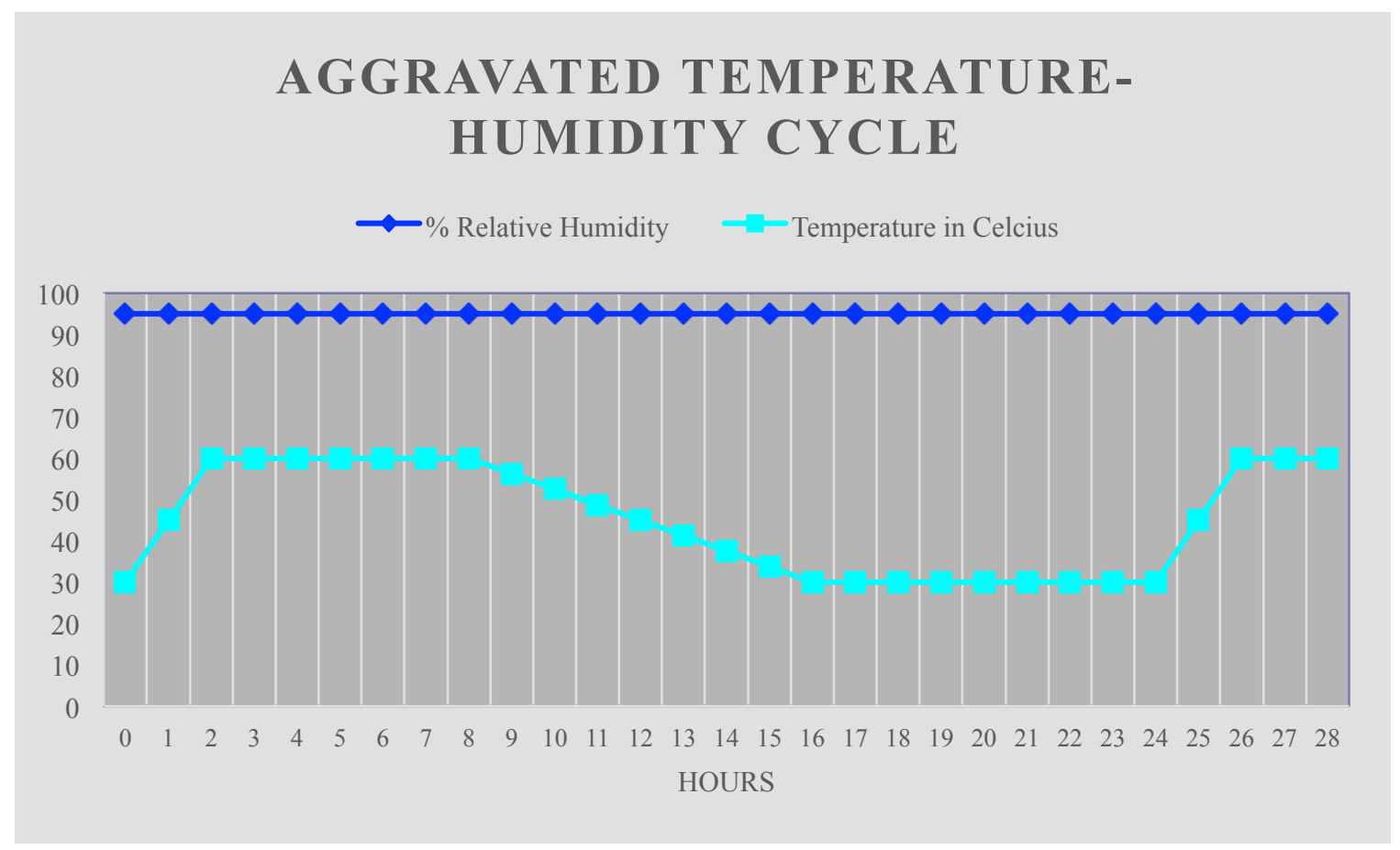

Figure 8- Temperature/Humidity Profile of MIL-STD-810G, Method 507.5G

Procedure for Humidity Test:

Step 1. With the test item installed in the test chamber in its required configuration, adjust the temperature to $23 \pm 2^{\circ} \mathrm{C}\left(73 \pm 4^{\circ} \mathrm{F}\right)$ and $50 \pm 5$ percent $\mathrm{RH}$, and maintain for no less than 24 hours.

Step 2. Adjust the chamber temperature to $30^{\circ} \mathrm{C}\left(86^{\circ} \mathrm{F}\right)$ and the $\mathrm{RH}$ to 95 percent.

Step 3. Expose the test item(s) to at least ten 24 -hour cycles ranging from $30-60^{\circ} \mathrm{C}(86-$ $\left.140^{\circ} \mathrm{F}\right)$. Unless otherwise specified in the test plan, conduct a test item operational check (for the minimum time required to verify performance) near the end of the fifth and tenth cycles. 
Step 4. At the completion of 10 or more successful cycles, adjust the temperature and humidity to $23 \pm 2^{\circ} \mathrm{C}\left(73+4^{\circ} \mathrm{F}\right)$ and $50 \pm 5$ percent $\mathrm{RH}$, and maintain until the test item has reached temperature stabilization (generally not more than 24-hours).

Step 5. Perform a thorough visual examination of the test item, and document any conditions resulting from test exposure.

Step 6. Conduct a complete operational checkout of the test item and document the results. See paragraph 5 for analysis of results.

Step 7. Compare these data with the pretest data

\subsubsection{Cleaning System Test}

Aside from accelerated environmental testing, the test subject must also be able to withstand typical cleaning systems used in military facilities. In our testing, panels were sent to military facilities provided by Raytheon to be tested. Testing include:

- Branson B-series Degreaser with ultrasonic using Asahiklin AK-225T solvent.

- Aqueous Technologies Trident batch cleaning system using Kyzen A4615 Asahiklink AK-225T solvent is a vapor degreaser that's designed to replace chlorofluorcarbon, perfluorcarbon, and other hydrochloroflurocarbon. It's ideal for general and precision cleaning.

Kyzen A4615 is a MEA-free aqueous blend specially designed for electronics processes for removal of some lead-free flux, tacky flux, misprinted paste, no clean flux, RMA flux, OA paste, oils, finger prints, light oxides. 
Samples were run 3 times in each system to simulate worst-case conditions before parts were reworked and run through more than once.

\subsubsection{Military Marking Ink Requirement}

MIL-STD-130N, Department of Defense standard practice identification marking of U.S.

military property determines the clarification, insight, guidance, and marking criteria regarding implementation of machine-readable information (MRI) for identification marking of U.S. military property and automatic data capture. This MIL standard provides the criteria by which product designers develop specific identification marking requirements for items: the marking content, size, location, application processes, and any product definition data that the marking be in accordance with this standard. For our purposes, the primary interest of MIL-STD-130N is if the samples are capable of producing minimum character heights of 6 pts or .08-inch height fonts.

\subsubsection{ASTM D3359 Tape Test}

In addition to accelerated life testing, the samples were also tested by tape test described in ASTM Designation: D3359 - 97, a common test intended to test for paint adhesion. Due to the size of our samples, Test Method A was used, "An X-cut is made in the film to the substrate, pressure-sensitive tape is applied over the cut and then removed, and adhesion is assessed qualitatively on the $0 \mathrm{~A}-5 \mathrm{~A}$ scale in the analysis of the paint.” The apparatus used was razor blade and one-inch wide pressure-sensitive tape with an adhesion strength agreed upon by Raytheon. The adhesion in accordance with the following scale: 
- 5A No peeling or removal

- 4A Trace peeling or removal along incisions or at their intersection

- 3A jagged removal along incisions up to $1 / 16$ in. on either side

- 2A jagged removal along most of incision up to $1 / 8$ in. on either side

- 1A removal from most of the area of the $\mathrm{X}$ under the tape

- 0A removal beyond the area of the X.[31] 


\section{Chapter 4 -Results and Analysis}

\subsection{Phase 1 Test Result}

In phase 1, painted panels were exposed to solvents in MIL-STD 202G method 215k and the procedures can be summarized in Table 6 .

\section{Table 6 - Summary of testing procedure of MIL-STD 202 G Method 215K}

\begin{tabular}{|c|c|c|c|}
\hline Testing Procedure & $\begin{array}{l}\text { Solvent I: } \\
\text { Alcohol } \\
\text { and } \\
\text { Mineral } \\
\text { Spirit }\end{array}$ & $\begin{array}{l}\text { Solvent II: } \\
\text { Terpene } \\
\text { defluxer }\end{array}$ & $\begin{array}{l}\text { Solvent III: } \\
\text { PGME, } \\
\text { MEA, } \\
\text { Water }\end{array}$ \\
\hline 1. Maintain solution temperature $\left({ }^{\circ} \mathrm{C}\right)$ & $20-30$ & $20-30$ & $63-70$ \\
\hline 2. Immerse sample for $\mathbf{3}$ minutes & $\mathrm{X}$ & $\mathrm{X}$ & $\mathrm{X}$ \\
\hline $\begin{array}{l}\text { 3. Brush with normal hand pressure (ten } \\
\text { strokes) }\end{array}$ & $\mathrm{X}$ & $\mathrm{X}$ & $\mathrm{X}$ \\
\hline 4. Repeat twice & $\mathrm{X}$ & $\mathrm{X}$ & $\mathrm{X}$ \\
\hline 5. Rinse in $25\left({ }^{\circ} \mathrm{C}\right)$ water & & $\mathrm{X}$ & $\mathrm{X}$ \\
\hline 6. Air dry & $\mathrm{X}$ & $\mathrm{X}$ & $\mathrm{X}$ \\
\hline
\end{tabular}

11 product lines were tested, all of which were painted with red and black, except for DuPont 1.2 HG and Green Polyurethane. DuPont 1.2 HG and Green Polyurethane was tested in white due to the delay and out of stock.

The panels were examined from a distance of at least 6 inches with normal lighting and without the aid of magnification for partially of fully missing plates, faded, smeared, blurred, or shifted to the extent that they cannot be readily identified. Of the 11 products tested, 5 passed all 3 solvent tests. The results were very definite, due to the way the paints failed in Table 7. The results were also analyzed similarly in Figure 10 for discoloration using DigitalColor Meter. However, the results were inconclusive due to lighting sensitivity and lack of difference in the colors. 
As shown in Table 7, The 4 water-based products, American Marking WJ series, Akzonobel Aerofine, DuPont 1.2 HG, and Sherwin Williams AQUA-BP, failed Solvent I, alcohol and mineral spirit solution. When exposed to solvent 1, the water-based products were able to be brushed off easily. The acetone-based, American Marking JS series also failed the test. After 3 exposures, missing markings and faded letters are clearly visible. Akzonobel Spray2Fix also failed due to faded letters. (Please refer to Appendix E for raw results) 
Table 7 - Snapshot of samples in Phase 1 Testing

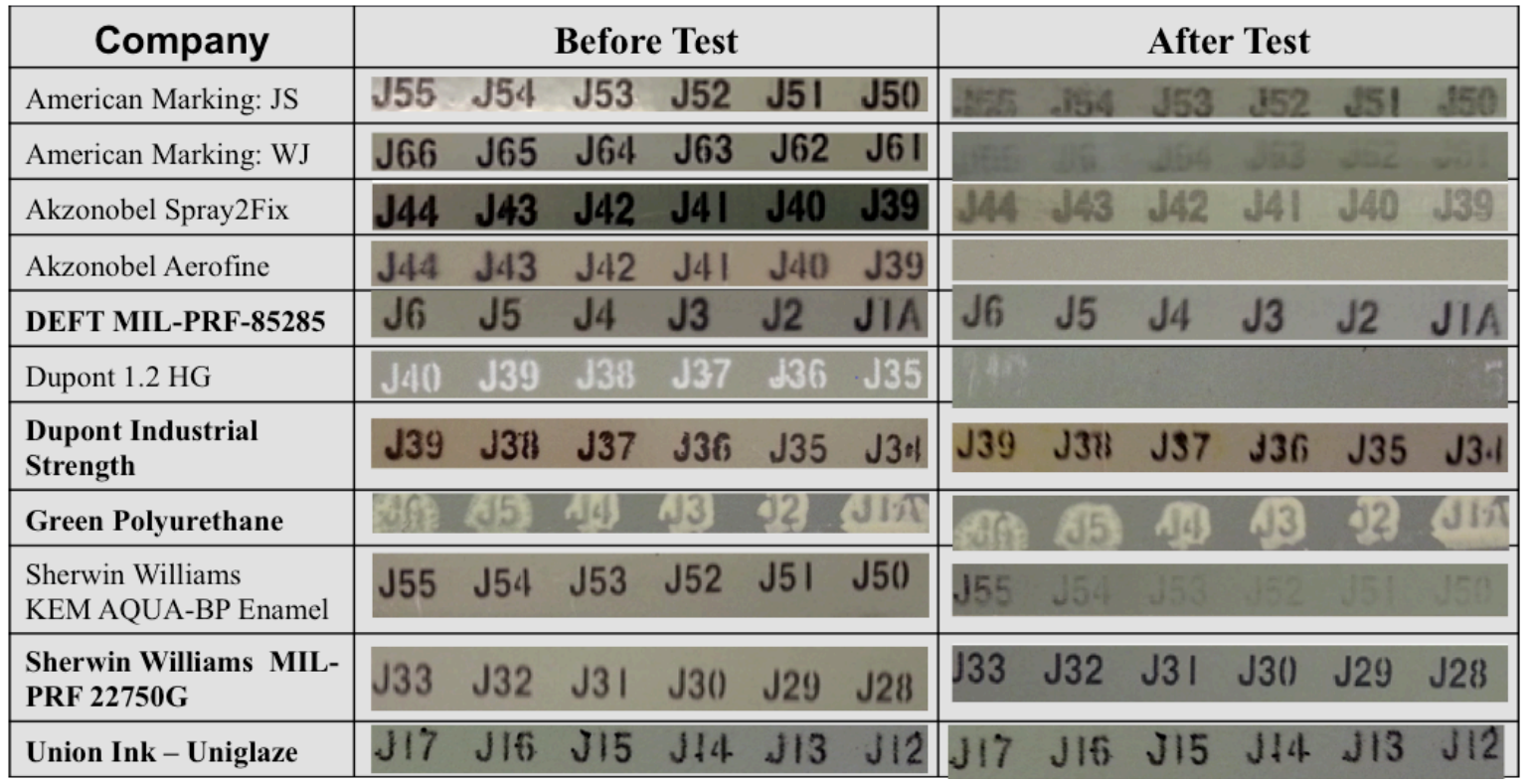

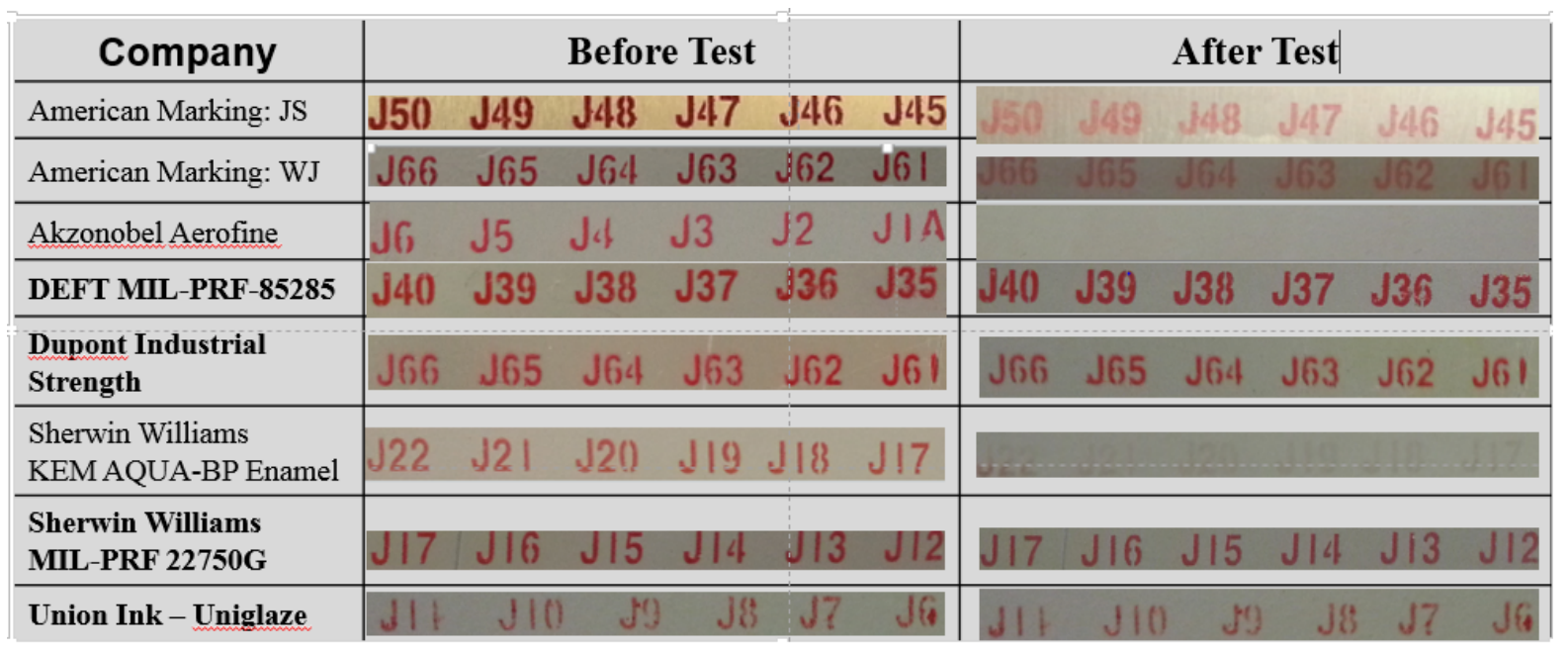


Of the 11 product lines tested, 5 product line remain as shown in Table 8 .

- DuPont Industrial Strength - Ultra low VOC polyurethane enamel high gloss topcoat.

- DEFT MIL-PRF-85285 - two compound polyurethane topcoat intended for use on exterior application on aircraft and aerospace equipment.

- Sherwin Williams MIL-PRF 22750G Type I-2.7 VOC compliant high solids two component epoxy topcoat. Intended for use as a top coat of interior ground equipment.

- Union Ink Uniglaze - Two compound epoxy ink intended for application such as printed circuit board markings and electronic equipment panels.

- Go Green World Products Green Polyurethane - Isocyanine polyurethane paint.

Table 8 - Results of Phase 1 Testing

\begin{tabular}{|l|c|c|c|}
\hline Company Name \& Product Line & $\begin{array}{c}\text { Solvent } \\
\text { test II } \\
\text { Alcohol } \\
\text { \& Mineral } \\
\text { Spirit }\end{array}$ & $\begin{array}{c}\text { Solvent } \\
\text { test III: } \\
\text { Terpene } \\
\text { Defluxer }\end{array}$ & $\begin{array}{c}\text { Solvent test } \\
\text { IV: } \\
\text { MEA\&PGME }\end{array}$ \\
\hline American Marking: JS series - Black/ Red & Failed & N/A & N/A \\
\hline American Marking: WJ series - Black / Red & Failed & N/A & N/A \\
\hline Akzonobel Spray2Fix - Black & Failed & N/A & N/A \\
\hline Akzonobel Aerofine - Black & Failed & N/A & N/A \\
\hline DEFT MIL-PRF-85285- Black/ Red & Pass & Pass & Pass \\
\hline DuPont 1.2 HG - White & Failed & N/A & N/A \\
\hline $\begin{array}{l}\text { DuPont Industrial Strength - Black/Red } \\
\text { Green Polyurethane - White }\end{array}$ & Pass & Pass & Pass \\
\hline $\begin{array}{l}\text { Sherwin Williams - KEM AQUA-BP Enamel - } \\
\text { Black/ Red }\end{array}$ & Failed & Nass & Pass \\
\hline $\begin{array}{l}\text { Sherwin Williams - MIL-PRF 22750G - } \\
\text { Black /Red }\end{array}$ & Pass & Pass & N/A \\
\hline Union Ink - Uniglaze - Black/Red & Pass & Pass & Pass
\end{tabular}


These results also confirmed what we already know: three of the five products that passed the test, Uniglaze, MIL-PRF-85285, and MIL-PRF22750G, have been used on tactical equipment.

\subsection{Phase 2 Test Results}

Phase II consisted of further solvent testing, a humidity test, a thermal shock test, and a cleaning system test. These test were conducted on black and red paints. Yellow and white paints were added for the thermal shock portion to ensure the absence of discoloration. (Please refer to Appendix F for raw results)

\subsubsection{Additional Solvent Resistivity}

In addition to the solvent test in Phase I, three other solvents: jet fuel, hydraulic oil, and glycol coolant were added in Phase II to simulate some of the solvents that tactical equipment could be exposed to. These samples were exposed to the solvent in the same manner as Solvent III of MIL-STD- 202G method 215K. The panels were examined from a distance of at least 6 inches with normal lighting and without the aid of magnification for entire or partially missing panels, as well to observe if any were faded, smeared, blurred, or shifted to the extent that they cannot be readily identified. The results are displayed in the Table 9 and 10. No noticeable degradation was observed. 
Table 9 - Snapshot of samples in Phase II, Additional Solvent Test

\begin{tabular}{|c|c|c|}
\hline Company & Before Test & After Test \\
\hline \multirow{2}{*}{$\begin{array}{l}\text { DEFT MIL-PRF- } \\
\mathbf{8 5 2 8 5}\end{array}$} & 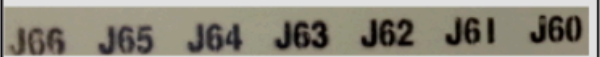 & 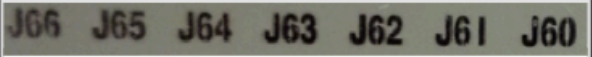 \\
\hline & $\begin{array}{lllllll}555 & J 54 & J 53 & J 52 & J 51 & J 50 & \text { J49 }\end{array}$ & $\begin{array}{|lllllll|}J 55 & J 54 & J 53 & J 52 & J 51 & J 50 & J 49 \\
\end{array}$ \\
\hline \multirow{2}{*}{$\begin{array}{l}\text { Dupont Industrial } \\
\text { Strength }\end{array}$} & $\begin{array}{|lllllll|}J I & J 10 & \text { J9 } & \text { J8 } & \text { J7 } & \text { J6 } & \text { J5 } \\
\end{array}$ & $\begin{array}{lllllll}J 11 & J 10 & \text { J9 } & \text { J8 } & \text { J7 } & \text { J6 } & \text { J5 }\end{array}$ \\
\hline & $\begin{array}{|lllllll|}\text { J44 } & J 43 & J 42 & J 41 & J 40 & J 39 & J 38 \\
\end{array}$ & $\begin{array}{lllllll}J 44 & J 43 & J 42 & J 41 & J 40 & J 39 & J 38\end{array}$ \\
\hline \multirow{2}{*}{ Green Polyurethane } & 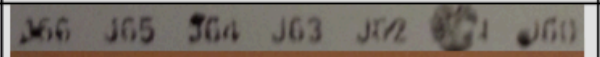 & 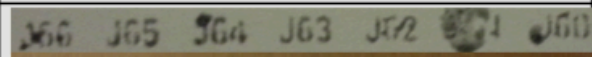 \\
\hline & 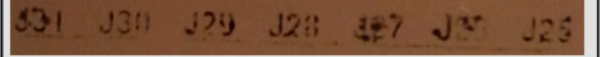 & 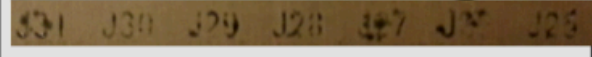 \\
\hline \multirow{2}{*}{$\begin{array}{l}\text { Sherwin Williams } \\
\text { MIL-PRF 22750G }\end{array}$} & $\begin{array}{lllllll}33 & \mathrm{~J} 32 & \mathrm{~J} 31 & \mathrm{~J} 311 & \mathrm{~J} 29 & \mathrm{~J} 211 & \mathrm{~J} 27\end{array}$ & $\begin{array}{lllllll}J 33 & J 32 & J 31 & J 31) & J 29 & J 28 & J 27\end{array}$ \\
\hline & $\begin{array}{llllllll}J 55 & J 54 & J 53 & J 52 & J 51 & J 50 & J 49\end{array}$ & $\begin{array}{lllllll}J 55 & J 54 & J 53 & J 52 & J 51 & J 50 & J 49\end{array}$ \\
\hline \multirow{2}{*}{ Union Ink - Uniglaze } & $\begin{array}{lllllll}\mathrm{J} 22 & \mathrm{~J} 21 & \mathrm{~J} 20 & \mathrm{J19} & \mathrm{Ji8} & \mathrm{J17} & \mathrm{J} 16\end{array}$ & $\begin{array}{lllllll}\mathrm{J} 22 & \mathrm{~J} 2 \mathrm{~J} & \mathrm{~J} 20 & \mathrm{J19} & \mathrm{Ji} & \mathrm{J17} & \mathrm{J} 16\end{array}$ \\
\hline & 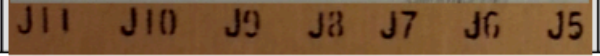 & 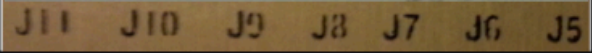 \\
\hline
\end{tabular}

Table 10 - Results of Phase II, Additional Solvent Test

\begin{tabular}{|l|l|l|l|}
\hline Company Name \& Product Line & Jet fuel & $\begin{array}{l}\text { Hydraulic } \\
\text { Oil }\end{array}$ & $\begin{array}{l}\text { Glycol + } \\
\text { Coolant }\end{array}$ \\
\hline DEFT MIL-PRF-85285 - Black & Pass & Pass & Pass \\
\hline DuPont Industrial Strength - Black & Pass & Pass & Pass \\
\hline Green Polyurethane - White & Pass & Pass & Pass \\
\hline $\begin{array}{l}\text { Sherwin Williams } \\
\text { MIL-PRF 22750G - Black }\end{array}$ & Pass & Pass & Pass \\
\hline Union Ink - Uniglaze - Black & Pass & Pass & Pass \\
\hline
\end{tabular}




\subsubsection{Thermal Shock \& Discoloration Test}

Thermal shock tested 5 samples, DEFT MIL-PRF-85285, DuPont Industrial Strength, Green Polyurethane, Sherwin Williams MIL-PRF22750G Type I, and Union Ink Uniglaze. In thermal shock testing, the results were evaluated by discoloration, visual check, and a peel test.

Table 11 and Figure 9 show that the samples passed all testing except for Green Polyurethane. Green Polyurethane failed due discoloration, as seen in Figure 10, and was eliminated from further testing. Visual inspection was performed on a stereoscope under 10x magnification to observe for cracks and flaking, but none were observed. The tape test was also performed, but all samples passed the test without flaking.

Table 11-Results of Phase II, Thermal Shock Test

\begin{tabular}{|c|c|c|c|c|}
\hline Company Name \& Product Line & Peel Test & $\begin{array}{l}\text { Visual } \\
\text { Check }\end{array}$ & \multicolumn{2}{|c|}{$\begin{array}{l}\text { Discoloration } \\
\text { (white) }\end{array}$} \\
\hline DEFT MIL-PRF-85285 & Pass & Pass & Pass & $132 / 132$ \\
\hline DuPont Industrial Strength & Pass & Pass & Pass & $132 / 132$ \\
\hline Green Polyurethane & Pass & Pass & Fail & $0 / 132$ \\
\hline $\begin{array}{l}\text { Sherwin Williams } \\
\text { MIL-PRF } 22750 \mathrm{G}\end{array}$ & Pass & Pass & Pass & $132 / 132$ \\
\hline Union Ink - Uniglaze & Pass & Pass & Pass & $132 / 132$ \\
\hline
\end{tabular}




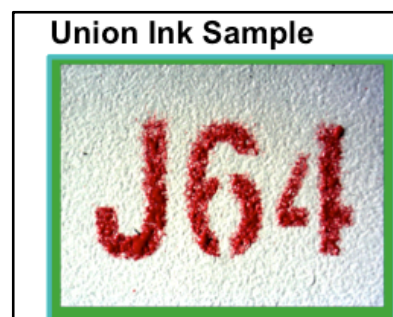

DEFT Sample
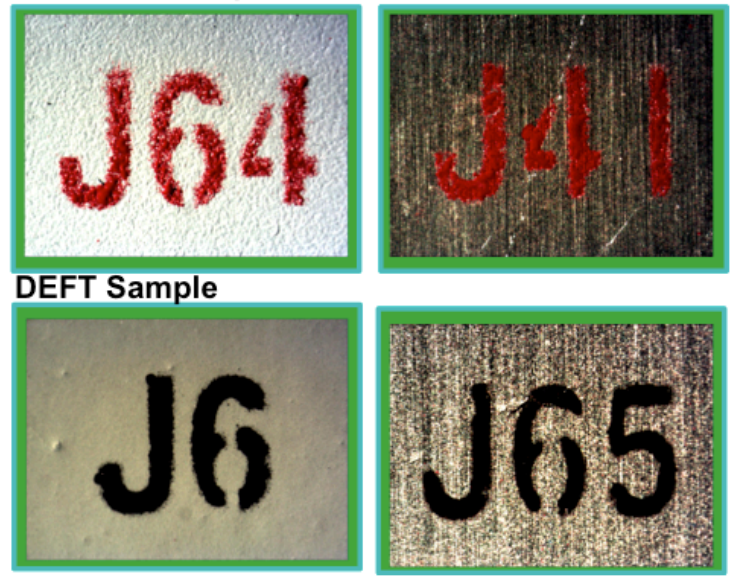

Green Polyurethane Sample
Sherwin Williams Sample

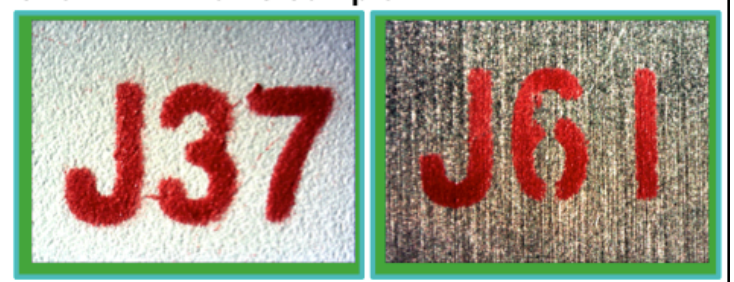

Dupont Sample
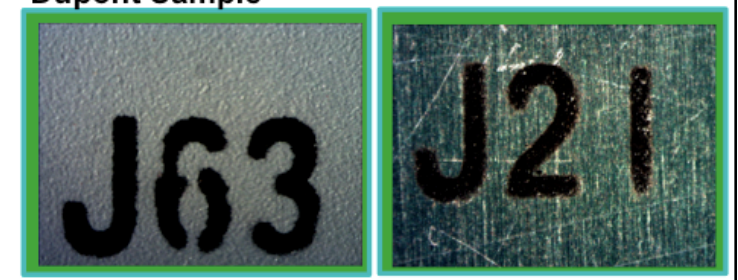

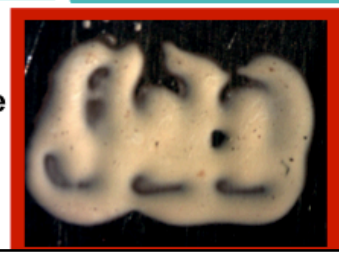

Figure 9 - Snapshot of 10x magnification of Thermal Shock results
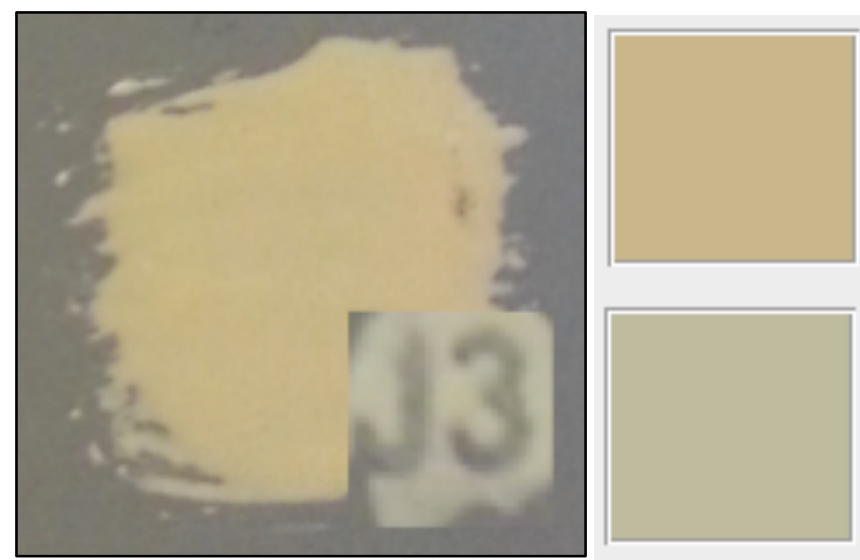

R: 204

G: 183

B: 144

R: 191

G: 187

B: 161

Figure 10- Discoloration of Green Polyurethane in white 


\subsubsection{Humidity Test}

Humidity testing was performed at Raytheon Facility in Goleta, CA using the humidity profile observed in Figure 5. The test ran for 10 days and results were observed under 10x magnification on a stereoscope, as seen in Table 12.

Table 12 - Results of Phase II, Humidity Test

\begin{tabular}{|l|l|l|l|}
\hline Company Name \& Product Line & \multicolumn{2}{l|}{ Visual Check } & Peel Test \\
\hline DEFT MIL-PRF-85285- Black & Pass & $\begin{array}{l}126 / 132 \\
95.45 \%\end{array}$ & Pass \\
\hline DuPont Industrial Strength - Black & Pass & $\begin{array}{l}131 / 132 \\
99.24 \%\end{array}$ & Pass \\
\hline Green Polyurethane - Black & Fail & $\begin{array}{l}0 / 132 \\
0 \%\end{array}$ & - \\
\hline Sherwin Williams & Pass & $\begin{array}{l}127 / 132 \\
96.21 \%\end{array}$ & Pass \\
MIL-PRF 22750G - Black & Pass & $\begin{array}{l}132 / 132 \\
100 \%\end{array}$ & Pass \\
\hline Union Ink - Uniglaze - Black & & \\
\hline
\end{tabular}

Figure 11 displays a snapshot of each sample. Unlike the previous test, the humidity test did not display a $100 \%$ pass rate on all of the samples. However, at least $95 \%$ of all samples passed the test, it was determined that the failure rate was most likely due to surface contamination that was not properly cleaned by acetone. The peel test also did not produce any flaking of the samples. 


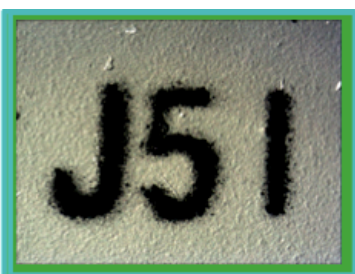

Union Ink Sample

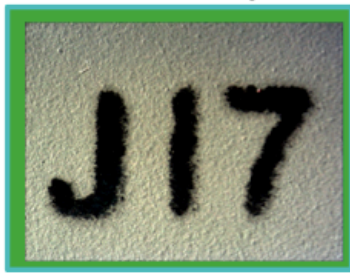

DEFT Sample
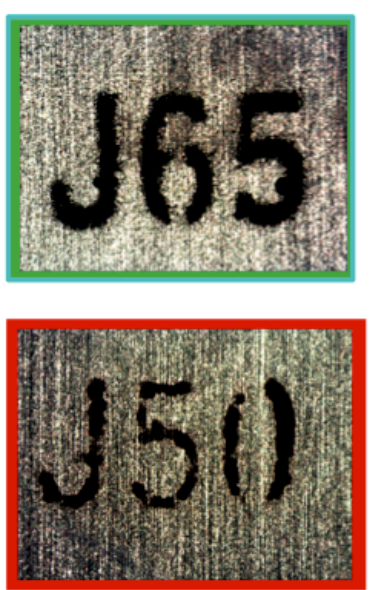

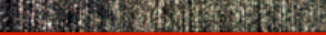

Figure 11 - Snapshot of 10x magnification of Humidity Shock results
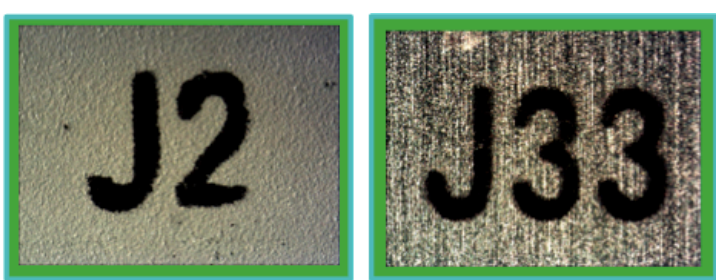

Sherwin Williams Sample

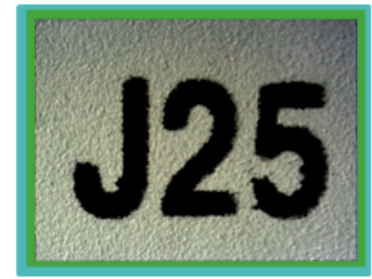

Dupont Sample

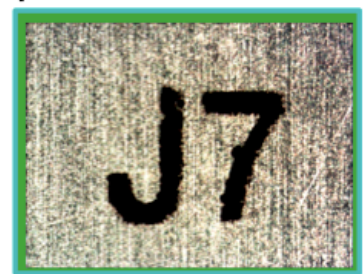

Figure 11 - Snapshot of IOx magnification of Humidity Shock results 


\subsubsection{Cleaning System Test}

Cleaning system testing was performed in Raytheon facility in Forest, MS. Samples were exposed to Branson B-series Degreaser with ultrasonic using Asahiklin AK-225T solvent and Aqueous Technologies Trident batch cleaning system using Kyzen A4615. Visual Check test indicated a $21.97 \%$ failure rate with DEFT MIL-PRF-85285, a $41.06 \%$ failure rate with DuPont Industrial Strength, a 5.3\% failure rate with Sherwin Williams MILPRF 22750G Type I, and 12.88\% failure rate with Union Ink. Union Ink and MIL-PRF $22750 \mathrm{G}$ was found to have the highest pass rate as shown in Table 13. The failure of the other three samples was due to missing parts in the letters. In Figures 12 and 13, a snapshot of the samples display some of the missing parts from the samples.

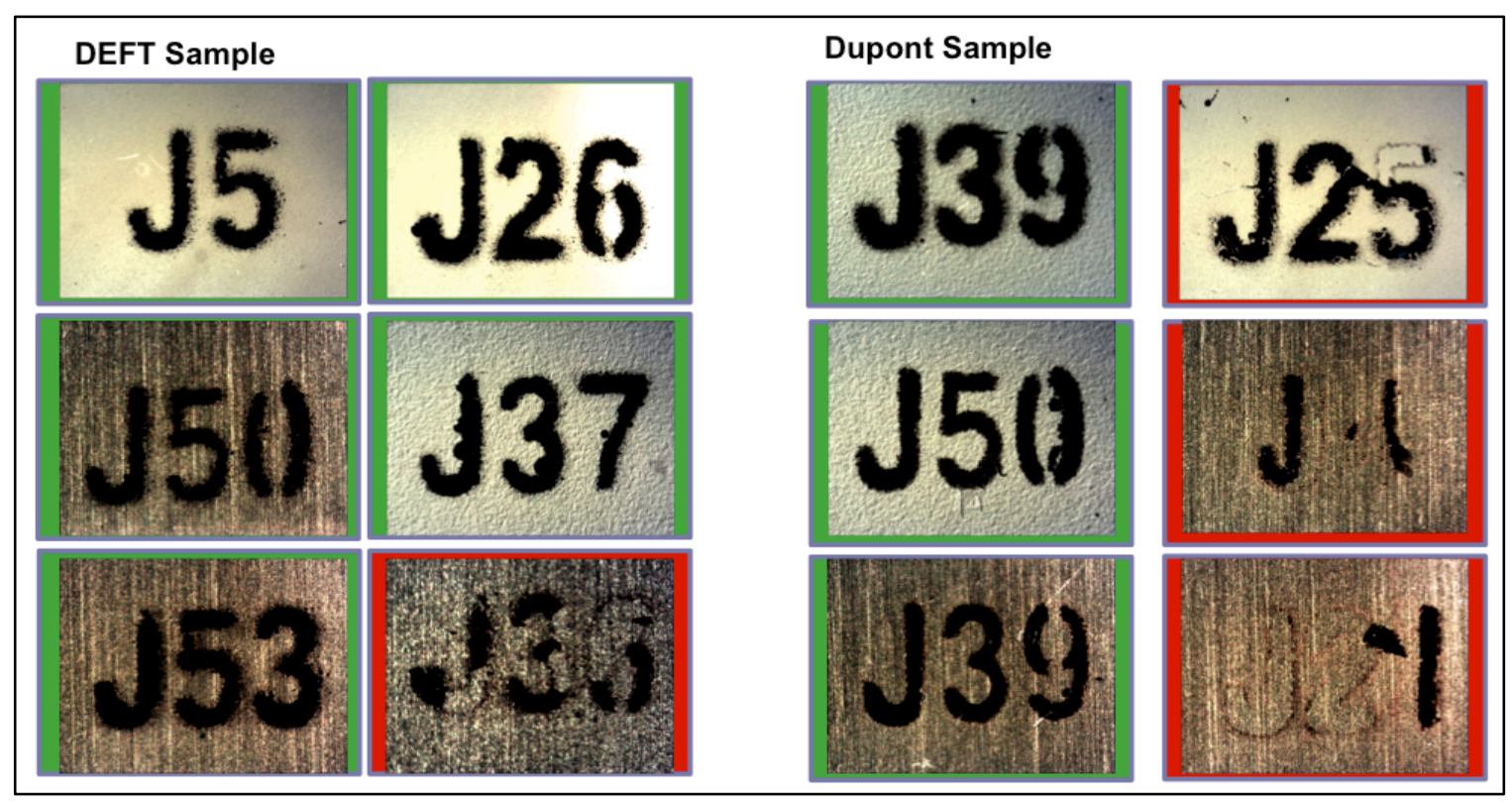

Figure 12 - Snapshot of $10 x$ magnification of Cleaning Systems Test of DEFT and DuPont samples. 


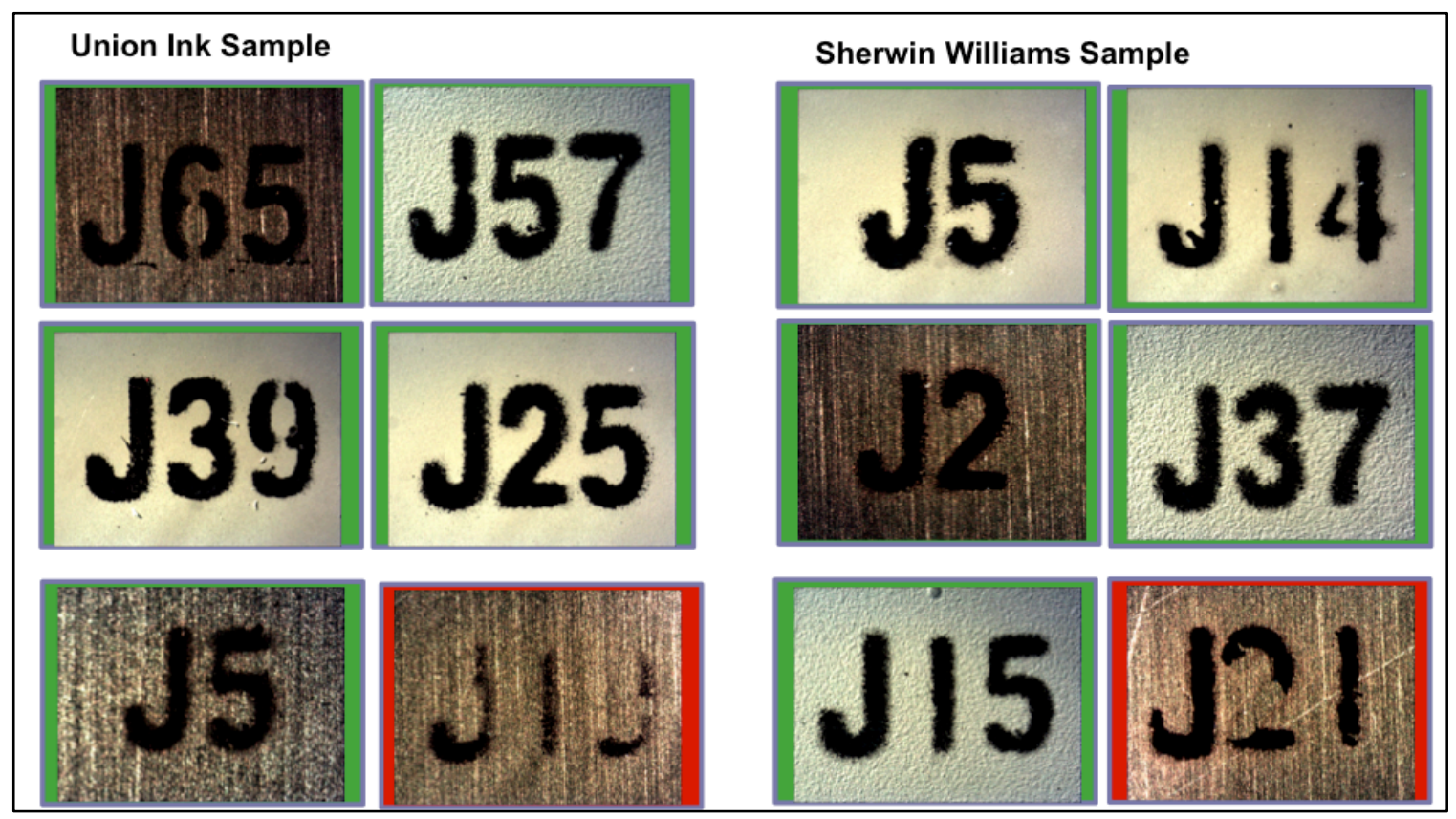

Figure 13 - Snapshot of $10 x$ magnification of Cleaning Systems Test of Union Ink and Sherwin Williams samples.

Table 13 - Phase II, Cleaning Systems Test

\begin{tabular}{|l|l|l|l|}
\hline Company Name \& Product Line & \multicolumn{2}{l|}{ Visual Check } & Peel Test \\
\hline DEFT MIL-PRF-85285- Black & Fail & $\begin{array}{l}103 / 132 \\
78.03 \%\end{array}$ & - \\
\hline DuPont Industrial Strength- Black & Fail & $\begin{array}{l}91 / 132 \\
58.94 \%\end{array}$ & - \\
\hline Green Polyurethane - Black & Fail & $\begin{array}{l}0 / 132 \\
0 \%\end{array}$ & - \\
\hline Sherwin Williams & Pass & $\begin{array}{l}125 / 132 \\
94.70 \%\end{array}$ & Pass \\
MIL-PRF 22750G - Black & Pass & $\begin{array}{l}115 / 132 \\
87.12 \%\end{array}$ & Pass \\
\hline Union Ink - Uniglaze - Black & & \\
\hline
\end{tabular}


To determine the cutoff and to justify for the failure rates, further investigation was needed to observe that Union Ink currently works for marking at Raytheon. Therefore, Union Ink was determined to be a suitable control to compare the data with. By that standard the only paint that passed the test was Sherwin Williams MIL-PRF 22750G Type I. 


\section{Chapter 5 - Conclusion and Future Work}

Eleven product lines were tested, including epoxy, polyurethane, and water-based solvent marking ink. Two product line, Sherwin Williams MIL-PRF-22750G Type I and Union Ink Uniglaze, passed:

- MIL-STD 202G Method 215K solvent test

- MIL-STD 202G Method 107G thermal shock test

- MIL-STD-810G, Method 507.5 humidity test

- Cleaning Systems Test

- ASTM D3359, measure adhesion by tape test

Sherwin Williams MIL-PRF-22750G Type I is a high solids epoxy topcoat designed for use as a topcoat for the interior of military ground equipment. Uniglaze Epoxy ink is designed for use on printed circuit board markings, electronic equipment panels, and automotive/aeronautical/nautical components. As with all marking and paint related products, these products also contain some harmful ingredients as shown in Table 14.

Comparing the composition of these two product in Table 15, the composition of Enthone 50 series ink contain far more carcinogenic compounds and reproductive toxins vs Sherwin Williams MIL-PRF 22750G Type I and Union Ink Uniglaze. (Please refer to Appendix B for Union Ink TDS and MSDS and Appendix C for Sherwin WIlliams TDS and MSDS)

Given the readily availability of alternatives, and their success through all levels of testing, it is recommended that all use and purchase of Enthone marking inks cease and that the Union Ink Uniglaze and Sherwin Williams MIL-PRF-22750 Type I be the replacements. 
Table 14 - Harmful Chemicals in Sherwin WIlliams MIL-PRF-22750G Type I and Union Ink Uniglaze

\begin{tabular}{|l|l|}
\hline $\begin{array}{l}\text { Sherwin Williams } \\
\text { Type I }\end{array}$ & $\begin{array}{l}\text { MIL-PRF-22750G } \\
\text { Catalyst } \\
\text { Ink }\end{array}$ \\
\hline Acetone & 2 - Propanol \\
\hline $\begin{array}{l}\text { Methyl n-amyl } \\
\text { ketone }\end{array}$ & $4-$ Nonlphenol \\
\hline $\begin{array}{l}\text { Diisobytyl Ketone } \\
\text { Epoxy Polymer }\end{array}$ & $\begin{array}{l}1,3- \\
\text { benzendimethanamine } \\
\text { Polyamine }\end{array}$ \\
\hline
\end{tabular}

Non-organic

Pigments

i.e. Titanium

Oxide, Carbon

Black

\begin{tabular}{l|l|l|l|}
\hline Union Ink Uniglaze & \\
\hline Ink & $\begin{array}{l}\text { Catalyst } \\
\text { UGLZ-9120, } \\
\text { UNGL-9130 }\end{array}$ \\
\hline $\begin{array}{l}\text { Epoxy Resin } \\
\text { Organo-titanates- } \\
\text { quat } \\
\text { 2-butoxyethanol }\end{array}$ & $\begin{array}{l}\text { Nophtha } \\
\text { Polyamide Resin }\end{array}$ \\
\hline $\begin{array}{l}\text { 1-methoxy-2- } \\
\text { propanol acetate } \\
\text { Solvent naphtha }\end{array}$ & \\
\hline $\begin{array}{l}\text { Butyl carbitol } \\
\text { acetate }\end{array}$ & \\
\hline
\end{tabular}

Table 15 - Carcinogenic and reproductive toxin comparison of Sherwin Williams MIL PRF-22750G Type I, Union Ink Uniglaze and Enthone 50 series product line.

\begin{tabular}{|l|c|c|c|}
\hline & $\begin{array}{l}\text { Sherwin Williams } \\
\text { MIL PRF-22750G } \\
\text { Type I }\end{array}$ & Union Ink Uniglaze & Enthone 50 Series \\
\hline $\begin{array}{l}\text { Ink to Catalyst } \\
\text { ratio }\end{array}$ & $4: 1$ & $4: 1$ to $6: 1$ & Varies on catalyst \\
\hline $\begin{array}{l}\text { Carcinogenic } \\
\text { 1 possible, depending } \\
\text { on the color } \\
\text { i.e. Titanium } \\
\text { Oxide(white), } \\
\text { Carbon Black(black) } \\
0 \text { in catalyst }\end{array}$ & $\begin{array}{c}0 \text { in ink } \\
1 \text { in catalyst }\end{array}$ & $\begin{array}{c}4 \text { in ink } \\
\text { catalyst: vary on the } \\
\text { catalyst used }\end{array}$ \\
\hline $\begin{array}{l}\text { reproductive } \\
\text { toxin or } \\
\text { suspected } \\
\text { reproductive } \\
\text { toxin }\end{array}$ & $\begin{array}{c}0 \\
\text { and }\end{array}$ & $\begin{array}{c}3 \text { in ink } \\
\text { catalyst: vary on the } \\
\text { catalyst used }\end{array}$ \\
\hline
\end{tabular}




\section{Bibliography}

[1] Wyrostek, Michael, and Paul Wynn. "Driving away from hex chrome coatings: With compliance deadlines for new environmental regs fastapproaching, surface finishers are challenged to manage the transition to alternative materials." Metal finishing 104.4 (2006): 22-29.

[2] Yaroschak, Paul. Hexavalent Chromium Minimization Strategy. OFFICE OF THE DEPUTY UNDER SECRETARY OF DEFENSE (INSTALLATIONS AND ENVIRONMENT) WASHINGTON DC, 2011.

[3]McKinley, Gene. Hexavalent Chromium Substitution Projects. AERONAUTICAL SYSTEMS CENTER WRIGHT-PATTERSON AFB OH, 2011.

[4]Varley, R. J., et al. "Investigation of factors impacting the in-service degradation of aerospace coatings." Progress in Organic Coatings 74.4 (2012): 679-686.

[5] Enthone Inc. March 14, 2001. Enthone 50-201AR(Yellow) MSDS, http://www.gogsgsupport.com/MSDS/Enthone/50\%20201AR\%20Yellow.pdf [6] Enthone Inc. February 22, 2001. Enthone 50-206R(Orange) MSDS, http://www.gogsgsupport.com/MSDS/Enthone/50\%20206R\%20Orange.pdf

[7] Enthone Inc., May 24, 2005. Enthone Catalysis 9 MSDS, http://www.gogsgsupport.com/MSDS/Enthone/Catalyst\%209.pdf

[8] Enthone Inc., August 21, 2003. Enthone Catalysis 5 MSDS, http://www.gogsgsupport.com/MSDS/Enthone/Catalyst\%205.pdf

[9] Sigma-Aldrich. Novemeber 13, 2012. 2-Ethyl-4methlimidazole MSDS, http://www.sigmaaldrich.com/catalog/product/aldrich/e36652?lang=en\&region=US 
[9] Sigma-Aldrich. April 3, 2014. Tetraethylenepentamine MSDS, http://www.sigmaaldrich.com/catalog/product/aldrich/t11509?lang=en\&region=US

[10] Sigma-Aldrich. April 3, 2014. ASTM ${ }^{\circledR}$ D5134 Qualitative Reference Naphtha Standard MSDS, http://www.sigmaaldrich.com/catalog/product/supelco/48265u?lang=en\&region=US [11] Sigma-Aldrich. April 4, 2014. 2-bytoxyethanol MSDS, http://www.sigmaaldrich.com/catalog/product/aldrich/719676?lang=en\&region=US [12] Sigma-Aldrich. March 25, 2014. Cadmium Sulfide MSDS, http://www.sigmaaldrich.com/catalog/product/aldrich/481882?lang=en\&region=US [13] Sigma-Aldrich. April 19, 2013. Bisphenol A MSDS, http://www.sigmaaldrich.com/catalog/product/aldrich/239658?lang=en\&region=US [14] Sigma-Aldrich. April 2, 2014. Chromium(VI) oxide MSDS, http://www.sigmaaldrich.com/catalog/product/sial/232653?lang=en\&region=US [15] Sigma-Aldrich. April 2, 2014. Lead MSDS, http://www.sigmaaldrich.com/catalog/product/aldrich/209708?lang=en\&region=US [16] Sigma-Aldrich. September 18, 2012. Ethylene Glycol Butyl Ether MSDS, http://www.sigmaaldrich.com/catalog/product/sial/537551?lang=en\&region=US

[17]_Office of Information and Public Affairs (2 September 1977). "CPSC Announces Final Ban On Lead-Containing Paint". U.S. Consumer Product Safety Commission.

[18]Vasudevan, T., et al. "Cadmium-and chromate-free coating schemes for corrosion protection of 15CDV6 steel." Metal Finishing 109.3 (2011): 15-21. 
[19] AK. Chatropadhyay, M.R. Zentner, Aerospace and Aircraft Coatings, Societies for Coatings Technology, Philadelphia, PA, 1990, p.18.

[20] Occupation Safety and Health Administration. U.S. Department of Labors.

Hexavalent Chromium. Washington: U.S. Department of Labors. April 27, 2014

https://www.osha.gov/SLTC/hexavalentchromium/healtheffects.html

[21] Joseph, Ron. "How to keep new hex-chrome PEL from grounding your aerospace business: An overview of methods for minimizing overspray from chromate-containing coatings in the work area." Metal finishing 104.3 (2006): 20-24.

[22] Occupational Safety and Health Administration. "Occupational exposure to hexavalent chromium. Final rule." Federal register 71.39 (2006): 10099.

[23] Tomachuk, C.R., Elsner, C.I., \& Di Sarli, A.R.. (2014). Electrochemical characterization of chromate free conversion coatings on electrogalvanized steel. Materials Research, 17(1), 61-68. Epub November 05, 2013. Retrieved August 09, 2014, from http://www.scielo.br/scielo.php?script=sci_arttext\&pid=S1516$14392014000100009 \& \operatorname{lng}=$ en\&tlng=en. 10.1590/S1516-14392013005000179.

[24] Jones, Scott. "Qualification and Flight Test of Non-Chrome Primers for C-130 Aircraft." 2011 Air Force Corrosion Conference, Aug. 16-18, 2011. Robins AFB, GA. US.

[25]Nanna, Michael E., and Gordon P. Bierwagen. "Mg-rich coatings: a new paradigm for Cr-free corrosion protection of Al aerospace alloys." JCT research 1.2 (2004): 69-80. [26]Battocchi, D., et al. "Comparison of testing solutions on the protection of Al-alloys using a Mg-rich primer." Corrosion science 48.8 (2006): 2226-2240. 
[27] Everyspec.com, March 3, 1969, MIL-C-27725B Military Specification http://chemsol.com/products/coating-compounds-corrosion/mil-c-27725-coatingcorrosion-preventive-for-aircraft-integral-fuel-tanks/

[28] Schweitzer, Philip A . (2005). Paint and Coatings Applications and Corrosion Resistance. Boca Raton, FL: CRC Press. 38,51,72-76.

[29]ASTM Standard F22, 2007, "Hydrophobic Surface Films by the Water-Break Test," ASTM International, West Conshohocken, PA, 2006

http://wenku.baidu.com/view/56124b0302020740be1e9b37

[30] Blackford, Roger. "Performance demands on aerospace paints relative to environmental legislation." Aircraft Engineering and Aerospace Technology 70.6 (1998): 451-455.

[31] ASTM Standard D3359-79, 1997, "Standard Test Methods for Measuring Adhesion by Tape Test,” ASTM International, West Conshohocken, PA 2006 http://www.metalroofpaint.ca/documents/ASTM\%20TAPE\%20ADHESION\%20TEST.p df 
Appendix A

Memo from Under Secretary of Defense, April $8^{\text {th }}, 2009$

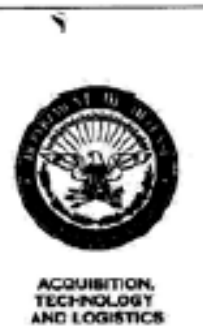

\author{
THE UNDER SECRETARY OF DEFENSE \\ SO10 DEFCNEE PENTACON \\ WASHINGTON, DC 20301-3010
}

MEMORANDUM FOR SECRETARIES OF THE MILITARY DEPARTMENTS

SUBJECT: Minimizing the Use of Hexavalent Chromium $\left(\mathrm{Cr}^{6+}\right)$

$\mathrm{Cr}^{\mathrm{s}+}$ is a significant chemical in numerous Department of Defense (DoD) weapons systems and platforms due to its corrosion protection properties. However, due to the serious human health and environmental risks related to its use, national and international restrictions and controls are increasing. These restrictions will continue to increase the regulatory burdens and life cycle costs for DoD and decrease materiel availability. OSD, DoD Components, and industry have made substantial investments in finding suitable replacements for $\mathrm{Cr}^{\text {it }}$ for many of the current DoD applications. In particular, a number of defense-selated industries are minimizing or eliminating the use of $\mathrm{Cr}^{6+}$ where proven substitutes are available that provide acceptable performance for the application.

This is an extraordinary situation that requires DoD to go beyond establishod hazardous materials management processes. To more aggressively mitigate the unique risks to DoD cperations now posed by $\mathrm{Ct}^{t+}$, I direct the DoD Military Departments to take the following actions:

- Invest in appropriate research and development on substitutes.

- Ensure testing and qualification procedures are funded and conducted to qualify technically and economically suitable substitute materials and processes.

- Approve the ese of alternatives where they can perform adequately for the intended application and operating eavironment. Where $\mathrm{Cr}_{r}{ }^{\mathrm{C}}$ is produced as a by-product from use or manufacture of other acceptable chromium oxides, explore methods to minimize $\mathrm{Cr}^{6+}$ production.

- Update all relevant techrical documents and specifications to authorize use of the qualfied alternatives and, therefore, minimize the use of materials containing $\mathrm{Cr}^{5-}$.

- Document the system-specific $\mathrm{Cr}^{6+}$ risks and efforts to qualify less toxic altematives in the Programmatic Environment, Safety, and Occupational Healti Evaluation for the system. Analyses should include any cost/schedule risks and life cycle cost comparisons among alternatives. Life cycle comparisons should address material handling and disposal costs and system overhaul cycle times/costs due to any differences in corrosion protection.

- Share knowledge derived from research, development, testing and evaluations (RDT\&E) and actual experiences with qualified alternatives. 
TDS and MSDS of Union Ink: Uniglaze

TDS

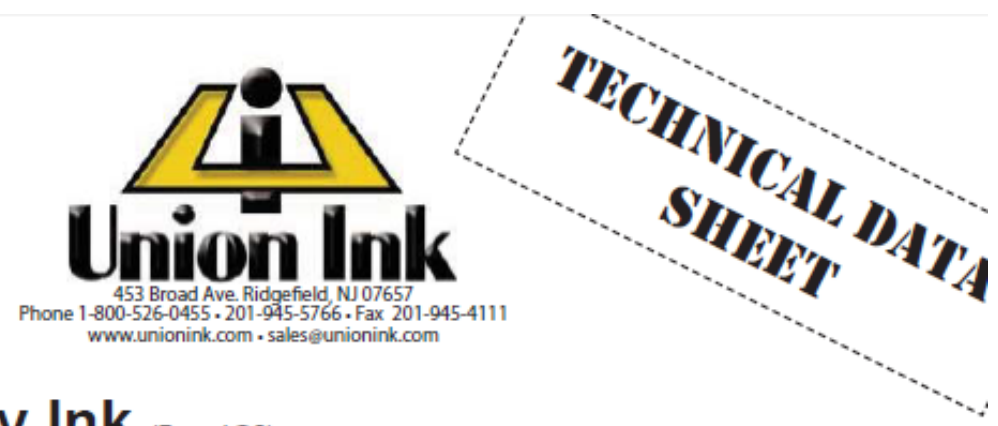

\section{Uniglaze Epoxy Ink}

(Page 1@2)

Rev. Feb. 2012

\section{Applications}

- Printed circuit board markings

- Electronic equipment panels

- Glass before or after mirroring

- Metal Casings

- Automotive / Aeronautical / Nautical components

- Polyethylene bottles (for superior product resistance)

- Polypropylene (Polyallomer Plastics)

\section{SPECIFICATIONS: UGLZ-Series}

Appearance: High Gloss, semi-gloss or flat, depending upon type of catalyst used. Black and white are available in both gloss and flat finishes. Uniglaze Inks have excellent flexibility, even for flexing and creasing on metal, polyethylene and other surfaces.

Opacity: Excellent.

Drying: Air Dry: 12 hours. Force Dry: $325^{\circ} \mathrm{F} .\left(162^{\circ} \mathrm{C}\right)$ for 5 to 10 minutes. $250^{\circ} \mathrm{F}$. $\left(121^{\circ} \mathrm{C}\right.$.) for 10 to 20 minutes Whites should not be cured above $250^{\circ} \mathrm{F}$. $\left(121^{\circ} \mathrm{C}\right.$.). When air drying, chemical resistance and hardness will be good after 72 hours but full cure may not be achieved for 7 days

Coverage: Approximately 800 to 1200 square feet per gallon.

Mesh: Monofilament meshes from 156 to 305 depending on substrate and art work.

Stencils: Direct or Capillary film type emulsions

Wash-up: Screen solvent SOLV-1540 or Safety Screen Solvent SOLV-1500

Mixing instructions:

UNIGLAZE Colors must be mixed with Catalyst prior to use according to the following recommendations (by volume or weight). See specifications for recommended mixing ratios in the following paragraphs.

\section{Features}

- Outstanding chemical resistance

- Excellent flexibility

- Excellent opacity

- Choose high gloss,semi-gloss or flat

- Meets many US military specs.
Ink to Catalyst Ratios:

UGLZ-9120 (Standard) \& UGLZ-9130 (Fast):

6 parts INK to 1 part Catalyst provides maximum gloss, hardness, electrical \& chemical resistance.

To gain maximum flexibility and adhesion the ratio can be moved towards 4 parts INK to 1 part Catalyst.

These ratios are not absolutely critical. However the end user is responsible for testing to ensure maximum performance on the materials being imprinted.

UGLZ-9141(Flat/Fast): When utilizing this catalyst care should be taken not to exceed the recommended ratio of 4 parts INK to 1 part Catalyst as the inks overall performance will be diminished.

When screen printing add Reducer SOLV-1498 as necessary. perhaps 10-20\%. When using the above mixtures for application by rubber stamp, reducer may not be necessary.

Pot life: Ink/Catalyst Mixture may be used for up to eight hours. Ambient temperatures and climatic conditions may alter pot life. Always be sure to keep ink and catalyst in a proper container and cover when not in use.

Shelf life: The shelf life of the unmixed ink and catalyst is at least two years from Date of Shipment if sealed and stored at room temperature (approx. $73^{\circ} \mathrm{F} / 23^{\circ} \mathrm{C}$ ). Uniglaze Inks, like most epoxies, are not recommended for outdoor weathering. Always pre-test for adhesion, chemical resistance or other specific requirements. 


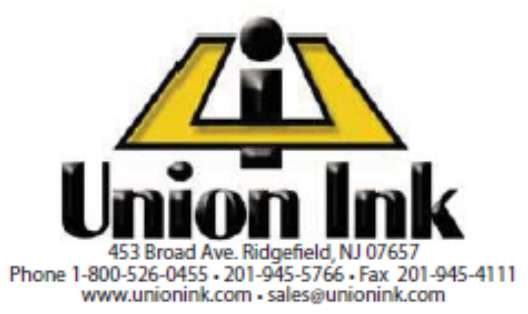

\section{Uniglaze Epoxy Ink (Page 2@2)}

\begin{tabular}{lll} 
Colors: & Colors Cont: & Catalysts: \\
UGLZ-1000 White & UGLZ-6001 Tahiti Green & UGLZ-9120 Gloss Catalyst (Reg) \\
UGLZ-1020 Extra Opaque White & UGLZ-6010 Parisian Green & UGLZ-9130 Gloss Catalyst (Fast) Rec. when mirroring glass. \\
UGLZ-1050 Flat White & UGZ7-7000 Dark Brown & UGLZ-9141 Flat Catalyst (Fast) Rec. when mirroring glass. \\
UGLZ-2001 Primrose Yellow & UGZ-7030 Sienna Brown & \\
UGLZ-2010 Lemon Yellow & UGLZ-8000 Black & Additives \& wash-ups: \\
UGLZ-2020 Chrome Yellow & UGL-8050 Flat Black & SOLV-1329 Tropical Retarder \\
UGLZ-2050 Orange & UGLZ-8000R Black (for Type II Cert.) & SOLV-1498 Standard Reducer \\
UGLZ-3000 Vermilion Red & UGZ-8050R Flat Black (for Type II Cert.) & SOLV-1500 Safety Wash \\
UGLZ-3005 Brite Red & UGLZ-9030 Clear For Gold & SOLV-1540 Screen Washing Thinner \\
UGLZ-3030 Maroon & UGZ-9040 Sharp Printing Compound & \\
UGLZ-4010 Magenta & UGLZ-9080 Half-tone Base & \\
UGLZ-5020 Mono Blue & UGL-9110 Overprint Gloss Clear & \\
UGLZ-5030 Ultra Blue & UGLZ-M120 Silver & \\
UGLZ-5040 Navy Blue & & \\
\hline
\end{tabular}

CERTIFICATES OF COMPLIANCE (C. OF C.'S)

If requested, AT THE TIME OF PLACING THE ORDER, we can test a batch and certify that particular Uniglaze ink batch will comply to certain federal, military and industrial specifications when properly applied and properly stored.

Contact our customer service department for testing and documentation charges or lot test data charges.

\section{Some of the specifications that Uniglaze meets and C. of C.'s can be issued for are:}

MIL-I-43553

MIS-11272A

MIS-19916C

2424192

2424193

61A5A65

WS19208A

13042164

MS18038 (AS)

MM817Y

CID A-A-56032
U.S. ARMY MISSILE COMMAND REDSTONE ARSENAL

U.S. ARMY MISSILE COMMAND REDSTONE ARSENAL U.S. ARMY MISSILE COMMAND REDSTONE ARSENAL BU WEPS

BU WEPS

U.S. NAVAL ORDINANCE

NAVAL SEAS SYSTEMS COMMANDS

U.S. ARMY MISSILE COMMAND REDSTONE ARSENAL

MILITARY STANDARD

MARTIN MARIETTA

INK MARKING, EPOXY BASE (TYPE I AND TYPE II)

Medical \& Surgical devices: Although this ink system is being utilized widely and successfully in the medical industry, Union Ink has not tested this product nor has it received any FDA approval regarding Bio-Compatibility or any autoclave sterilization processes, as it relates to markings on actual surgical devices or any part thereof. It is the sole responsibility of the end user to have this ink tested for feasibility on such devices.

\section{ALWAYS TEST BEFORE USING IN PRODUCTION!}

While Union Ink Company believes that the data contained herein are factual and the opinions expressed are those of qualified experts regarding the results of the tests conducted, the data are not to be taken as a warranty or representation for which Union Ink Company assumes legal responsibility. They are offered solely for your consideration, investigation, and verification. Always pre-test inks on surfaces to be printed. 
MSDS of all inks

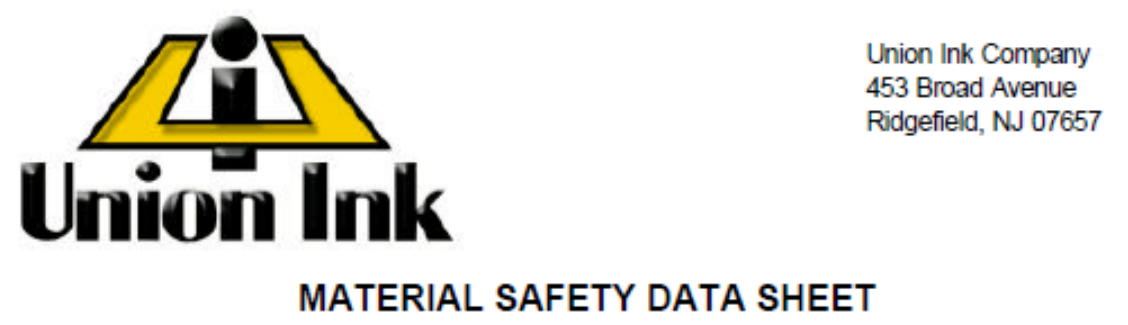

1. CHEMICAL PRODUCT AND COMPANY IDENTIFICATION

SUPPLIER LOCATION:

HAZARDOUS MATERIAL INFORMATION SYSTEM:

Union Ink Company

453 Broad Avenue

Ridgefield, NJ 07657

201-945-5766

IN CASE OF EMERGENCY CONTACT: 201-945-5766

\begin{tabular}{|r|c|}
\hline Health: & 2 \\
\hline Flammability: & 2 \\
\hline Reactivity: & 0 \\
\hline Personal Protection: & ${ }^{*}$ \\
\hline * See Section 8 for PPE
\end{tabular}

PRODUCT NAME: Uniglaze

CHEMICAL FAMILY: Epoxy Mixture

DATE REVISED: $2 / 29 / 2012$

SUPERSEDES: $1 / 31 / 2012$ VERSION: 6

PRODUCT CODES: UGLZ-

$\begin{array}{lll}1000 & 2010 & 3020 \\ 1020 & 2020 & 3030 \\ 1050 & 2050 & 4010 \\ 1627 & 3000 & 4153 \\ 2001 & 3005 & 5040\end{array}$

6010

7000

7030

$8050 \mathrm{R}$

P110U

$\mathrm{P} 1235$

$\mathrm{P} 123 \mathrm{C}$

$\mathrm{P} 182 \mathrm{U}$

$\mathrm{P} 189 \mathrm{C}$

$\mathrm{P} 241 \mathrm{C}$

$\mathrm{P} 297 \mathrm{C} \quad \mathrm{P} 425 \mathrm{C}$

P298C P469U

\section{P5783}

Kimberly C. Leitch $\quad$ (704) 553-0046 ext. 155

PREPARED BY:

\section{HAZARDS IDENTIFICATION}

EMERGENCY OVERVIEW: DANGERI Combustible. Causes respiratory tract irritation.

PRIMARY ROUTE OF ENTRY: $\quad$ Respiratory, eye and skin contact

EYE CONTACT: May cause severe discomfort or irritation.

SKIN CONTACT: $\quad$ May cause skin irritation and sensitization

INHALATION: Respiratory irritation. Breathing high vapor concentrations may cause CNS depression resulting in dizziness, light-headedness, headache, nausea, and loss of coordination. Continued inhalation may result in unconsciousness and death. Prolonged and repeated exposure to high concentrations may cause hearing loss.

INGESTION:

May be harmful. Aspiration hazard. 


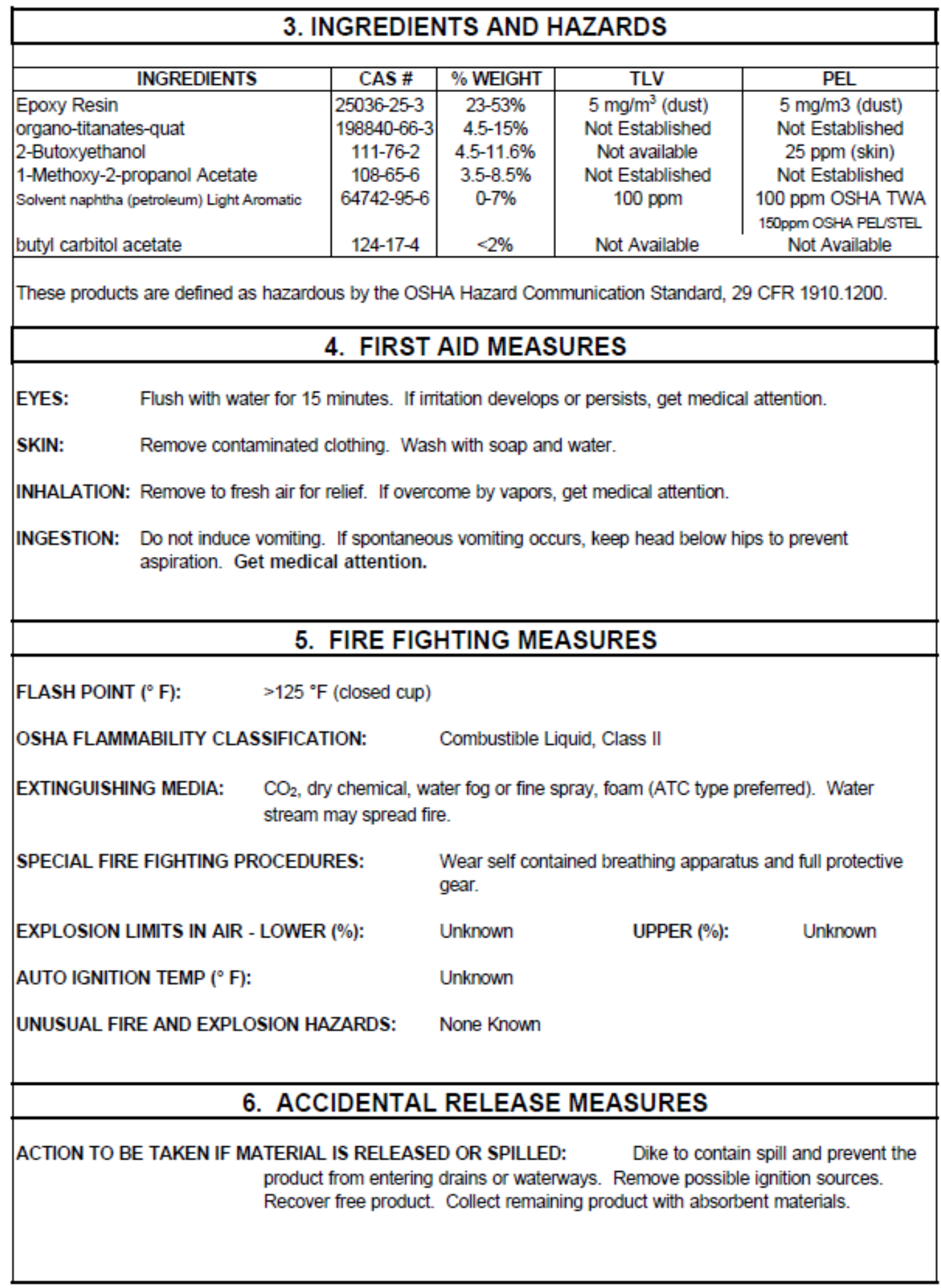




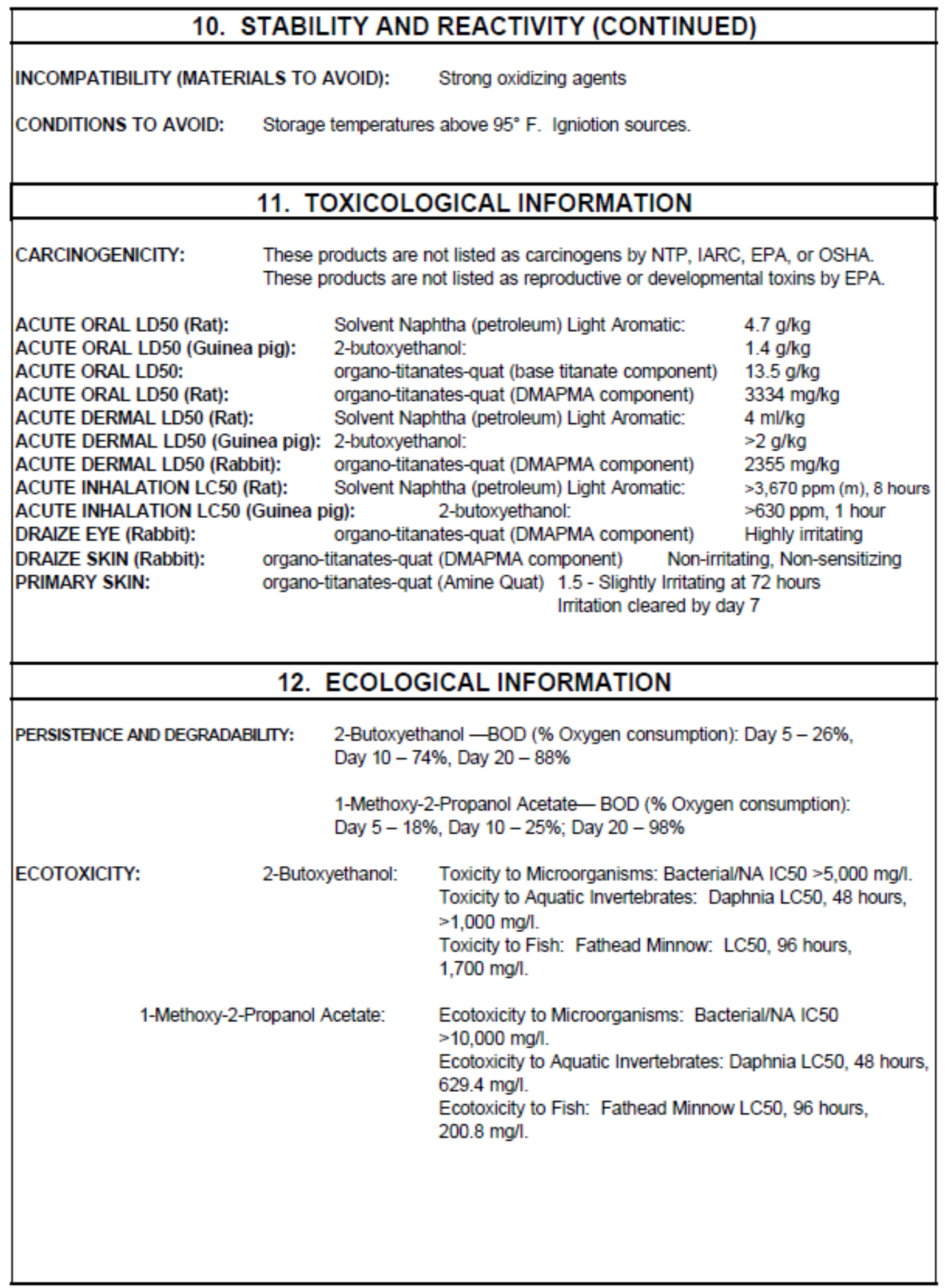


MSDS of Catalyst

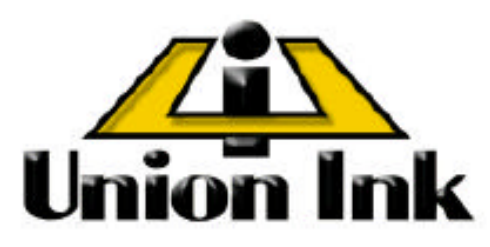

Union Ink Company

453 Broad Avenue

Ridgefield, NJ 07657

MATERIAL SAFETY DATA SHEET

\section{CHEMICAL PRODUCT AND COMPANY IDENTIFICATION}

SUPPLIER LOCATION:

HAZARDOUS MATERIAL INFORMATION SYSTEM:

Union Ink Company

453 Broad Avenue

Ridgefield, NN 07657

201-945-5766

IN CASE OF EMERGENCY CONTACT: 201-945-5766

\begin{tabular}{|r|c|}
\hline Health: & 3 \\
\hline Flammability: & 2 \\
\hline Reactivity: & 0 \\
\hline Personal Protection: & ${ }^{*}$ \\
\hline${ }^{*}$ See Section 8 for PPE
\end{tabular}

PRODUCT NAME:

Uniglaze Gloss Catalyst

DATE REVISED: $1 / 25 / 2012$

CHEMICAL FAMILY: Epoxy

PRODUCT CODE: $\quad$ UGLZ-9120, UGLZ-9130

SUPERSEDES: $10 / 10 / 2011$

VERSION: 4

PREPARED BY: Kimberly C. Leitch (704) 553-0046 ext. 155

\section{HAZARDS IDENTIFICATION}

EMERGENCY OVERVIEW: WARNING! Causes eye irritation and may cause skin irritation and sensitization. Inhalation of heated vapors may cause respiratory irritation and sensitization.

PRIMARY ROUTE OF ENTRY: $\quad$ Eye, Skin, Inhalation

EYE CONTACT: $\quad$ This material causes moderate to severe eye irritation. Direct contact with the material or exposure to vapors or mists may cause stinging, tearing, redness and blurred vision.

SKIN CONTACT: $\quad$ This material causes moderate skin irritation. Repeated and prolonged contact may cause sensitization in some individuals.

INHALATION:

Inhalation of vapors from the heated product may cause irritation or sensitization of the nose and throat. May cause headaches, dizziness, anaesthesia, drowsiness, unconsciousness, and other central nervous system effects, including death

INGESTION: Minimal toxicity, and not a likely route of exposure. Aspiration of liquid into lungs is possible. 


\begin{tabular}{|c|c|c|c|c|}
\hline \multicolumn{5}{|c|}{ 3. INGREDIENTS AND HAZARDS } \\
\hline INGREDIENTS & CAS \# & $\%$ WEIGHT & TLV & PEL \\
\hline $\begin{array}{l}\text { Naphtha (petroleum) heavy aromatic } \\
\text { Polyamide Resin } \\
\text { 2,4,6-Tris(dimethylaminomethyl)Phenol } \\
\text { Naphthalene }\end{array}$ & \begin{tabular}{|c|}
$64742-94-5$ \\
$68410-23-1$ \\
$90-72-2$ \\
$91-20-3$ \\
\end{tabular} & $\begin{array}{l}25-35 \% \\
65-75 \% \\
<5 \\
<3\end{array}$ & $\begin{array}{c}\text { Not determined } \\
\text { Not determined } \\
\text { Not determined } \\
10 \mathrm{ppm}\end{array}$ & $\begin{array}{c}\text { Not determined } \\
\text { Not determined } \\
\text { Not determined } \\
10 \mathrm{ppm}\end{array}$ \\
\hline \multicolumn{5}{|c|}{ These products are defined as hazardous by the OSHA Hazard Communication Standard, 29 CFR 1910.1200. } \\
\hline \multicolumn{5}{|c|}{ 4. FIRST AID MEASURES } \\
\hline \multicolumn{5}{|c|}{$\begin{array}{l}\text { EYES: } \quad \text { Flush with water for } 15 \text { minutes. If irritation develops or persists, get medical attention. } \\
\text { SKIN: } \quad \text { Remove contaminated clothing. Wash with soap and water. } \\
\text { INHALATION: Remove to fresh air for relief. If overcome by vapors, get medical attention. } \\
\text { INGESTION: Do not induce vomiting. If spontaneous vomiting occurs, keep head below hips to prevent } \\
\text { aspiration. Get medical attention. }\end{array}$} \\
\hline \multicolumn{5}{|c|}{ 5. FIRE FIGHTING MEASURES } \\
\hline \multicolumn{5}{|c|}{ FLASH POINT $\left({ }^{\circ} \mathrm{F}\right): \quad 145^{\circ} \mathrm{F}$ (TCC ASTM D 56$)$} \\
\hline \multicolumn{2}{|c|}{ OSHA FLAMMABILITY CLASSIFICATION: } & \multicolumn{3}{|l|}{ Combustible } \\
\hline \multicolumn{5}{|c|}{$\begin{array}{ll}\text { EXTINGUISHING MEDIA: } & \mathrm{CO}_{2} \text {, dry chemical, water fog or fine spray, foam (ATC type preferred). Water } \\
\text { stream may spread fire. }\end{array}$} \\
\hline \multicolumn{2}{|c|}{ SPECIAL FIRE FIGHTING PROCEDURES: } & \multicolumn{3}{|c|}{$\begin{array}{l}\text { Wear self contained breathing apparatus and full protective } \\
\text { gear. }\end{array}$} \\
\hline \multicolumn{2}{|c|}{ EXPLOSION LIMITS IN AIR - LOWER (\%): } & $0.8 @ 77^{\circ} \mathrm{F}$ & \multicolumn{2}{|c|}{ UPPER (\%): 5} \\
\hline \multicolumn{2}{|l|}{ AUTO IGNITION TEMP ( $\left.{ }^{\circ} \mathrm{F}\right)$ : } & \multicolumn{3}{|l|}{$849^{\circ} \mathrm{F}$} \\
\hline \multicolumn{2}{|c|}{ UNUSUAL FIRE AND EXPLOSION HAZARDS: } & \multicolumn{3}{|l|}{ None Known } \\
\hline \multicolumn{5}{|c|}{ 6. ACCIDENTAL RELEASE MEASURES } \\
\hline \multicolumn{5}{|c|}{$\begin{array}{l}\text { ACTION TO BE TAKEN IF MATERIAL IS RELEASED OR SPILLED: } \quad \text { Dike to contain spill and prevent the } \\
\text { product from entering drains or waterways. Remove possible ignition sources. } \\
\text { Recover free product. Collect remaining product with absorbent materials. }\end{array}$} \\
\hline
\end{tabular}




\begin{tabular}{|c|c|c|c|}
\hline \multicolumn{4}{|c|}{ 10. STABILITY AND REACTIVITY (CONTINUED) } \\
\hline \multicolumn{2}{|c|}{ INCOMPATIBILITY (MATERIALS TO AVOID): } & \multirow{2}{*}{\multicolumn{2}{|c|}{ Strong oxidizing agents and acids }} \\
\hline CONDITIONS TO AVOID: & Storage temperatur & & \\
\hline \multicolumn{4}{|c|}{ 11. TOXICOLOGICAL INFORMATION } \\
\hline CARCINOGENICITY: & \multicolumn{3}{|c|}{$\begin{array}{l}\text { This product contains naphthalene. The Intemational Agency for Research on } \\
\text { Cancer evaluated naphthalene and concluded that there was sufficient evidence } \\
\text { for carcinogenicity in experimental animals, but inadequate evidence for cancer } \\
\text { in exposed humans. Accordingly, IARC classified naphthalene as a possible } \\
\text { human carcinogen (Group 2B). } \\
\text { The U.S. National Toxicology Program (NTP) has evaluated naphthalene and found } \\
\text { that it may be reasonably anticipated to be a human carcinogen. }\end{array}$} \\
\hline ACUTE ORAL LD50 (Rat): & Polyamide Resin: & $>5 \mathrm{~g} / \mathrm{kg}$ & \\
\hline SKIN (Rabbit): & Polyamide Resin: & Moderate & \\
\hline EYE (Rabbit): & Polyamide Resin: & Severe & \\
\hline \multicolumn{4}{|c|}{ 12. ECOLOGICAL INFORMATION } \\
\hline \multicolumn{4}{|c|}{ The following test results are for a similar product to the polyamide resin used in this product:: } \\
\hline \multicolumn{2}{|c|}{ Fish Toxicity, OECD 203 (Golden Orfe): } & LC50 (96hr): & $2.3 \mathrm{mg} / \mathrm{l}$ \\
\hline \multicolumn{2}{|c|}{ Crustacean Toxicity, OECD 202 (Daphnia): } & EC50(48hr): & $0.55 \mathrm{mg} / \mathrm{l}$ \\
\hline \multicolumn{2}{|l|}{ Algistatic Effect, OECD 201: } & $\begin{array}{l}\operatorname{ErC50}(24-48 \mathrm{hr}): \\
\operatorname{EbC50}(72 \mathrm{hr}):\end{array}$ & $\begin{array}{l}2.9 \mathrm{mg} / \mathrm{l} \\
2.3 \mathrm{mg} / \mathrm{l}\end{array}$ \\
\hline \multicolumn{3}{|c|}{ Ready Biodegradation, OECD301B (Modified Sturm): } & $0 \%$ degraded after 28 days. \\
\hline \multicolumn{2}{|c|}{ Partition Coefficient, OECD 117/1: } & Log10Pow & 3.51 \\
\hline \multicolumn{4}{|c|}{ 13. DISPOSAL CONSIDERATIONS } \\
\hline RCRA: & \multicolumn{3}{|c|}{$\begin{array}{l}\text { Under EPA-RCRA ( } 40 \text { CFR 261.21), should this product become a waste } \\
\text { material it would be an ignitable hazardous waste (Hazardous Waste \# D001). }\end{array}$} \\
\hline WASTE DISPOSAL: & \multicolumn{3}{|c|}{$\begin{array}{l}\text { Incinerate liquid and contaminated solids in accordance with local, state, and } \\
\text { federal regulations. }\end{array}$} \\
\hline EMPTY DRUMS: & \multicolumn{3}{|c|}{$\begin{array}{l}\text { Empty contains retain product residue (liquid and/or vapor) and can have the same } \\
\text { hazardous waste characteristics as the material they previously contained. } \\
\text { Empty drums should be completely drained, properly bunged and promptly } \\
\text { retumed to a drum reconditioner or properly disposed of. }\end{array}$} \\
\hline
\end{tabular}


Appendix C

TDS and MSDS of Sherwin Williams

TDS

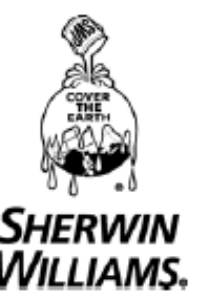

Product Finishes

CC-M17

MIL-PRF-22750G, Type I \& Type II
High Solids Epoxy Topcoat

Gloss White 17925

Semi-

Semi-Gloss Tan 23446 ........ F92 $\mathrm{H} 101$

Flat Gray 36375 .

Catalyst.

F93A603

Semi-Gloss Seafoam Green 24533. F92G227

\begin{tabular}{|c|c|c|}
\hline 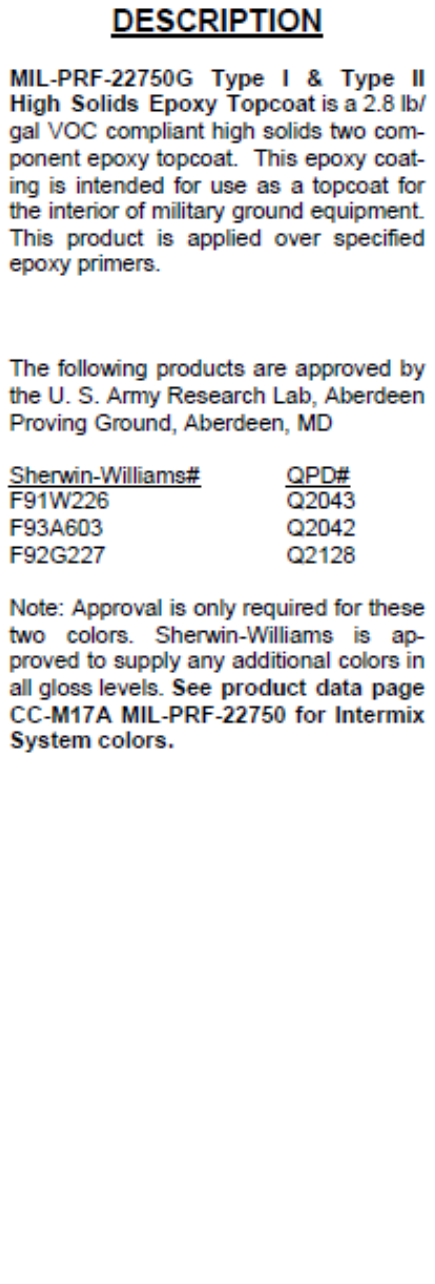 & 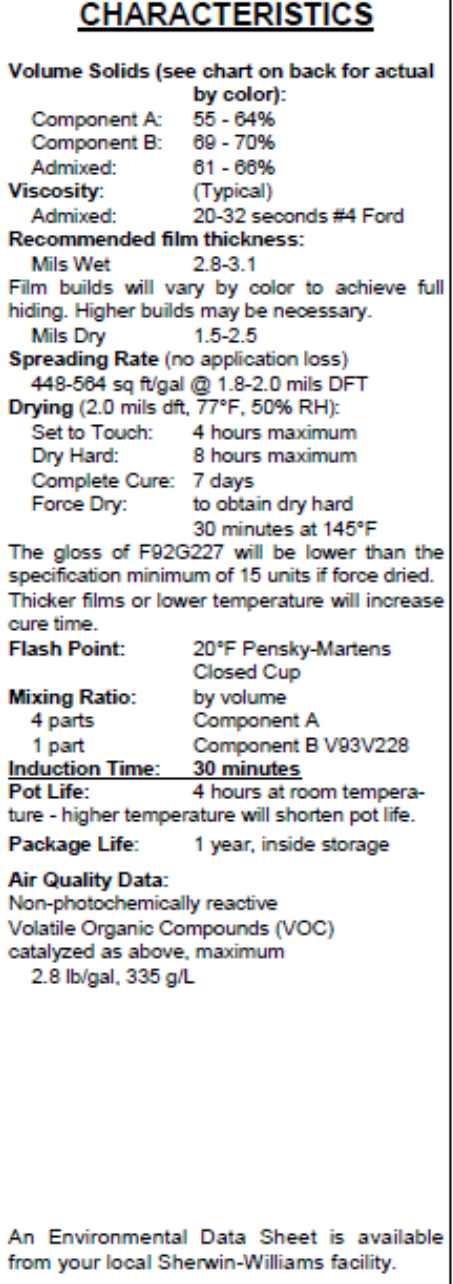 & $\begin{array}{l}\text { SPECIFICATIONS } \\
\text { Steel: Surface must be clean and free of } \\
\text { grease, dirt, oil, rust, fingerprints, and other } \\
\text { contaminants to insure optimum adhesion } \\
\text { and performance properties. Chemical } \\
\text { pretreatment, TT-C-490, Type I, zinc phos- } \\
\text { phate or DOD-P-15328D wash primer. } \\
\text { E90G4, gives best adhesion and perform- } \\
\text { ance results. Where blasting is appropri- } \\
\text { ate, blast in accordance with SSPC-SP10 } \\
\text { or SSPC-SP5. For optimum adhesion pre- } \\
\text { treat blasted surface immediately. Prime } \\
\text { with wash primer E90G4 within two hours } \\
\text { after blasting. } \\
\text { Aluminum: Clean with acidic cleaner or } \\
\text { other appropriate cleaner depending on } \\
\text { contamination. Pretreat with chromate } \\
\text { conversion coating MIL-DTL-5541, wash } \\
\text { primer DOD-P-15328 (E90G4), or anodize } \\
\text { per MIL-A-8625-MIL-C-8514 (E90G16). } \\
\text { Galvanized and other metals: Clean and } \\
\text { remove oxidation contamination on surface, } \\
\text { followed by treatment with DOD-P-15328D } \\
\text { wash primer (E90G4). MIL-C-8514 } \\
\text { (E90G 16). or anodize per MIL-A-8625. } \\
\text { Due to the variability in these surface, test- } \\
\text { ing adhesion on each situation is recom- } \\
\text { mended. } \\
\text { Primers must be applied under the top- } \\
\text { coat. For ferrous substrates, use MIL- } \\
\text { DTL-53022 primers. } \\
\text { For non-ferrous substrates, MIL-P-23377 } \\
\text { (E90G203) (Type I, Class C2 , } 2.8 \text { VOC): or } \\
\text { MIL-P-53022 (see above). } \\
\text { Check the data sheet of each primer for } \\
\text { recoat time of topcoat. } \\
\text { Testing: Due to the wide variety of sub- } \\
\text { strates, surface preparation methods, } \\
\text { application methods, and environments, } \\
\text { the customer should test the complete } \\
\text { system for adhesion, compatibility and } \\
\text { performance prior to full scale applica- } \\
\text { tion. }\end{array}$ \\
\hline
\end{tabular}




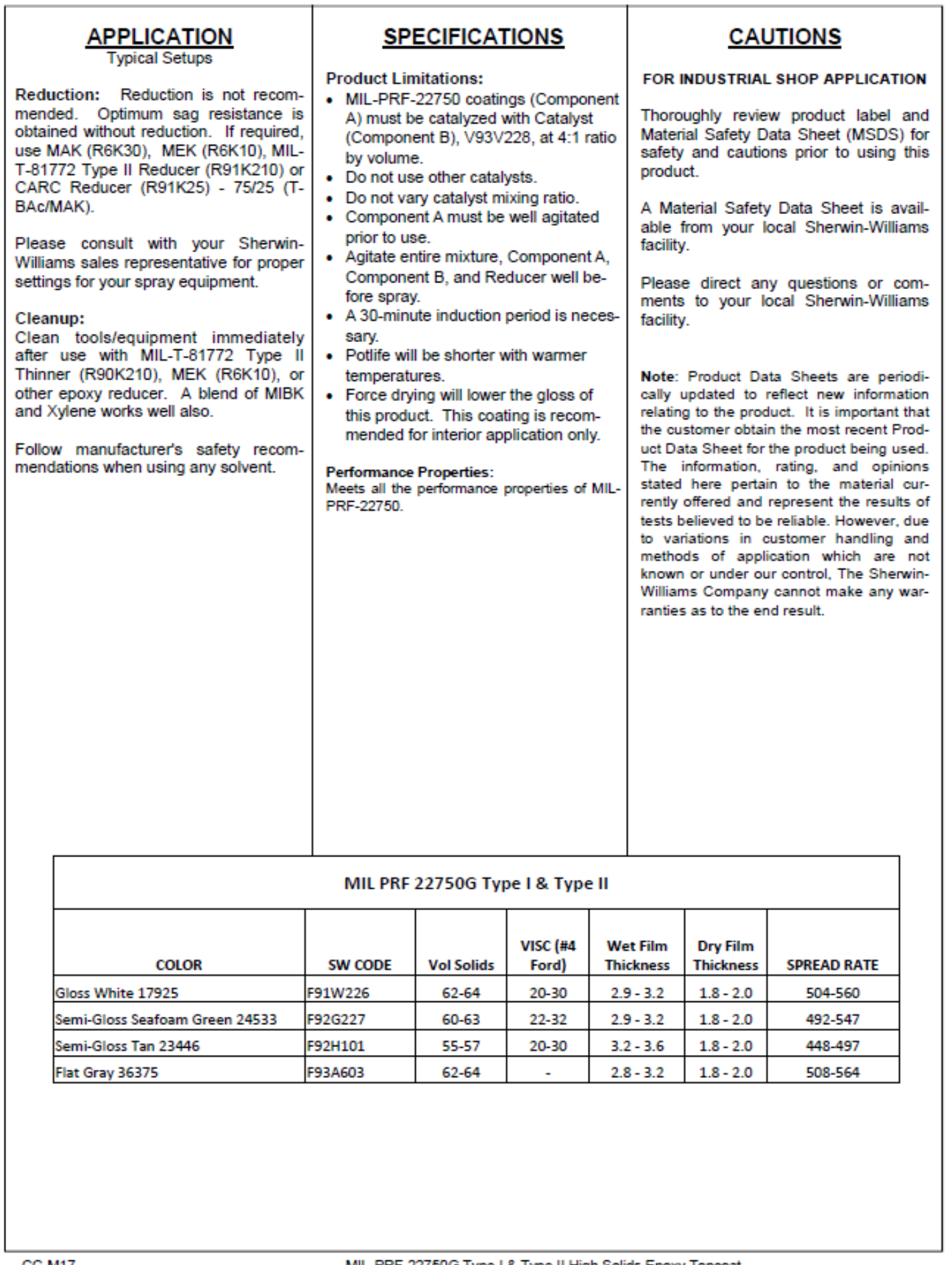


MSDS of white Ink

MATERIAL SAFETY DATA SHEET

V93V 00228

\section{SECTION 1 - PRODUCT AND COMPANY IDENTIFICATION}

\section{PRODUCT NUMBER \\ V93V00228}

PRODUCT NAME

V93V00228 MIL-PRF-22750G T1 HIGH SOLIDS EPOXY TOPCOAT CATALYST

MANUFACTURER'S NAME

THE SHERWIN-WILLIAMS CO

101 Prospect Avenue N.W.

Cleveland, $\mathrm{OH} 44115$

\begin{tabular}{l} 
Telephone Numbers and Websites \\
\begin{tabular}{|r|r|}
\hline Regulatory Information & $(216) 566-2902$ \\
\hline Medical Emergency & $(216) 568-2917$ \\
\hline Transportation Emergency" & $(800) 424-9300$ \\
\hline "for Chemical Emergency ONL Y (spill, leak, fire, exposure, or \\
accident)
\end{tabular} \\
\hline
\end{tabular}

\section{SECTION 2 - COMPOSITION/INFORMATION ON INGREDIENTS}

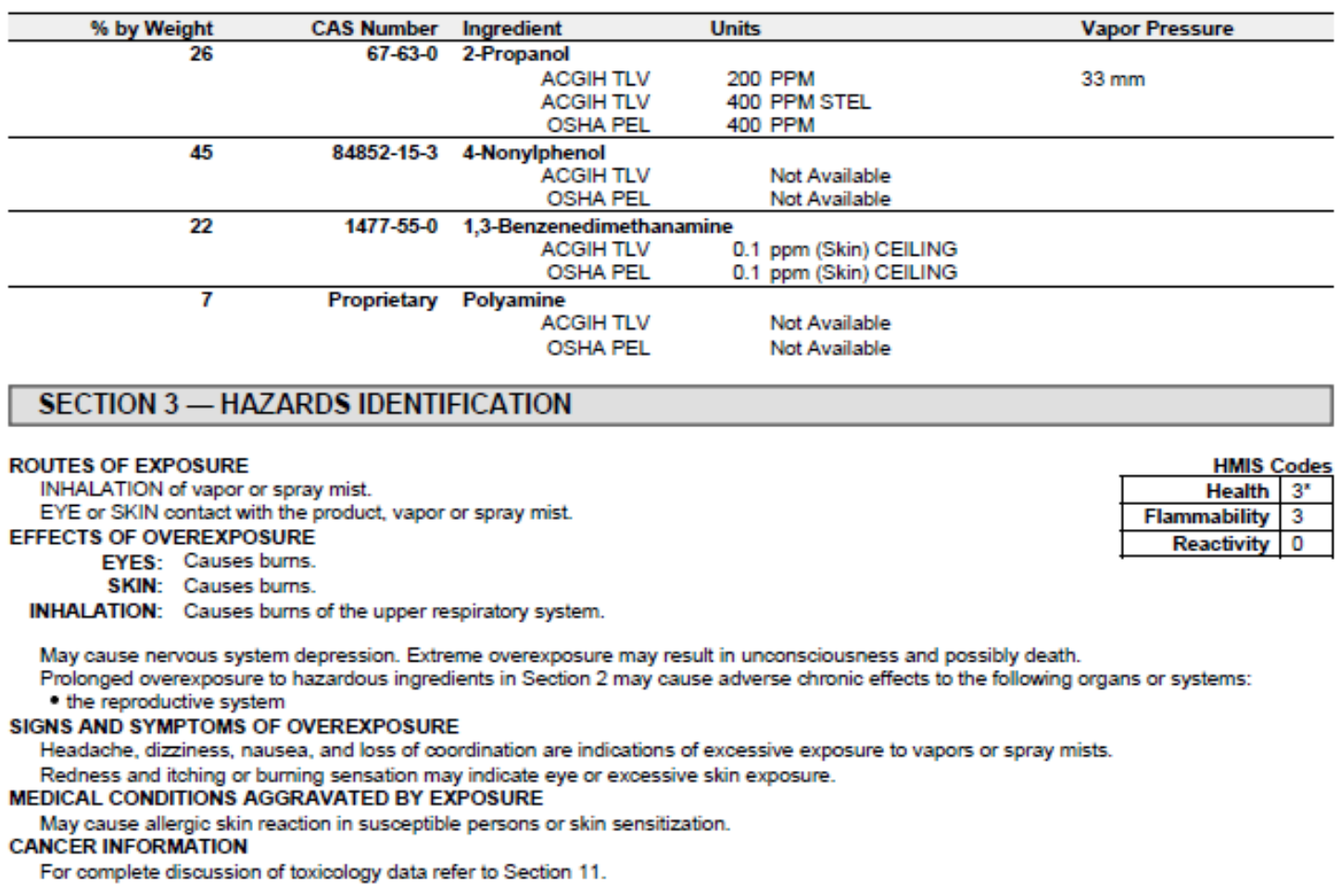




\section{Catalyst MSDS}

MATERIAL SAFETY DATA SHEET

V93V00228

DATE OF PREPARATION

0400

SECTION 1 - PRODUCT AND COMPANY IDENTIFICATION

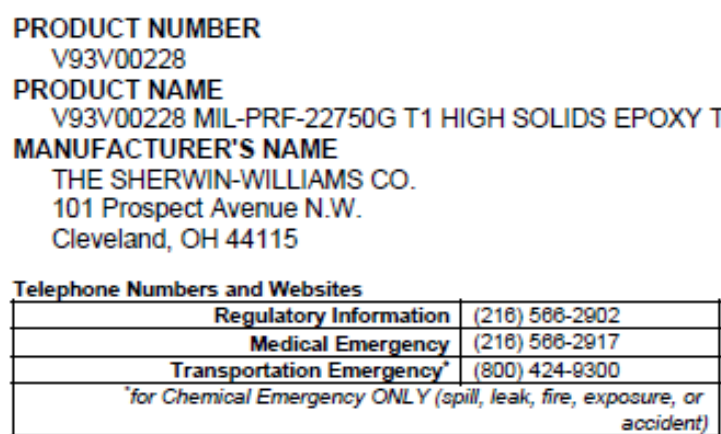

SECTION 2 - COMPOSITION/INFORMATION ON INGREDIENTS

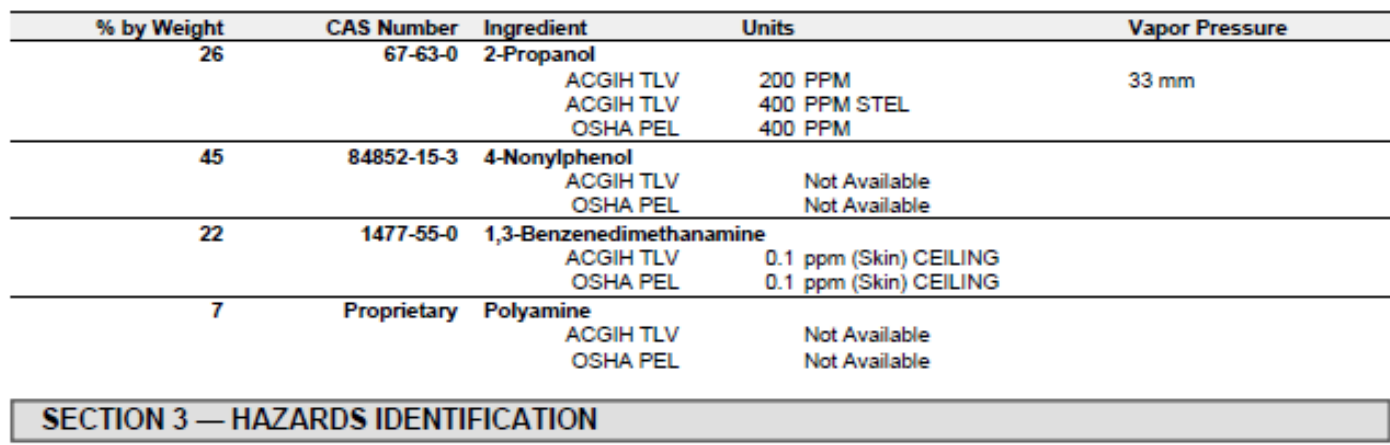

ROUTES OF EXPOSURE

INHALATION of vapor or spray mist.

EYE or SKIN contact with the product, vapor or spray mist.

EFFECTS OF OVEREXPOSURE

EYES: Causes burns.

SKIN: Causes burns.

INHALATION: Causes burns of the upper respiratory system.

\begin{tabular}{|r|l|}
\multicolumn{2}{c}{ HMIS Codes } \\
\hline Health & $3^{x}$ \\
\hline Flammability & 3 \\
\hline Reactivity & 0 \\
\hline
\end{tabular}

May cause nervous system depression. Extreme overexposure may result in unconsciousness and possibly death.

Prolonged overexposure to hazardous ingredients in Section 2 may cause adverse chronic effects to the following organs or systems:

- the reproductive system

SIGNS AND SYMPTOMS OF OVEREXPOSURE

Headache, dizziness, nausea, and loss of coordination are indications of excessive exposure to vapors or spray mists.

Redness and itching or burning sensation may indicate eye or excessive skin exposure.

MEDICAL CONDITIONS AGGRAVATED BY EXPOSURE

May cause allergic skin reaction in susceptible persons or skin sensitization.

CANCER INFORMATION

For complete discussion of toxicology data refer to Section 11. 
Appendix D

Curing Schedule of 11 Products

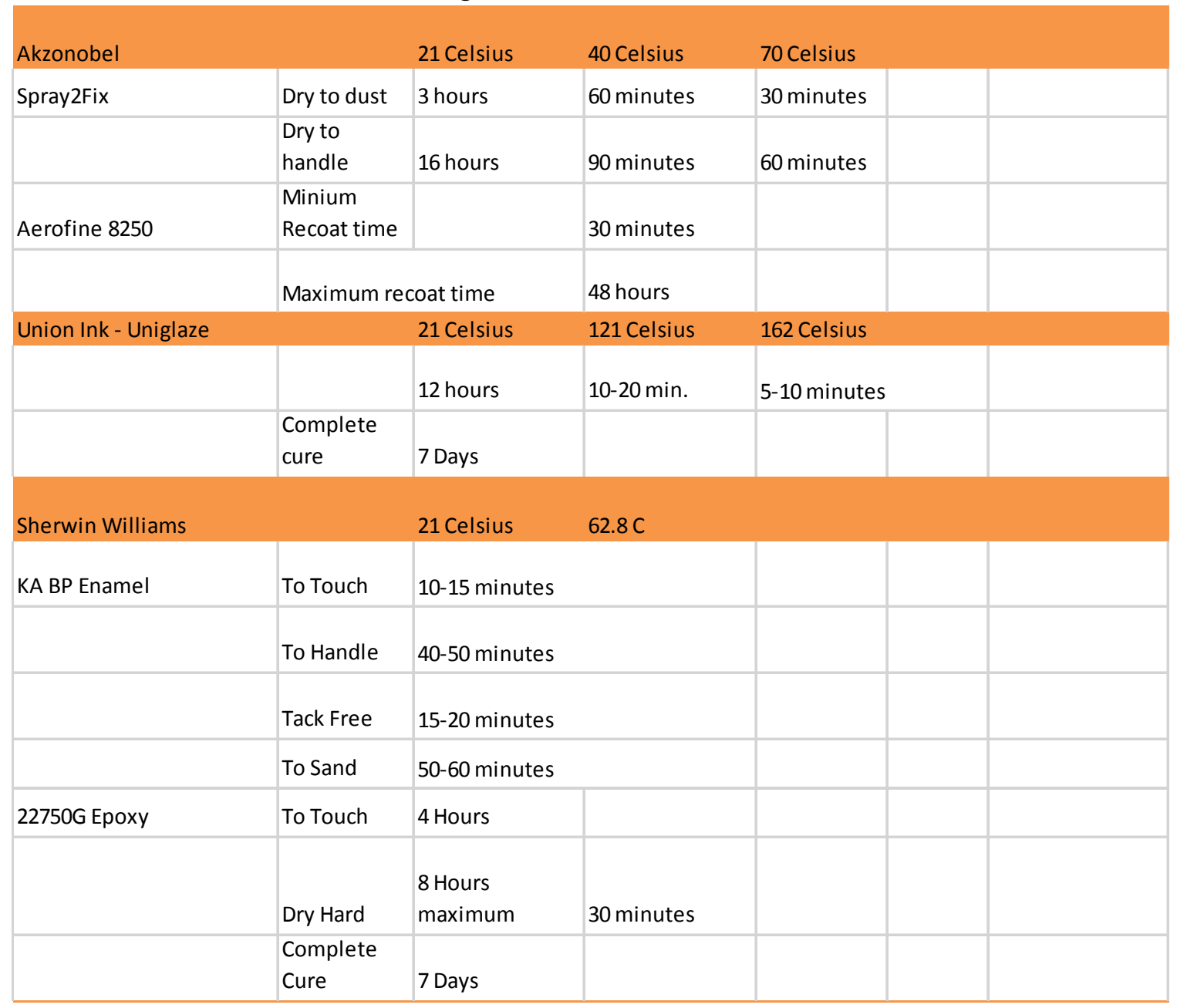




\begin{tabular}{|c|c|c|c|c|c|c|}
\hline \multirow{2}{*}{\multicolumn{2}{|c|}{ DEFT }} & \multirow{3}{*}{21 Celsius } & \multirow{3}{*}{$(48.9 C) 120 F$} & \multicolumn{3}{|c|}{$(71.1 C) 16$} \\
\hline & & & & $(60 \mathrm{C}) 140 \mathrm{~F}$ & $\mathrm{OF}$ & $(82.2 \mathrm{C}) 180 \mathrm{~F}$ \\
\hline \multirow[t]{4}{*}{ 85285E Polyurethane } & To Touch & & & & & \\
\hline & Dry Hard & 12 Hours & 45 minutes & 30 minutes & $\begin{array}{l}20 \\
\text { minutes }\end{array}$ & 15 minutes \\
\hline & Dry to Tape & 12 Hours & & & & \\
\hline & Full Cure & 14 Days & & & & \\
\hline \multicolumn{2}{|l|}{ Green Polyurethane } & \multicolumn{5}{|l|}{21 Celsius } \\
\hline & $\begin{array}{l}\text { Complete } \\
\text { Cure }\end{array}$ & 4 Days & & & & \\
\hline \multicolumn{2}{|l|}{ Dupont } & \multicolumn{2}{|l|}{25 Celsius } & \multicolumn{3}{|c|}{$120-140 F(48-60 C)$} \\
\hline \multirow[t]{3}{*}{ HG 1.2} & Tack Free & 20-30 minutes & & & & \\
\hline & Dry to recoat & 30 minutes & & & & \\
\hline & Hard Dry & 2 Hours & & 15-20 Minut & & \\
\hline \multirow[t]{5}{*}{ Industual Strength } & To Touch & 3 Hours & & & & \\
\hline & Tack Free & 3 Hours & & & & \\
\hline & To Handle & 4.5 hours & & & & \\
\hline & Hard Dry & 18 hours & & & & \\
\hline & Full Cure & 7 Days & & & & \\
\hline \multicolumn{2}{|l|}{ American Marking } & \multicolumn{5}{|l|}{25 Celsius } \\
\hline \multirow[t]{2}{*}{ Wj Series } & To Touch & 50 minutes & & & & \\
\hline & Dry Hard & 5 Hours & & & & \\
\hline \multirow[t]{2}{*}{ JS Series } & To Touch & 50 minutes & & & & \\
\hline & Dry Hard & 4 Hours & & & & \\
\hline
\end{tabular}




\section{Appendix E}

\section{Phase 1 Test Results}

\section{American Marking JS and WJ series Before and After Test}

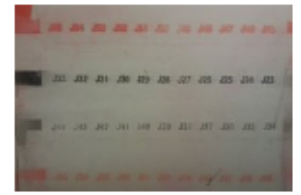

20130924084848

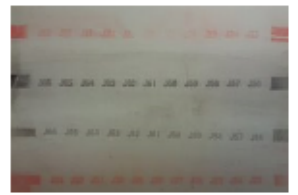

20130924084938

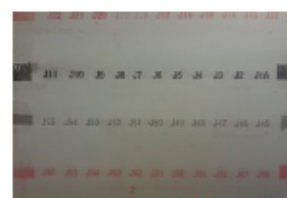

20130924_085022

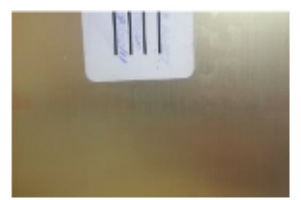

$20130924 \quad 085056$

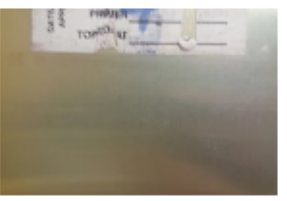

20130924085134

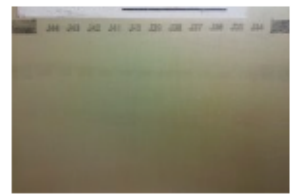

$20130 \$ 24085231$

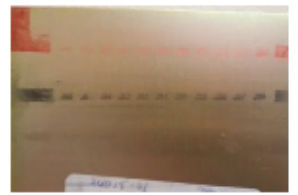

20130924085307

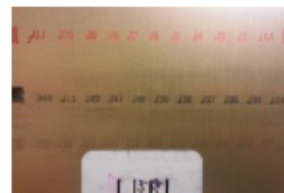

20130924084901

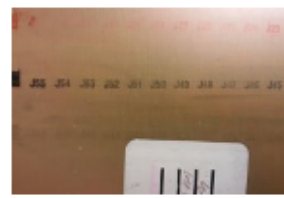

20130924084959

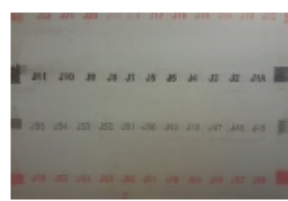

20130924_085023

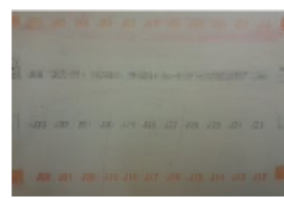

20130924085110

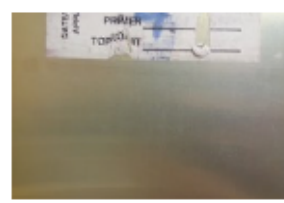

20130924085135

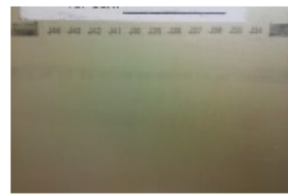

20130924085232

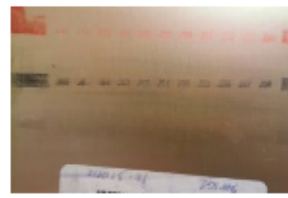

20130924085311

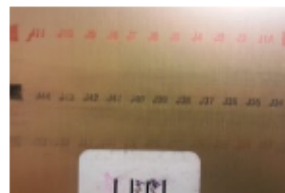

20130924084903

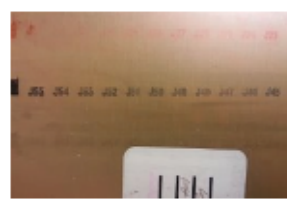

20130924085000

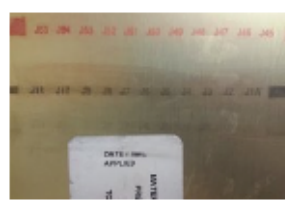

20130924085038

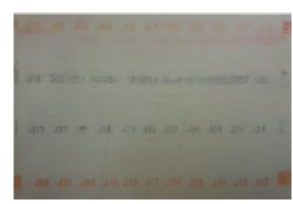

$20130924 \quad 085112$

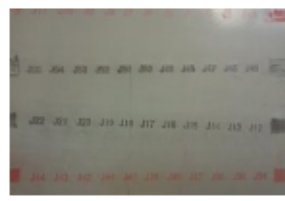

20130924085155

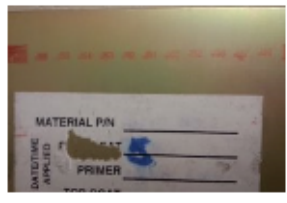

20130924085243

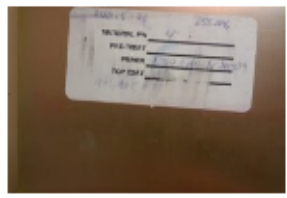

20130924085334

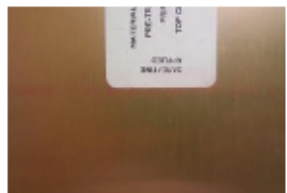

20130924084914

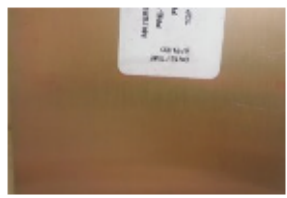

20130924085006

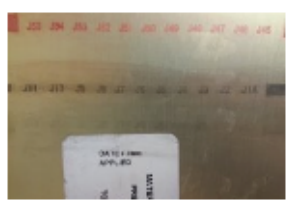

20130924085039

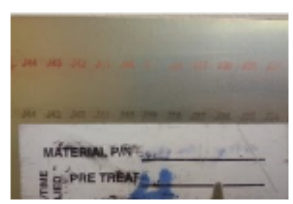

20130924085124

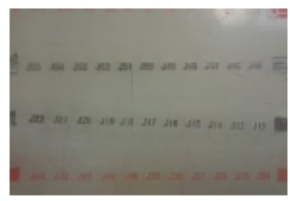

20130924085157

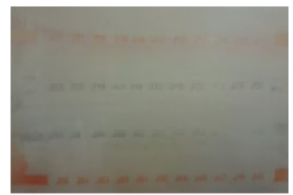

20130924085253

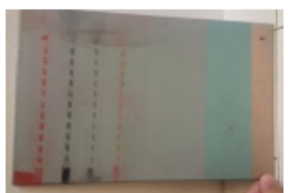

20130924085356

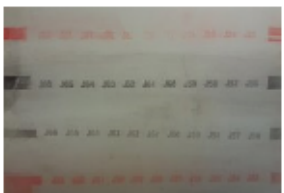

20130924084935

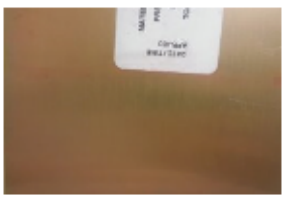

20130924085010

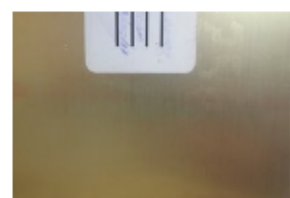

20130924_085054

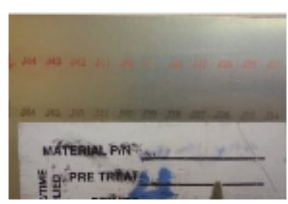

20130924_085125

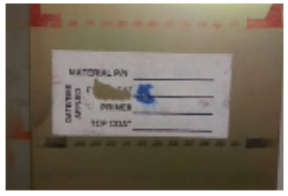

20130924085222

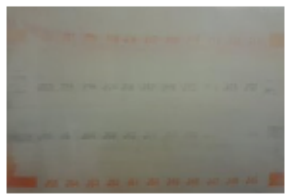

20130924085255

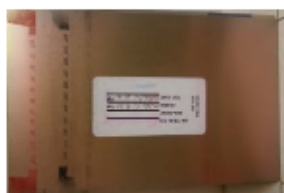

20130924085405 


\section{DEFT, Akzonobel Spray2Fix, Sherwin William Photo 9 to next page}

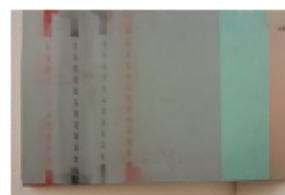

20130924085438

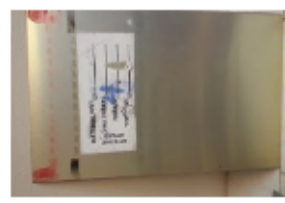

20130924085537

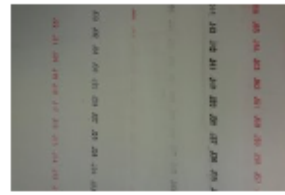

20130924085718

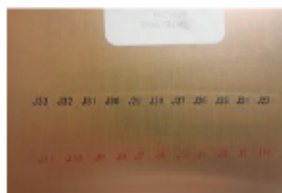

20130924_085752

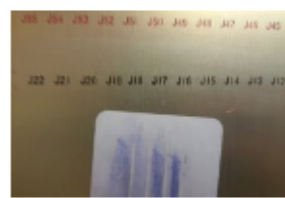

$2013092408584 \mathrm{~B}$

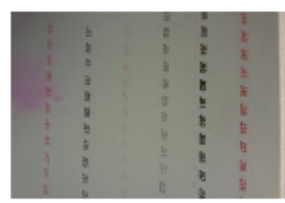

20130924085926

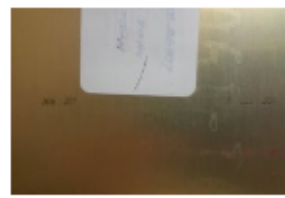

20130924090012

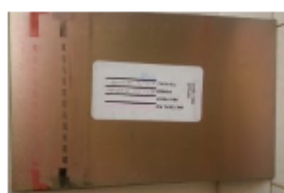

20130924 085448

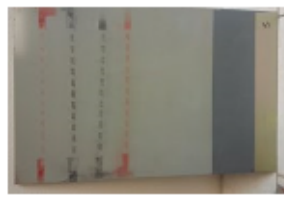

20130924085555

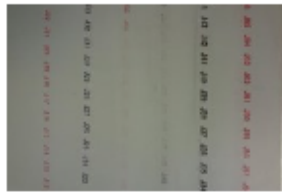

20130924085720

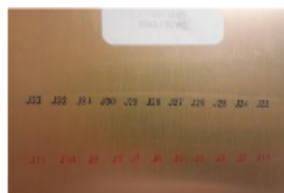

20130924085754

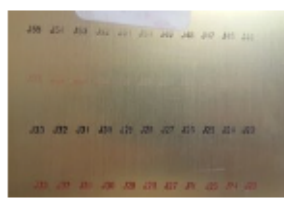

20130924085858

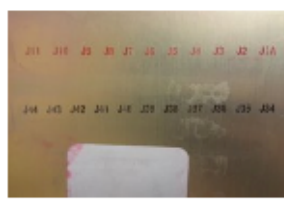

20130924085941

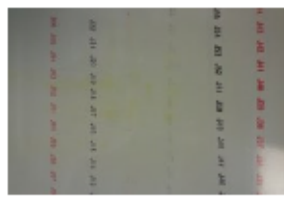

20130924090044

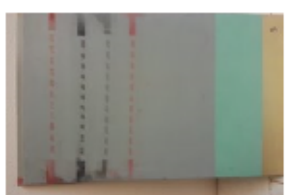

20130924_085504

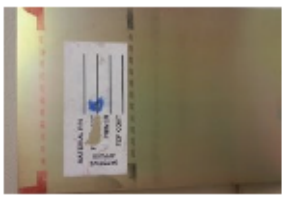

20130924085610

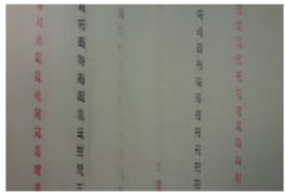

20130924085726

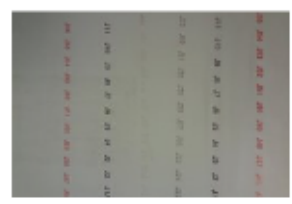

20130924085827

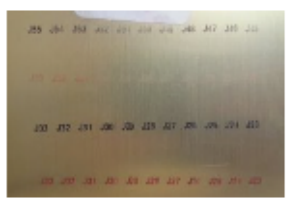

20130924085905

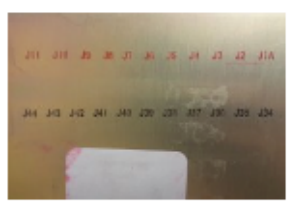

20130924085943

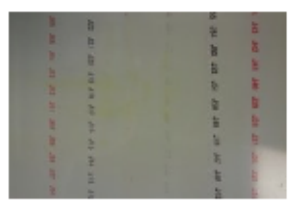

20130924090051

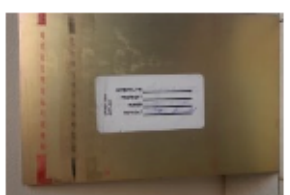

20130924085515

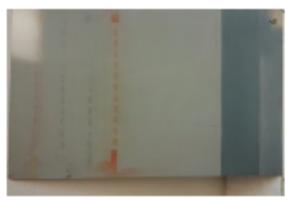

20130924085629

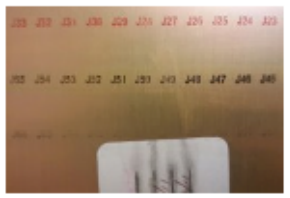

20130924085741

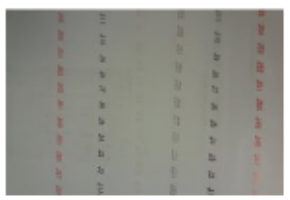

20130924_085831

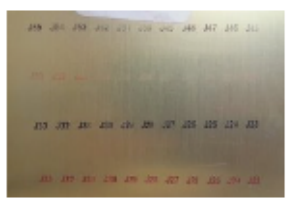

20130924085907

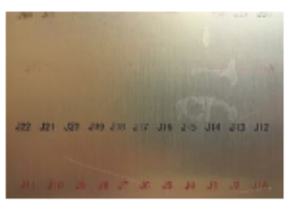

20130924090004

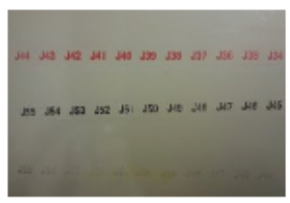

20130924090105

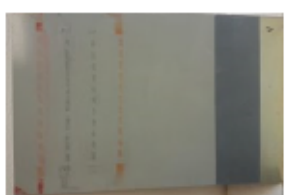

$20130924 \quad 085528$

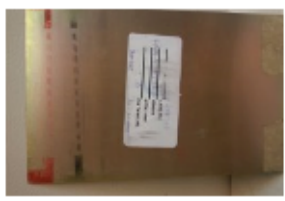

20130924085640

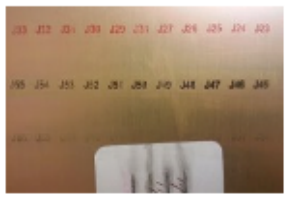

20130924085742

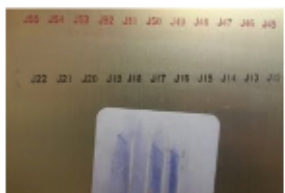

20130924_085846

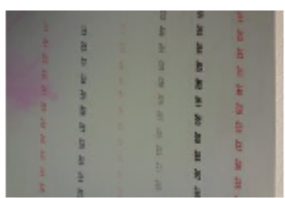

20130924085924

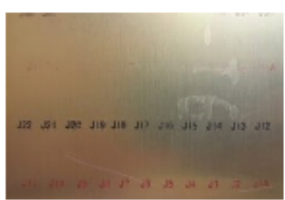

20130924090006

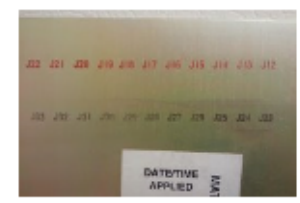

20130924090119 


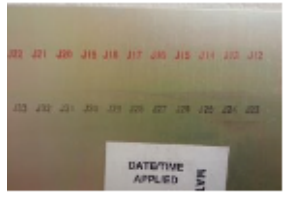

20130924090120

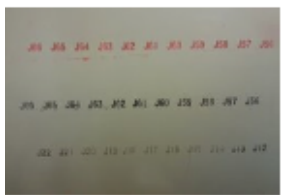

20130924090208

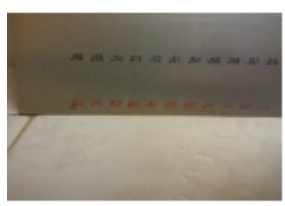

20130924_090306

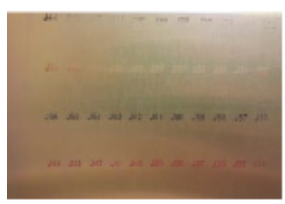

20130924_090351

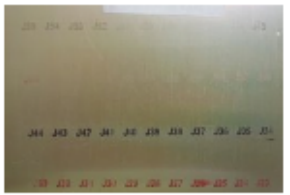

20130924090129

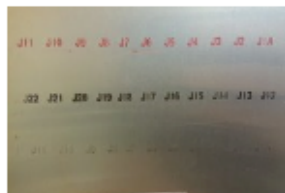

20130924090230

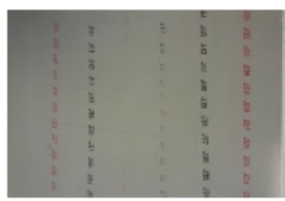

20130924_090324

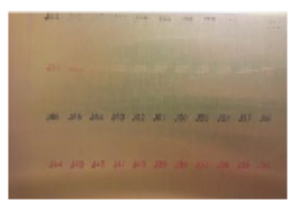

20130924090353

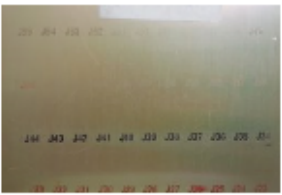

20130924090131

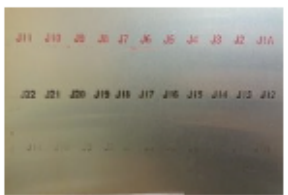

20130924090231

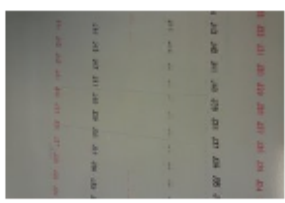

20130924090329

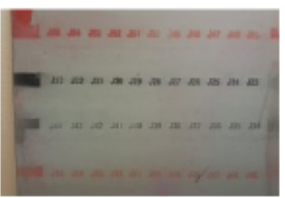

20130924_084837

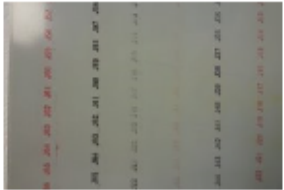

20130924090150

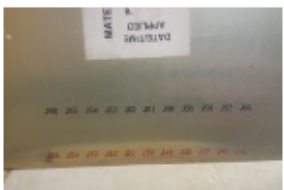

20130924_090300

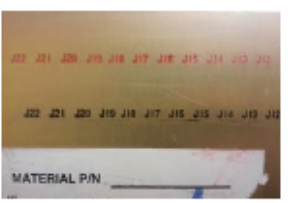

20130924_090342

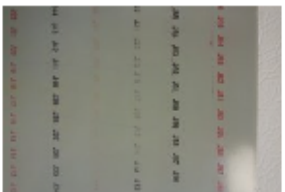

20130924090157

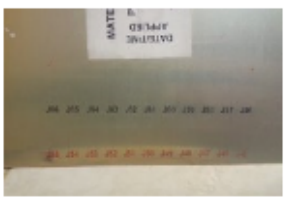

20130924090301

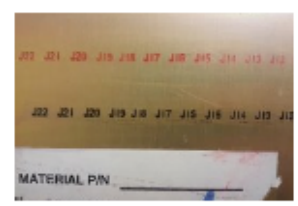

20130924090345 
Union Ink and Green Polyurethane

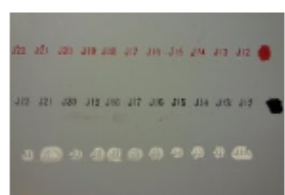

20140226_124900

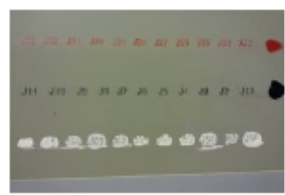

20140226_124928

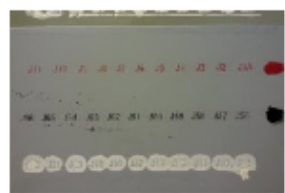

20140226_124959

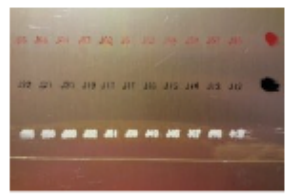

20140226_125024

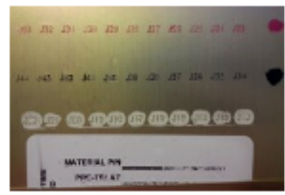

20140226_125104

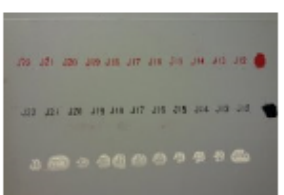

20140226_124915

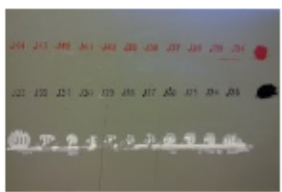

20140226_124942

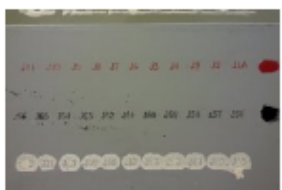

20140226_125000

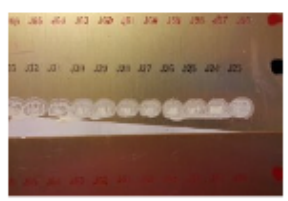

20140226_125029

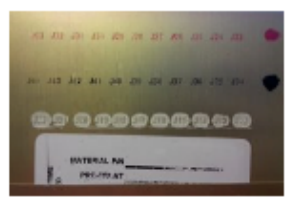

20140226_125111

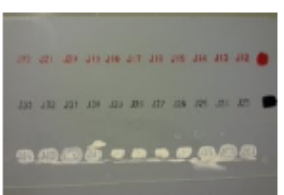

20140226_124922

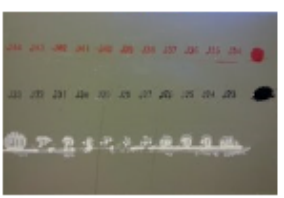

20140226_124943

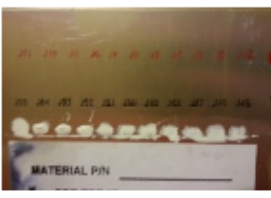

20140226_125018

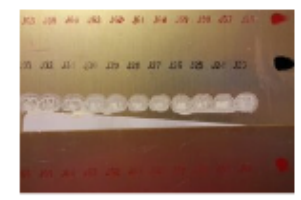

20140226_125033

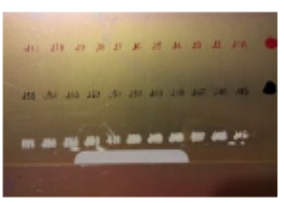

20140226_125113

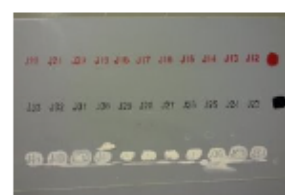

20140226_124923

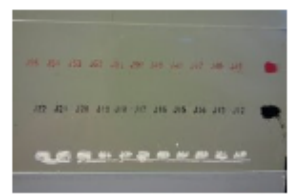

20140226_124950

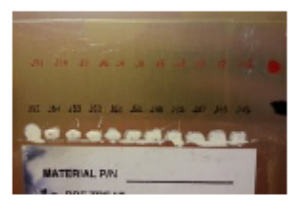

20140226_125019

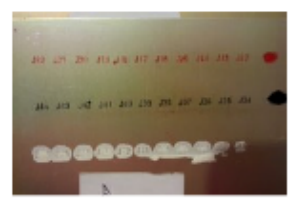

20140226_125056

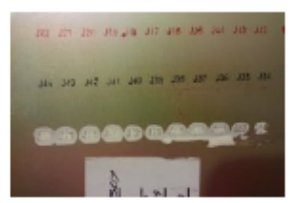

20140226_125116

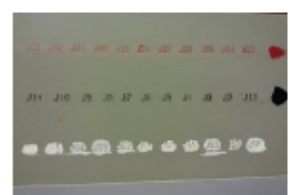

20140226_124927

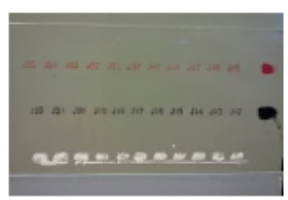

20140226_124951

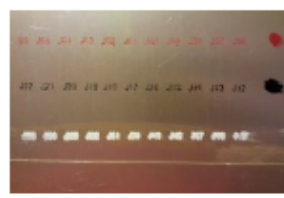

20140226_125023

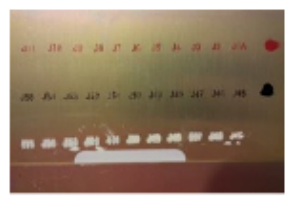

20140226_125059 
DuPont 1.2 HG, DuPont IS, Aerofine before

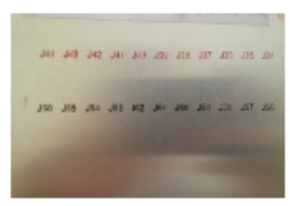

20131104_100820

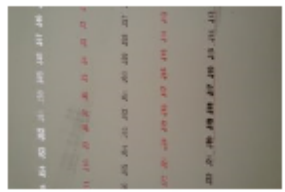

20131104_100900

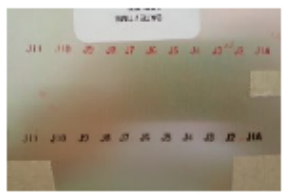

20131104_100938

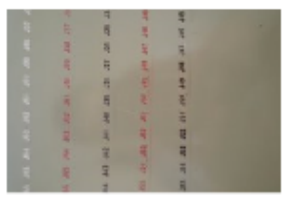

20131104_100509

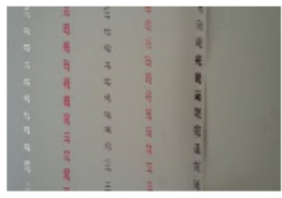

20131104_100551

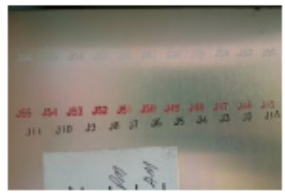

20131104_100715

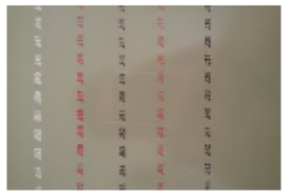

20131104_100753

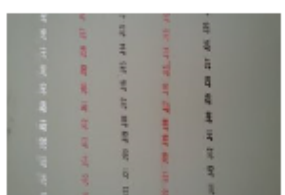

20131104_100831

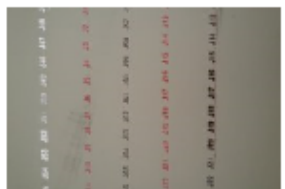

20131104_100902

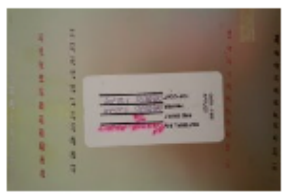

20131104_100958

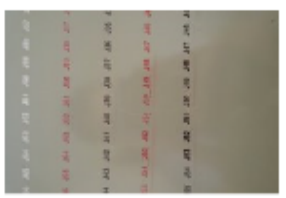

20131104_100513

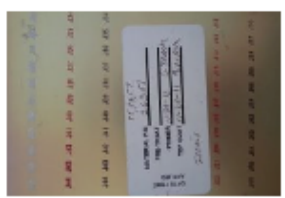

20131104_100602

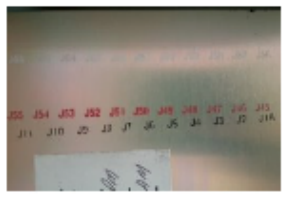

20131104_100718

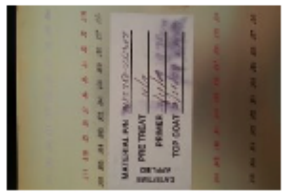

20131104_100807

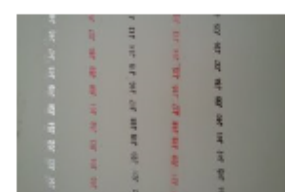

20131104_100833

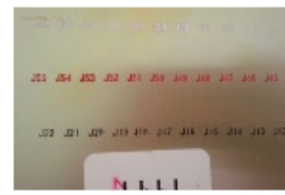

20131104_100928

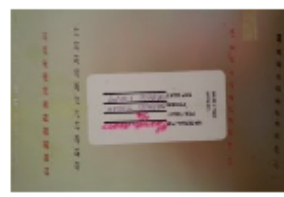

20131104_101002

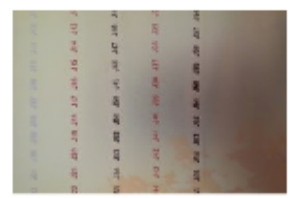

20131104_100529

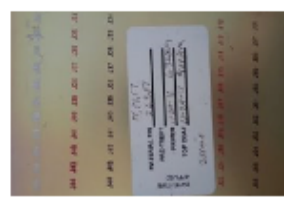

20131104_100604

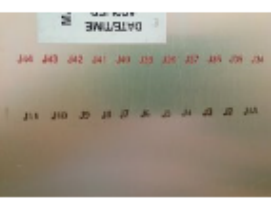

20131104_100727

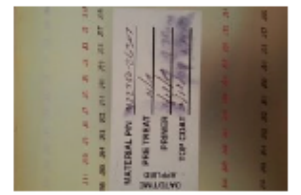

20131104_100813

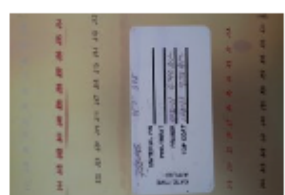

20131104_100845

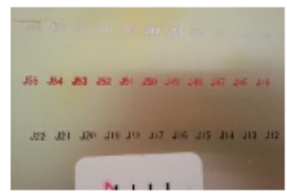

20131104_100931

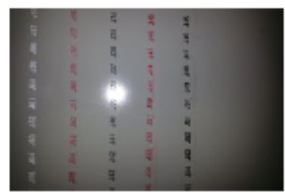

20131104_100457

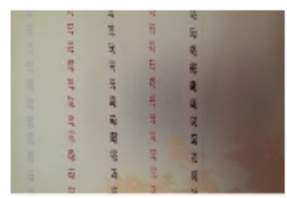

20131104_100531

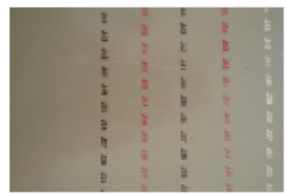

20131104_100621

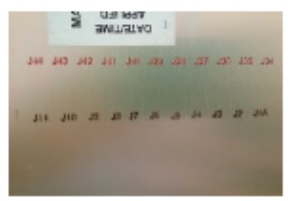

20131104_100729

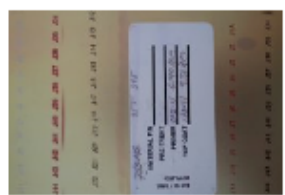

20131104_100848

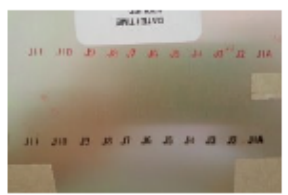

20131104_100937

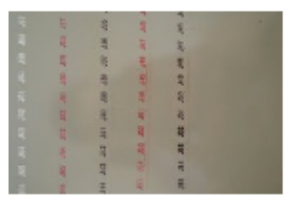

20131104_100507

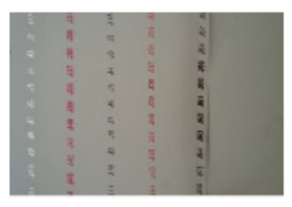

20131104_100548

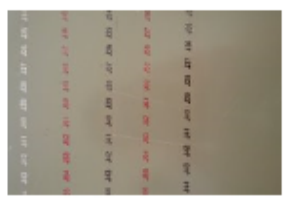

20131104_100624

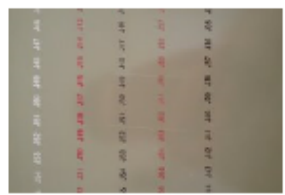

20131104_100752 
DuPont 1.2 HG, DuPont IS, Aerofine After

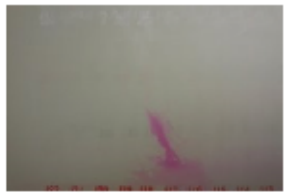

20140113_113629

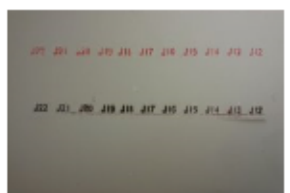

20140113_113706

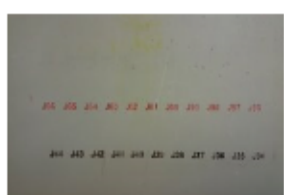

20140113_113337

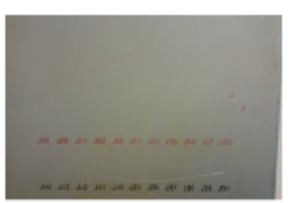

20140113_113505

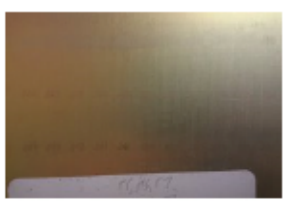

20140113_113604

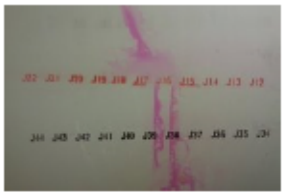

20140113_113634

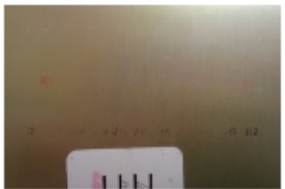

20140113_113716

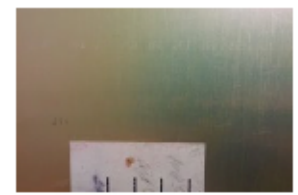

20140113_113351

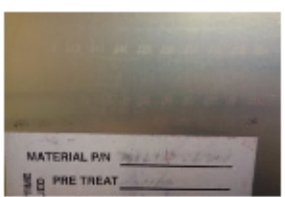

20140113_113520

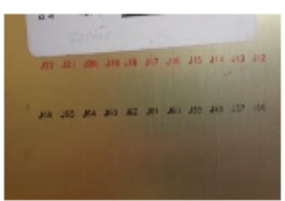

20140113_113610

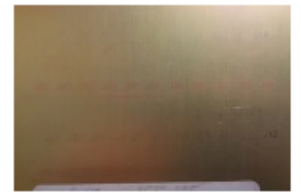

20140113_113648

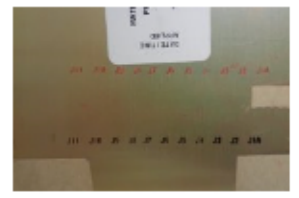

20140113_113723

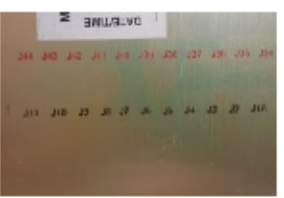

20140113_113400

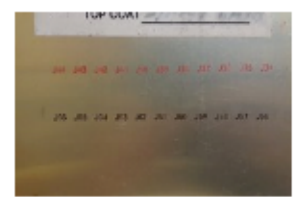

20140113_113527

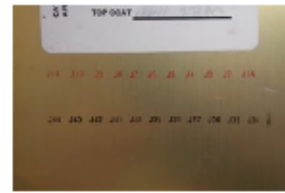

20140113_113653

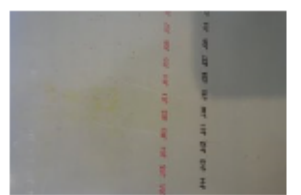

20140113_113256

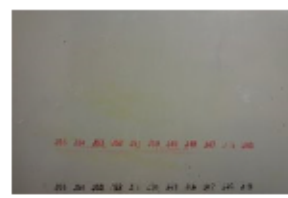

20140113_113419

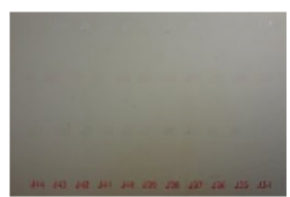

20140113_113544

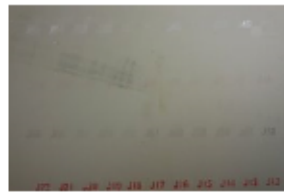

20140113_113703

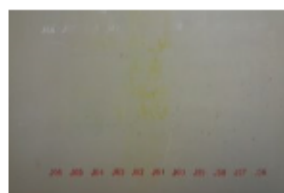

20140113_113334

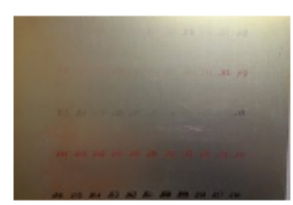

20140113_113444

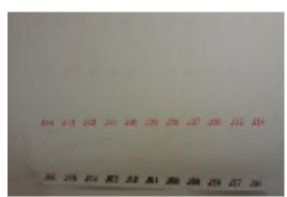

20140113_113547 


\section{Appendix F}

\section{Phase 2 Test Results}

\section{Before}

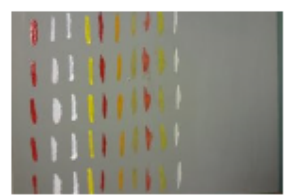

20131114090834

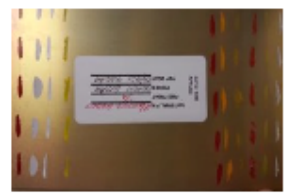

20131114090932

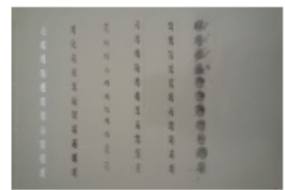

$20131118 \quad 120519$

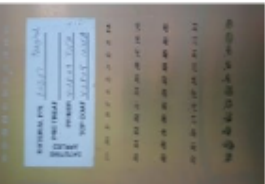

$20131118+120552$

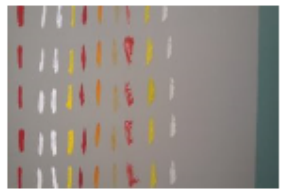

20131118 120633

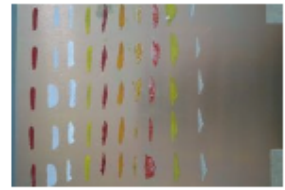

$20131118 \quad 120718$

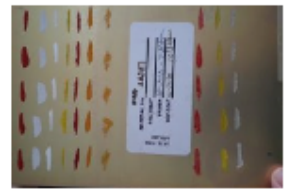

20131118120755

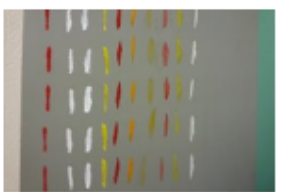

20131114090847

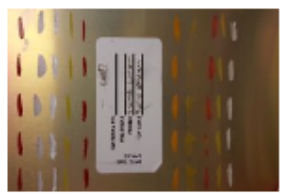

2013111409093

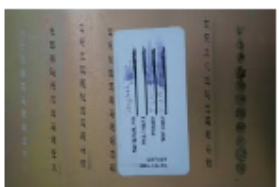

20131118120524

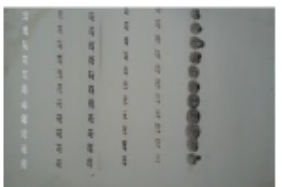

20131118_120559

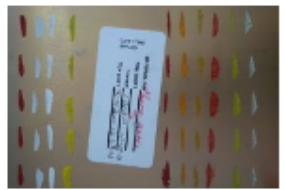

$20131118 \quad 120645$

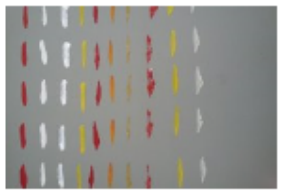

$20131118 \quad 120723$

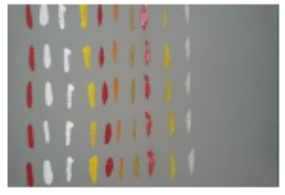

20131118120800

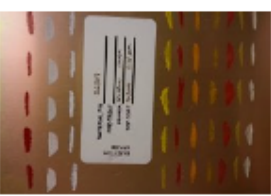

20131114090912

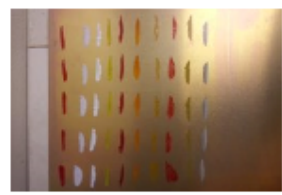

20131114090945

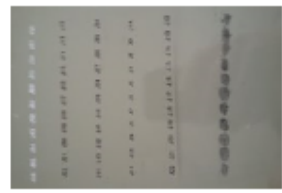

20131118120530

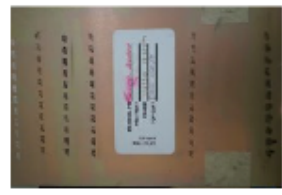

$20131118+120608$

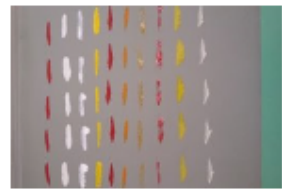

20131118 120652

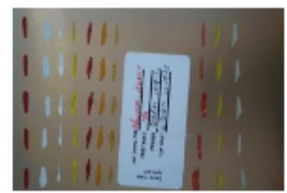

$20131118 \quad 120720$

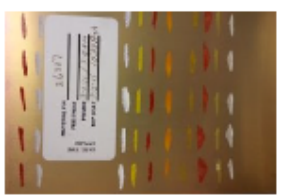

20131114090918

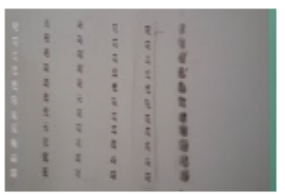

$20131118 \quad 120435$

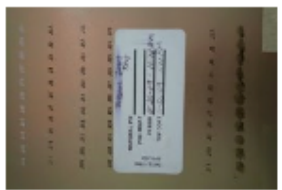

$20131118 \quad 120536$

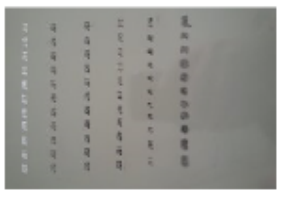

20131118_120614

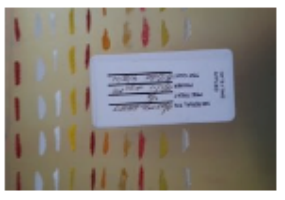

20131118120659

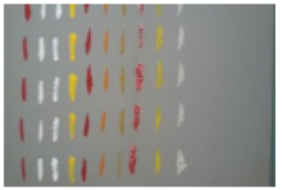

$20131118 \quad 120737$

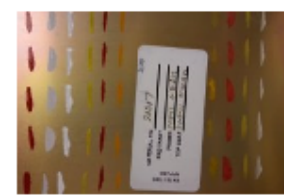

20131114090926

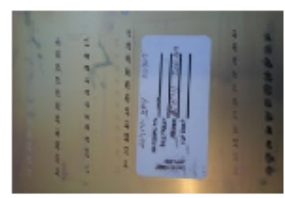

$20131118 \quad 120508$

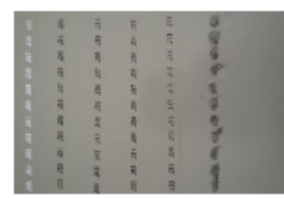

$20131118 \quad 120544$

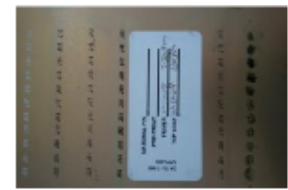

20131118_120622

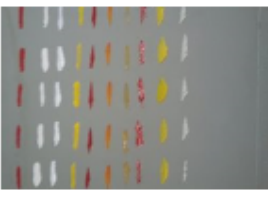

$20131118 \quad 120704$

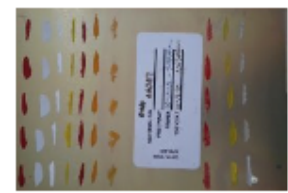

$20131118 \quad 120745$ 


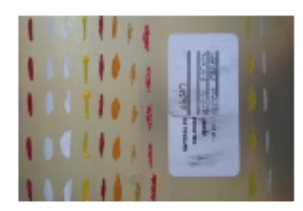

20131118_120807

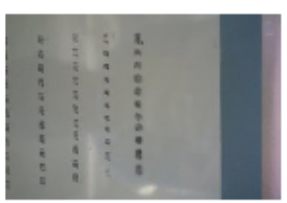

20131105125631

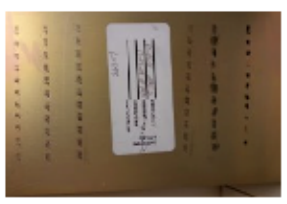

20131114090426

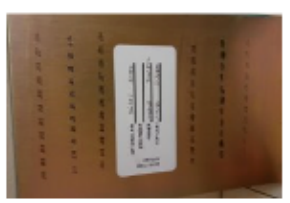

20131114_090500

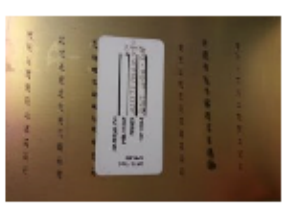

20131114090545

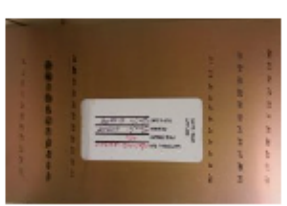

20131114090617

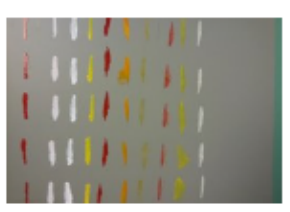

$2013111409075 \mathrm{~B}$

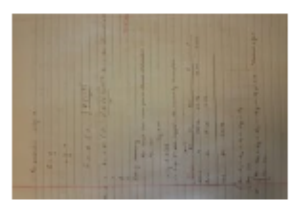

$20131118 \quad 131530$

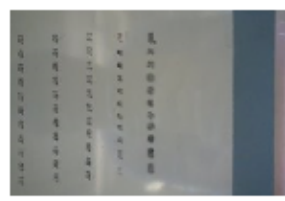

20131105125633

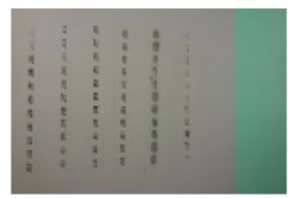

20131114090432

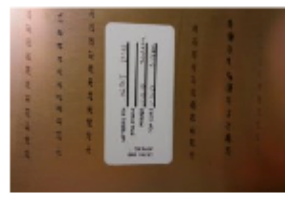

20131114_090505

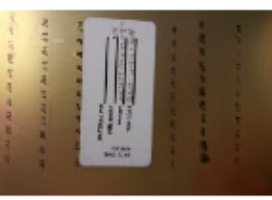

20131114090549

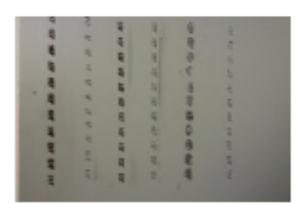

20131114090628

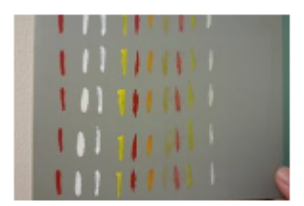

20131114 090811

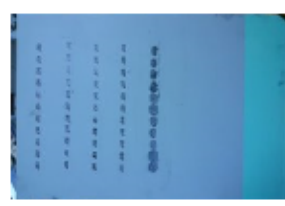

$20131105 \_115017$

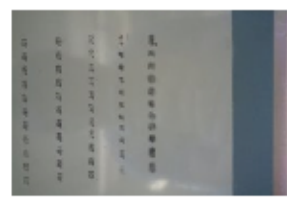

$20131105 \quad 125635$

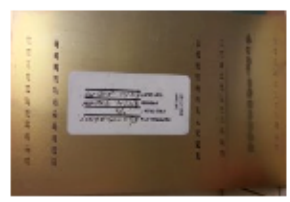

20131114090442

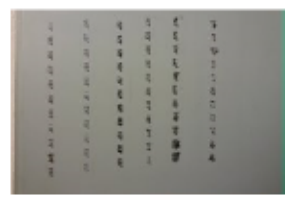

20131114_090523

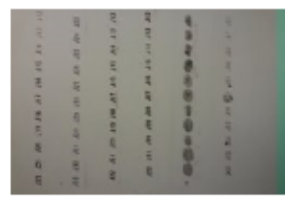

20131114090559

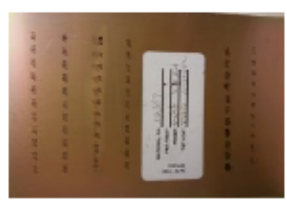

20131114090645

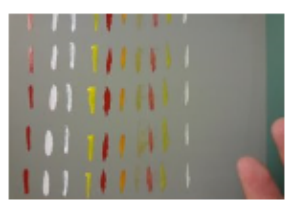

20131114 090819

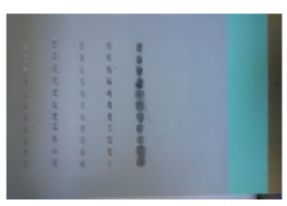

$20131105 \quad 115249$

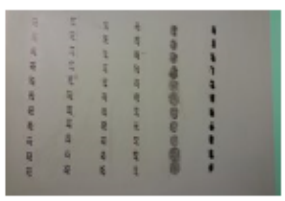

20131114090414

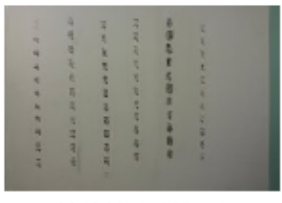

20131114090449

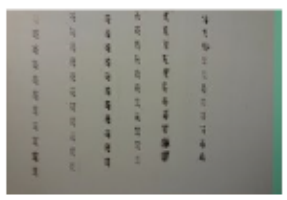

20131114_090525

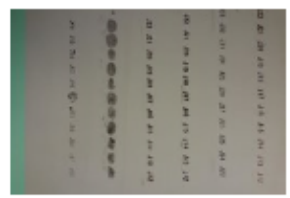

20131114090604

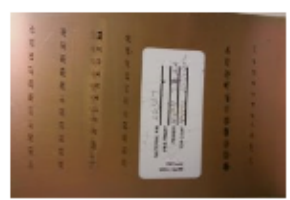

20131114090648

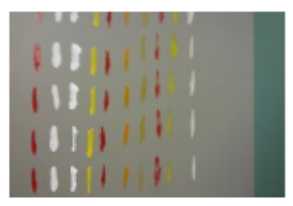

20131114 090825

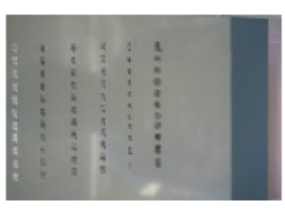

20131105_125627

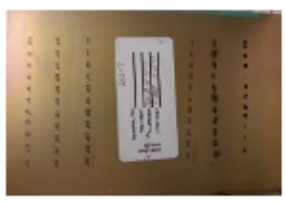

20131114090423

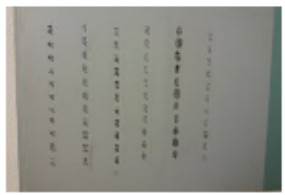

20131114_090454

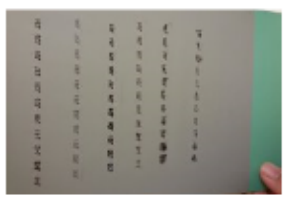

20131114_090535

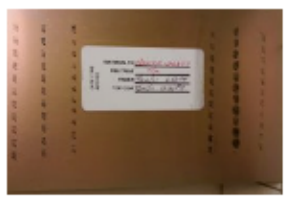

20131114090615

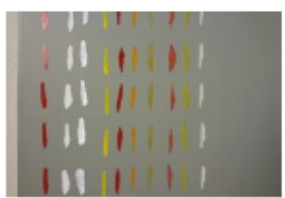

20131114090737

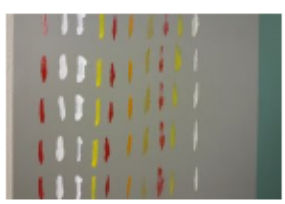

20131114090827 
10X Stereoscope After Images

Table 16 - Key to Images, Each Prefix indicates type of paint and suffix indicates panel number.

\begin{tabular}{|c|c|c|c|}
\hline$H \mathbf{x}-\mathbf{y}$ & Description & $L \mathbf{x}-\mathbf{y}$ & Description \\
\hline $\mathbf{H}$ & Cleaning System Test & $\mathrm{L}$ & Humidity Test \\
\hline $\mathbf{x}$ & Panel Number & $\mathrm{x}$ & Panel Number \\
\hline $\mathbf{y}$ & & $\mathrm{y}:$ & \\
\hline$y-1$ & Union Ink & $y-1$ & DuPont IS \\
\hline$y-2$ & Union Ink & $y-2$ & SW \\
\hline$y-3$ & DEFT & $y-3$ & Union Ink \\
\hline$y-4$ & DEFT & $y-4$ & DEFT \\
\hline$y-5$ & Green Poly & $y-5$ & Green Poly \\
\hline$y-6$ & SW & $y-6$ & DuPont IS \\
\hline$y-7$ & SW & $y-7$ & SW \\
\hline$y-8$ & Union Ink & $y-8$ & Union Ink \\
\hline$y-9$ & Union Ink & $y-9$ & DEFT \\
\hline$y-10$ & DEFT & $y-10$ & Green Poly \\
\hline$y-11$ & DEFT & & \\
\hline$y-12$ & Green Poly & & \\
\hline$y-13$ & SW & & \\
\hline$y-14$ & SW & & \\
\hline
\end{tabular}



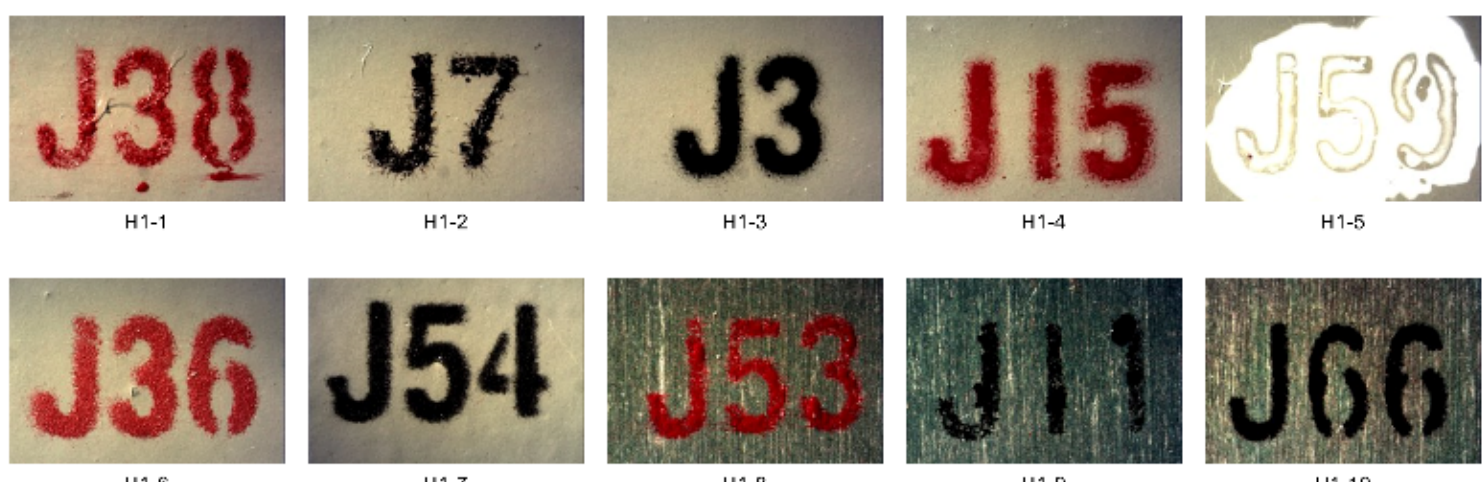

H1-9
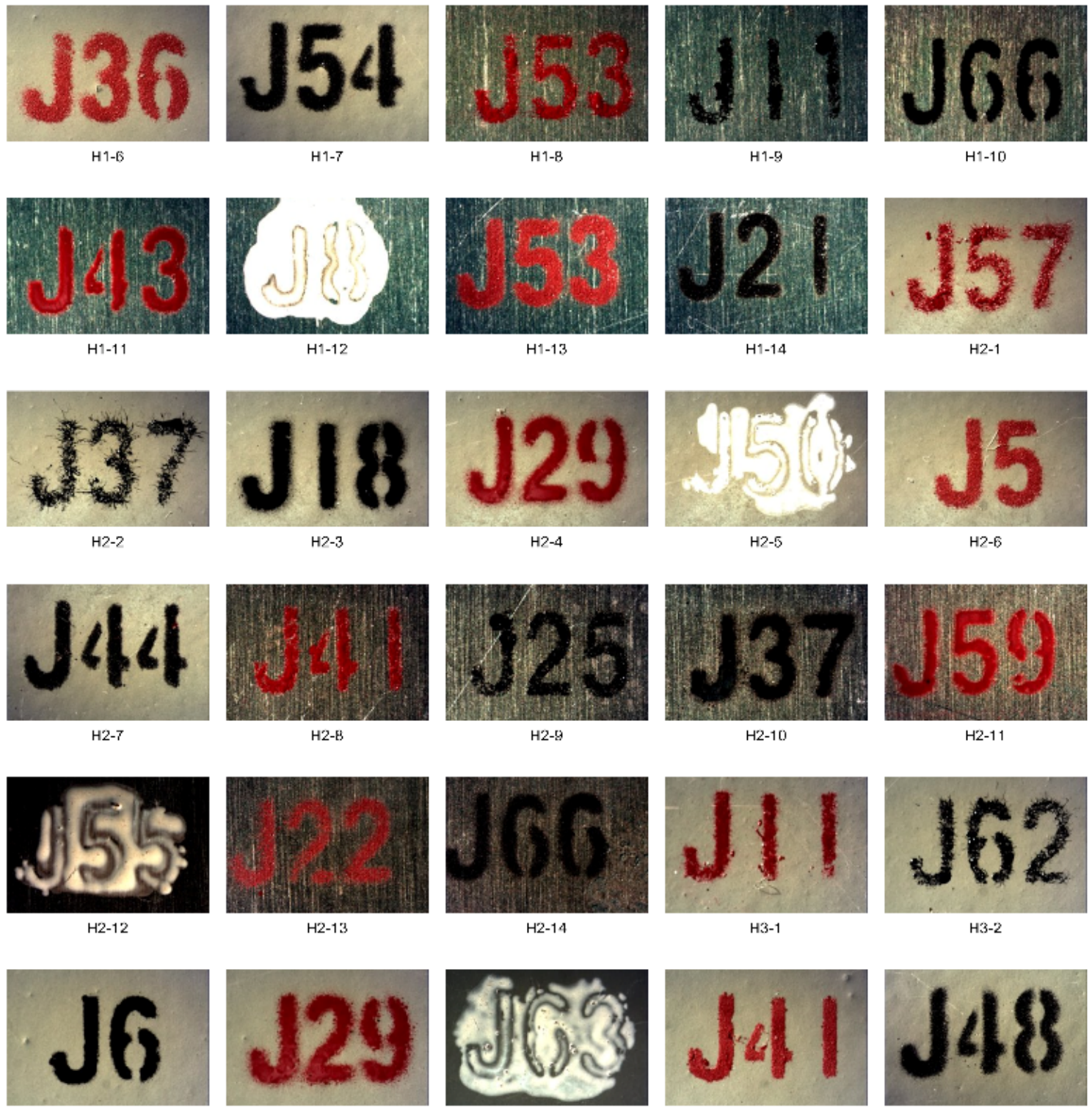

H3-5

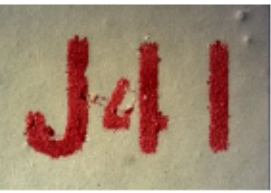

H3-6

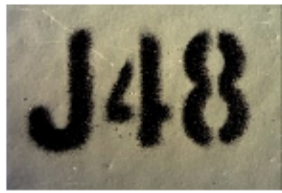

H3-7 

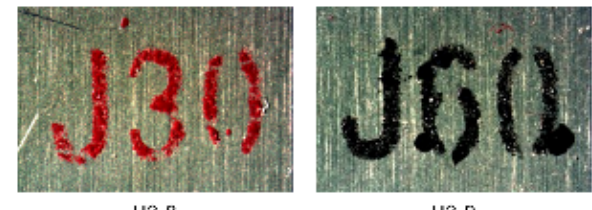

H3-9

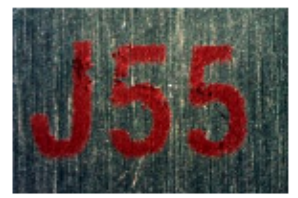

H3-13

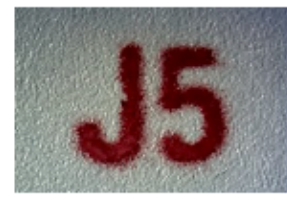

H4-4

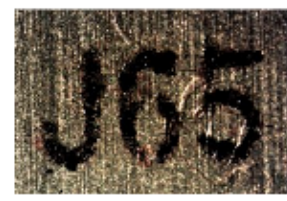

H4-9

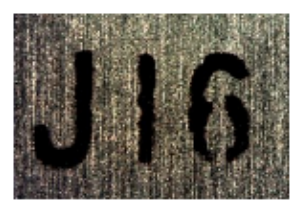

H4-14
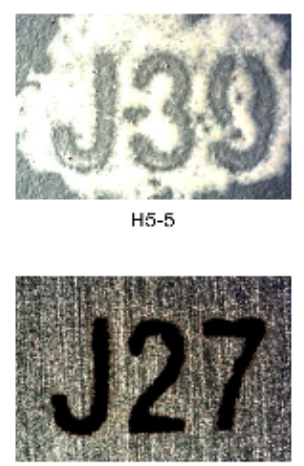

H5-10

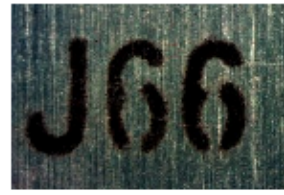

H3-14

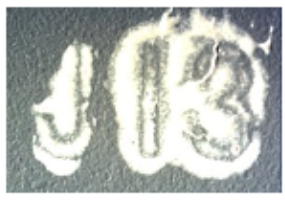

H4-5

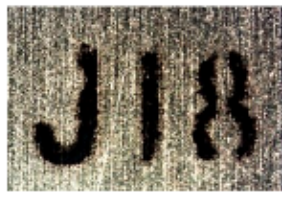

H4-10

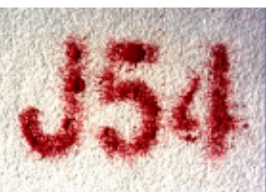

H5-1

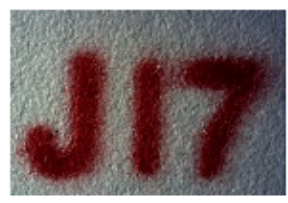

H5-6

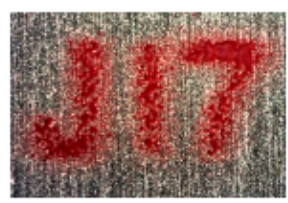

H5-11

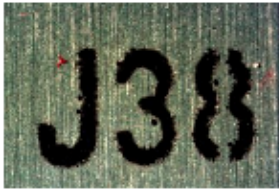

H3-10

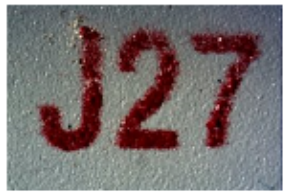

H4-1

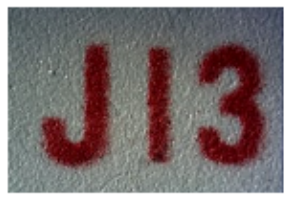

H4-6

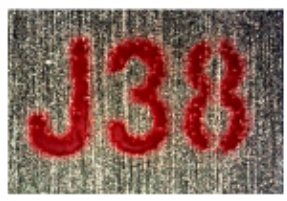

H4-11

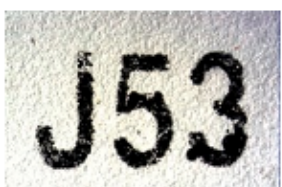

H5-2
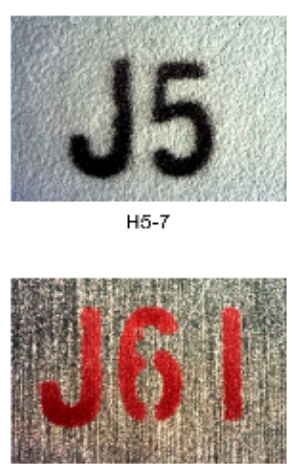

H5-12

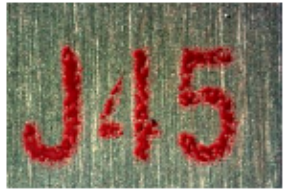

H3-11

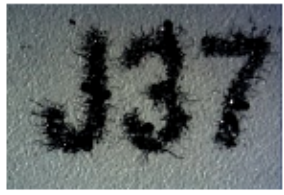

H4-2

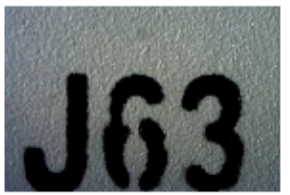

H4-7

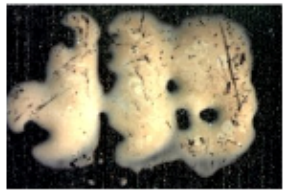

H4-12

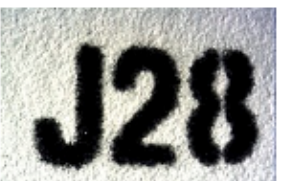

H5-3

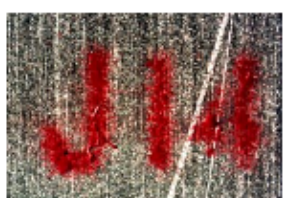

H5-B

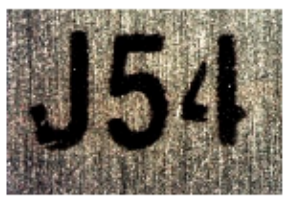

H5-13

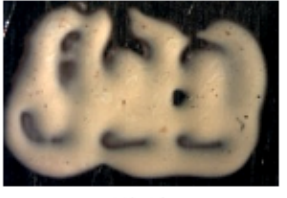

H3-12

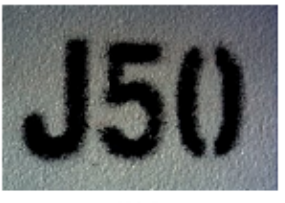

H4-3

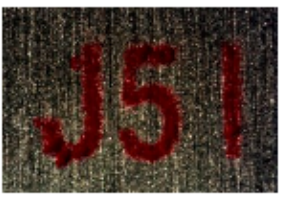

H4-8

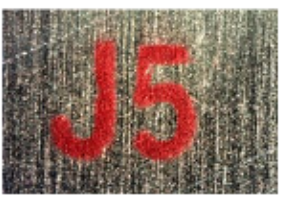

H4-13

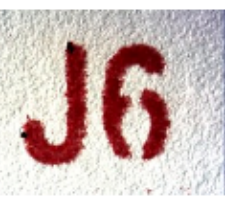

H5-4
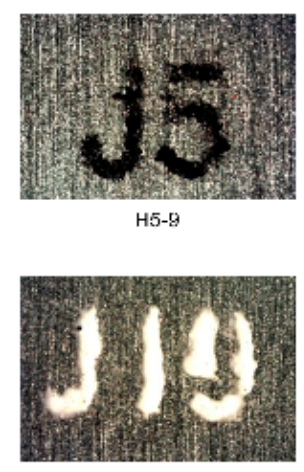

H5-14 


\section{J64}

H6-

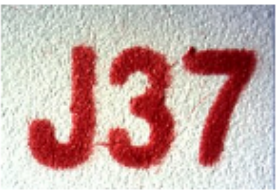

H6-6

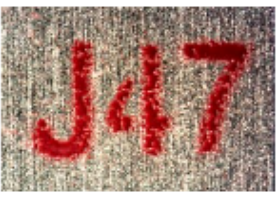

H6-11

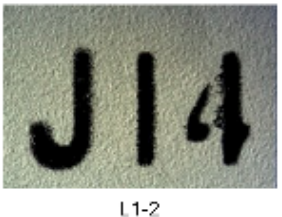

1-2

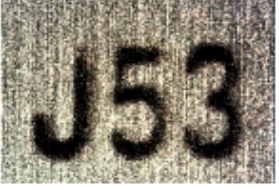

L1-7

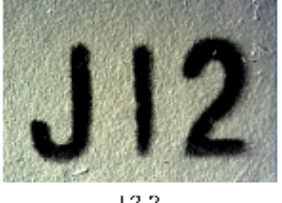

L2-2

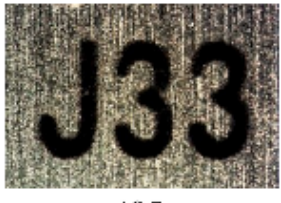

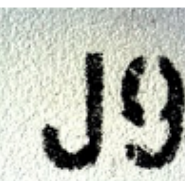

H6-2

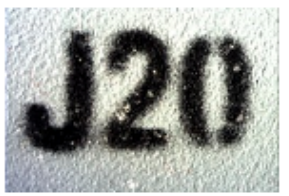

H6-7

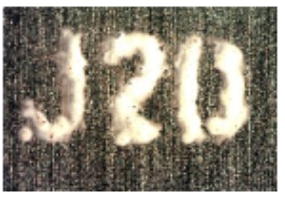

H6-12

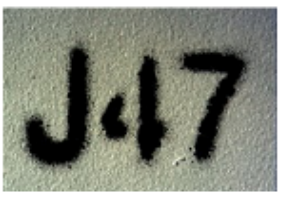

L1-3

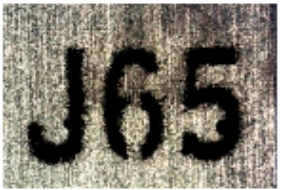

L1-8

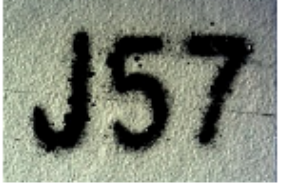

L2-3

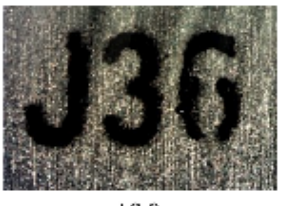

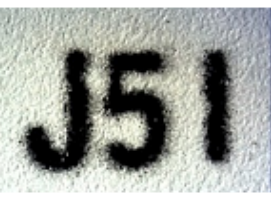

H6-3

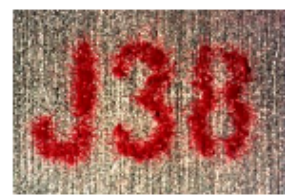

H6-8

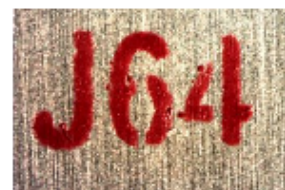

H6-13

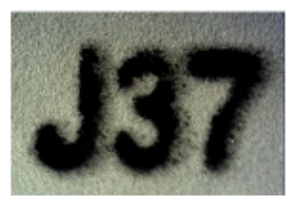

L1-4

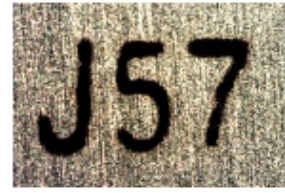

L1-9

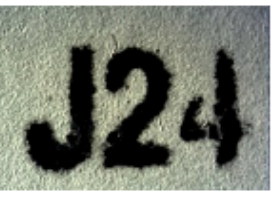

L2-4

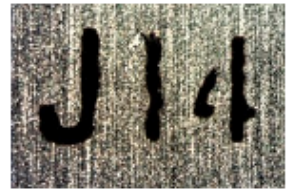

L2-9

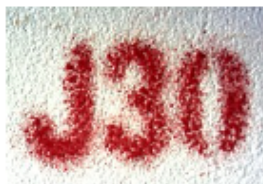

H6-4

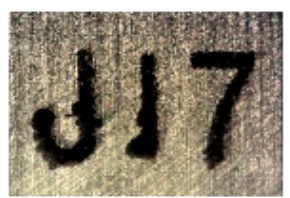

H6-9

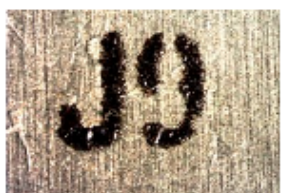

H6-14

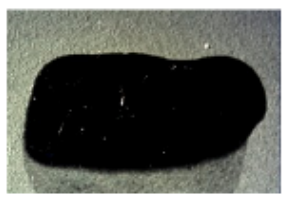

L1-5

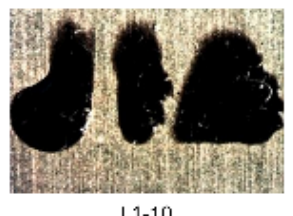

L1-10

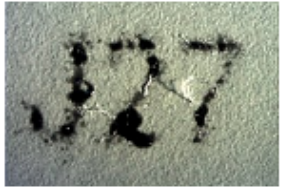

L2-5

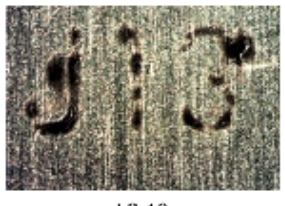

L2-10

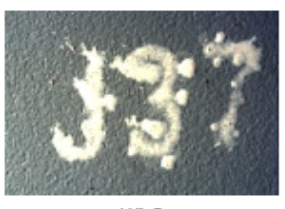

H6-5
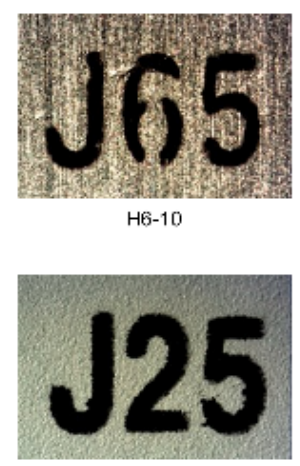

L1-1

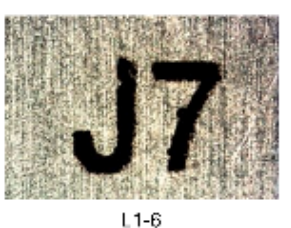

L1-6

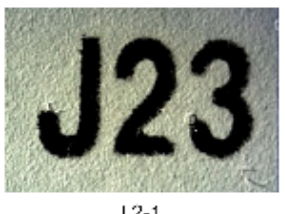

L2-1

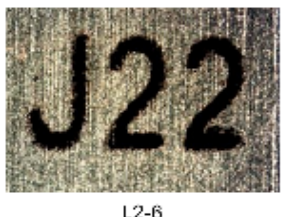

L2-6

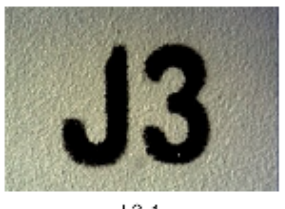




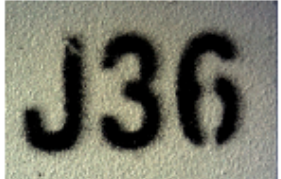

L3-2

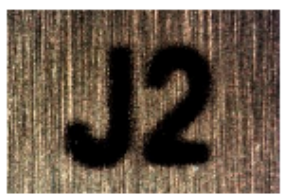

L3-7

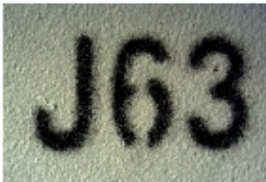

L4-2

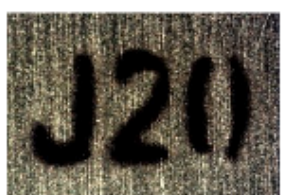

L4-7

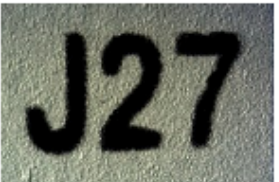

L5-2

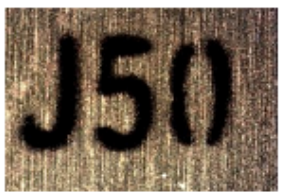

L5-7

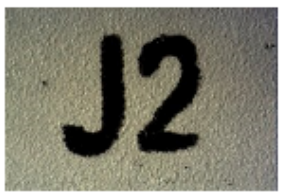

L6-2

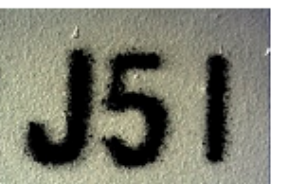

L3-3

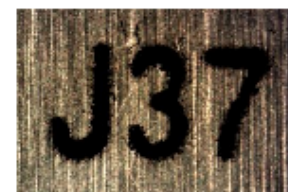

L3-8

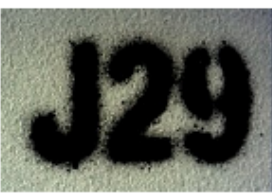

L4-3

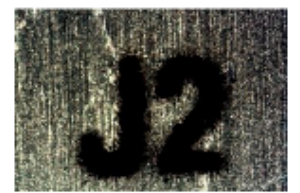

14-8

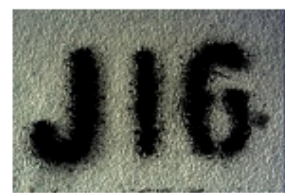

L5-3

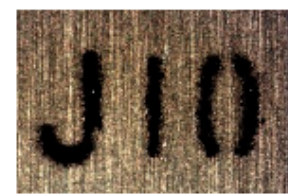

L5-8

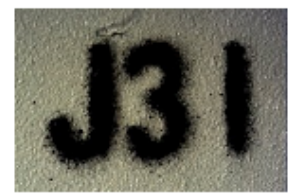

L6-3

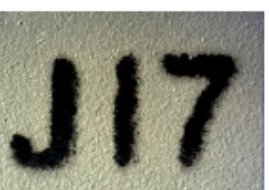

L3-4

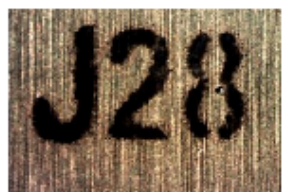

L3-9

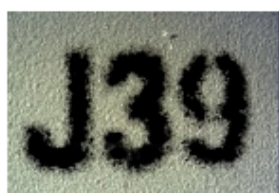

L4-4

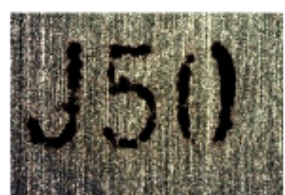

L4-9

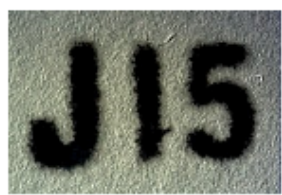

L5-4

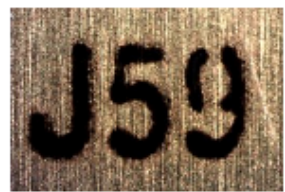

เ5-9

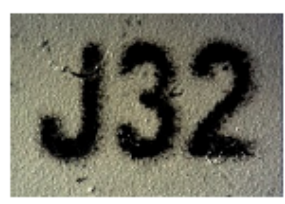

L6-4

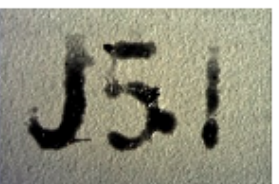

L3-5

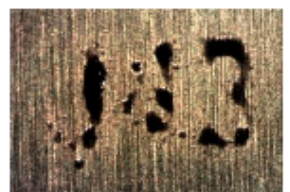

L3-10

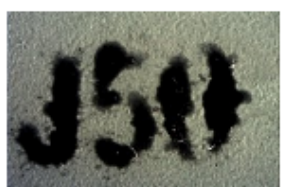

L4-5

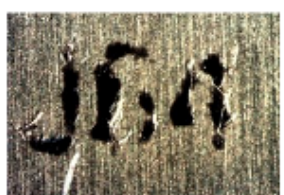

L4-10

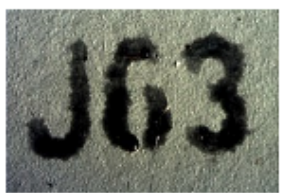

L5-5

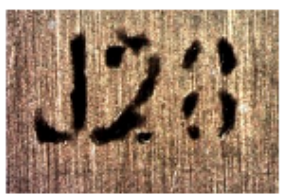

L5-10

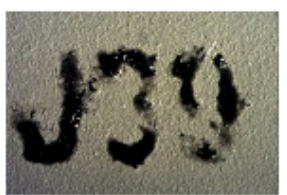

L6-5

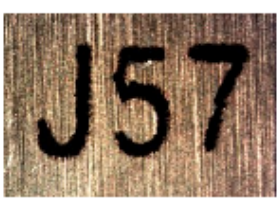

L3-6

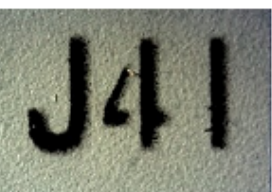

L4-1

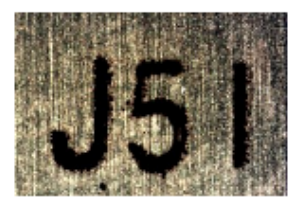

L4-6

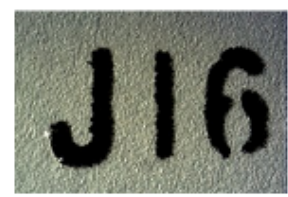

L5-1

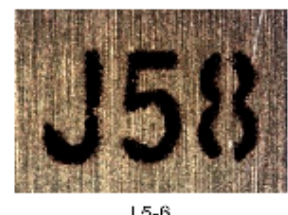

L5-6

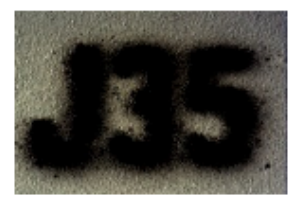

L6-1

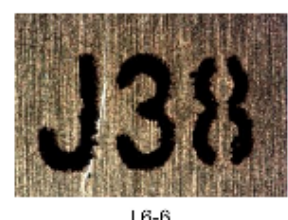

L6-6 


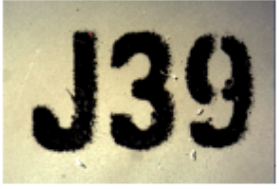

L10-2

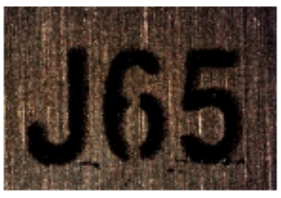

L10-7

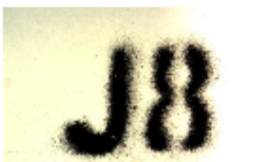

L11-2

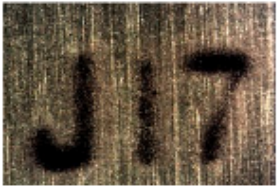

L11-7

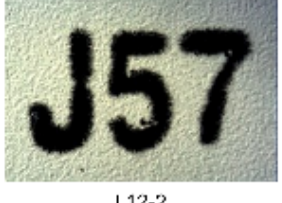

L12-2

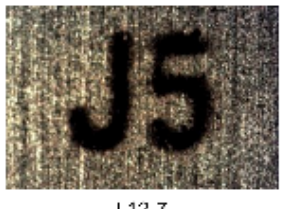

J5

L10-3

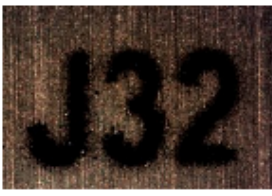

L10-8

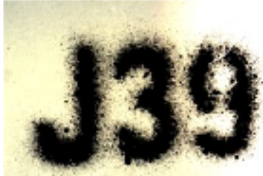

L11-3

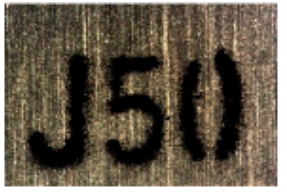

L11-8
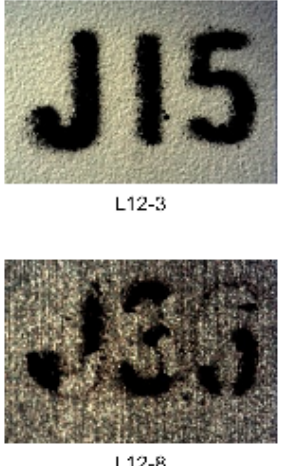

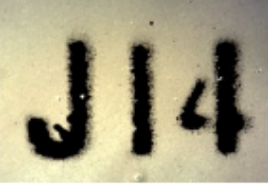

L10-4

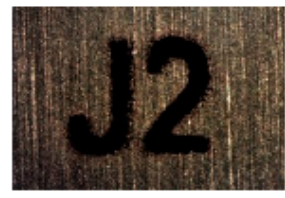

L10-9

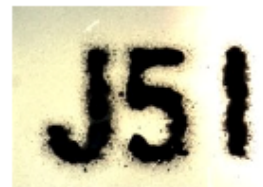

L11-4

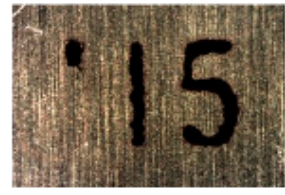

L11-9

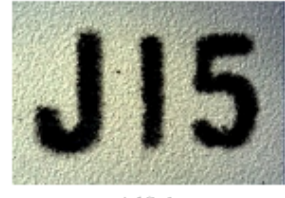

L12-4

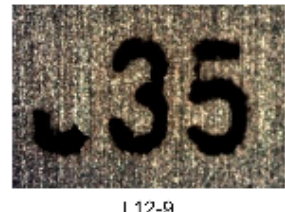

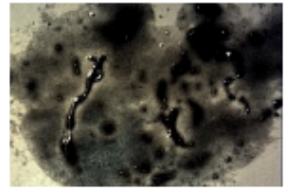

L10-5

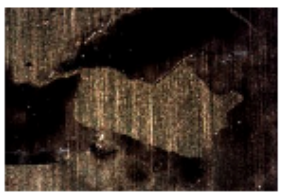

L10-10

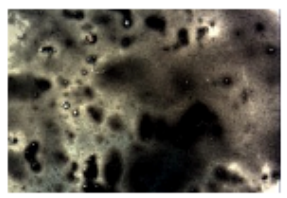

L11-5
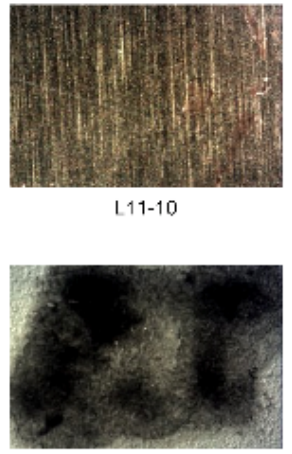

L12-5

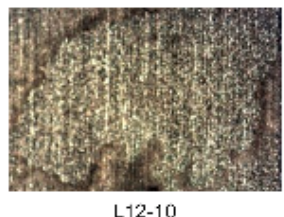

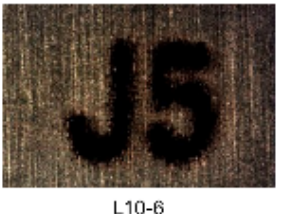

L10-6

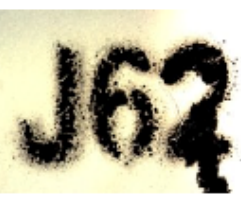

L11-1
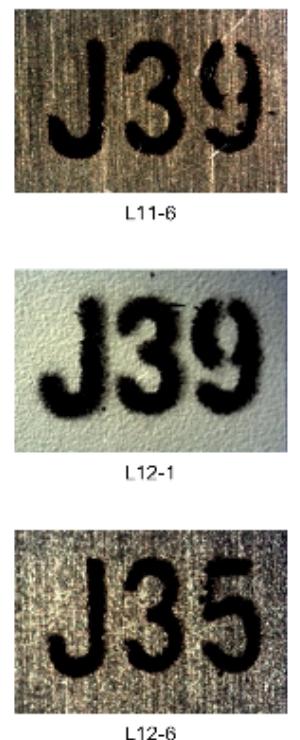

L12-6 